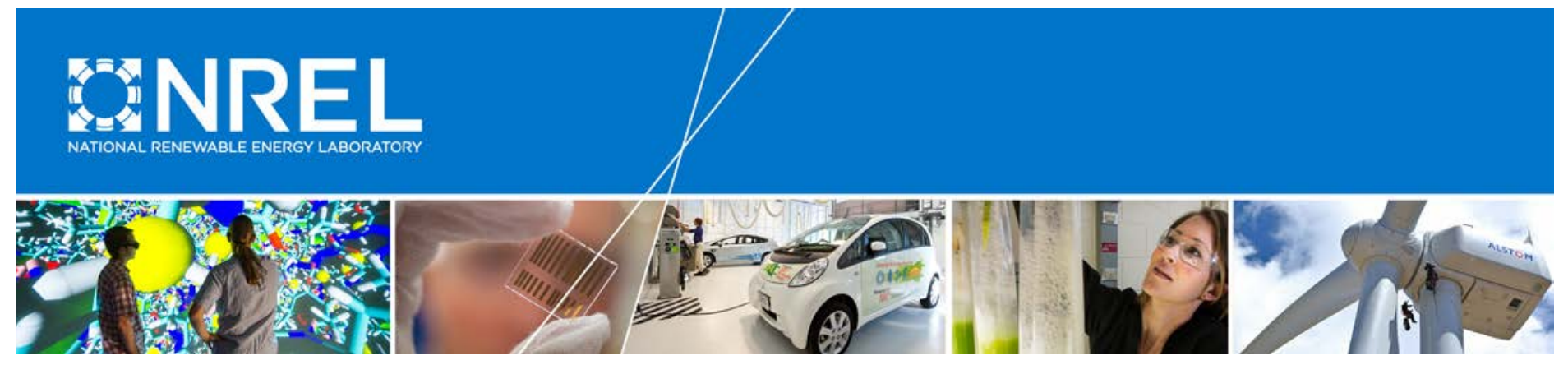

\title{
Operational Benefits of Meeting California's Energy Storage Targets
}

Josh Eichman, Paul Denholm, and Jennie Jorgenson National Renewable Energy Laboratory

Udi Helman Helman Analytics

NREL is a national laboratory of the U.S. Department of Energy Office of Energy Efficiency \& Renewable Energy Operated by the Alliance for Sustainable Energy, LLC

This report is available at no cost from the National Renewable Energy Laboratory (NREL) at www.nrel.gov/publications.

Technical Report

NREL/TP-5400-65061

December 2015 


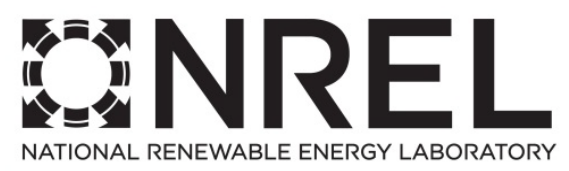

\section{Operational Benefits of Meeting California's Energy Storage Targets}

Josh Eichman, Paul Denholm, and Jennie Jorgenson National Renewable Energy Laboratory

Udi Helman Helman Analytics

Prepared under Task No. SA12.0384

NREL is a national laboratory of the U.S. Department of Energy Office of Energy Efficiency \& Renewable Energy Operated by the Alliance for Sustainable Energy, LLC

This report is available at no cost from the National Renewable Energy Laboratory (NREL) at www.nrel.gov/publications.

National Renewable Energy Laboratory 15013 Denver West Parkway Golden, CO 80401

303-275-3000 • www.nrel.gov

\section{Technical Report}

NREL/TP-5400-65061

December 2015

Contract No. DE-AC36-08G028308 


\section{NOTICE}

This report was prepared as an account of work sponsored by an agency of the United States government. Neither the United States government nor any agency thereof, nor any of their employees, makes any warranty, express or implied, or assumes any legal liability or responsibility for the accuracy, completeness, or usefulness of any information, apparatus, product, or process disclosed, or represents that its use would not infringe privately owned rights. Reference herein to any specific commercial product, process, or service by trade name, trademark, manufacturer, or otherwise does not necessarily constitute or imply its endorsement, recommendation, or favoring by the United States government or any agency thereof. The views and opinions of authors expressed herein do not necessarily state or reflect those of the United States government or any agency thereof.

This report is available at no cost from the National Renewable Energy Laboratory (NREL) at www.nrel.gov/publications.

Available electronically at SciTech Connect http:/www.osti.gov/scitech

Available for a processing fee to U.S. Department of Energy and its contractors, in paper, from:

U.S. Department of Energy

Office of Scientific and Technical Information

P.O. Box 62

Oak Ridge, TN 37831-0062

OSTI http://www.osti.gov

Phone: 865.576.8401

Fax: 865.576.5728

Email: reports@osti.gov

Available for sale to the public, in paper, from:

U.S. Department of Commerce

National Technical Information Service

5301 Shawnee Road

Alexandria, VA 22312

NTIS http://www.ntis.gov

Phone: 800.553 .6847 or 703.605 .6000

Fax: 703.605.6900

Email: orders@ntis.gov 


\section{Acknowledgments}

The authors would like to acknowledge the valuable feedback received from Aaron Bloom (NREL), Erik Ela (EPRI), Jack Ellis (Consultant), Tao Guo (Energy Exemplar), Alan Lamont (LLNL), Shucheng Liu (CAISO), Seungwook Ma (U.S. DOE), Tim Mason (Consultant), Dave Mooney (NREL), Carl Silsbee, (Consultant), Aidan Tuohy (EPRI), Patrick Young (CPUC), and Keith White (CPUC). Any errors or omissions are solely the responsibility of the authors. This work was funded by the U.S. Department of Energy Office of Energy Efficiency and Renewable Energy. 


\section{List of Abbreviations and Acronyms}

AS

CAISO California Independent System Operator

CC Combined Cycle

CEC California Energy Commission

CPUC California Public Utilities Commission

CSP Concentrated Solar Power

CT Combustion Turbine

DR Demand Response

DOE Department of Energy

ENE\&RES Energy and Reserves

EPRI Electric Power Research Institute

IOU Investor-Owned Utility

LAP Load Aggregation Point

LF Load Following

LLNL Lawrence Livermore National Laboratory

LSE Load Serving Entity

LTPP Long Term Procurement Plan

MUNI Municipally Owned Utility

PG\&E Pacific Gas and Electric

PNNL Pacific Northwest National Laboratory

RA Resource Adequacy

RPS Renewable Portfolio Standard

POU Publicly-Owned Utility

SCE Southern California Edison

SDG\&E San Diego Gas and Electric

SMUD Sacramento Municipal Utility District 
LADWP Los Angeles Department of Water and Power

IID Imperial Irrigation District

TIDC Turlock Irrigation District

VO\&M Variable Operation and Maintenance

WECC Western Energy Coordinating Council 


\section{Abstract}

In October 2013, the California Public Utilities Commission (CPUC) issued rules for its jurisdictional utilities to procure a minimum of 1,325 megawatts (MW) of energy storage systems by 2020 . The goal of this study is to examine the operational value of this storage portfolio in California and the rest of the Western Electricity Coordinating Council (WECC) region. We perform this analysis using a set of databases and grid simulation tools developed and implemented by the CPUC, the California Independent System Operator (CAISO), and the California Energy Commission (CEC) for the CPUC's long-term procurement plan (LTPP). The 2014 version of the LTPP database contains information about the western grid in the year 2024, including 33\% and 40\% renewable energy portfolios to meet California's renewable portfolio standard (RPS). The study also uses the CPUC's planning assumptions about the composition of the final storage portfolio. In addition, the study examines several sensitivity scenarios, including variations in the services energy storage can provide, the capacity and duration of storage resources, electric power export limitations between California and the rest of WECC, and a range of negative energy prices that could occur in periods of surplus renewable energy.

Modeled results show that the storage portfolio, when providing energy and operating reserves, reduces the total WECC-wide production costs by $\$ 78$ million per year in the 33\% scenario. This value increases to $\$ 144$ million per year in the $40 \%$ scenario, primarily because of the increase in off-peak and peak price differences that are due to additional solar generation. These values are equivalent to $\$ 59 / \mathrm{kW}$-year for the storage portfolio for the $33 \%$ scenario and $\$ 109 / \mathrm{kW}$-year for the $40 \%$ scenario.

This study shows that much of the storage value is derived from the provision of operating reserves (a subset of ancillary services). Providing both energy and operating reserves with storage achieves the maximum value (avoided production costs) while reserves markets alone provide the system with a majority of that value. In addition, energy storage resources that provide reserves may require less energy storage capacity, reducing their cost. However, the study also finds that if it were dedicated to regulation (the highest value reserve product in the current CAISO markets), the added storage could provide more than $80 \%$ of the regulation requirement for all of California. This would likely greatly reduce regulation prices and potential market revenues. Furthermore, the study finds that much of the value from storage in all applications is derived from avoided start costs of thermal generators. The addition of storage in California also decreases renewable curtailment by about $35 \%$ in the $33 \%$ renewable energy scenario and $19 \%$ in the $40 \%$ renewable scenario. The storage portfolio has a mixed impact on emissions across the WECC, generally reducing them. In addition to performing the production cost simulations, we also calculate simulated market revenues to storage resources. Generally, the results suggest two to three times greater energy arbitrage value between historical CAISO market prices (2014) and simulated future prices. However, this study and others emphasize the challenges associated with full valuation of energy storage, including not only quantifying and realizing the operational benefits of storage, but also capturing the additional benefits associated with capacity value, avoided or deferred transmission and distribution upgrades, and avoided transmission and distribution losses. 


\section{Table of Contents}

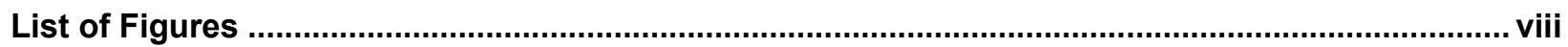

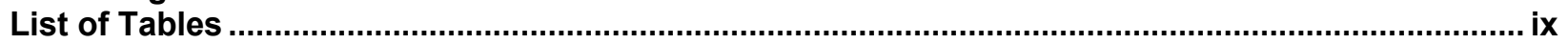

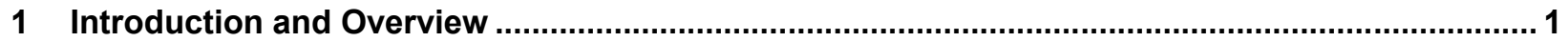

2 California's Energy Storage Policy and Related Policies ............................................................ 6

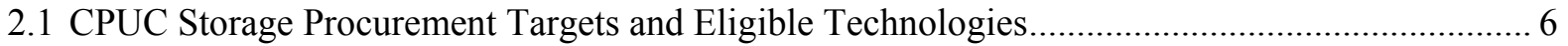

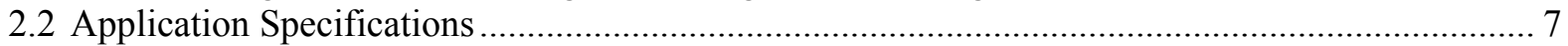

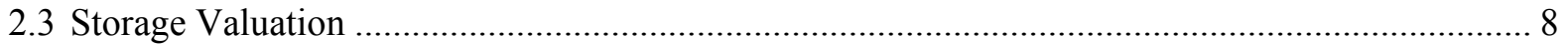

3 Research on Valuation of Energy Storage in California and Western U.S. Power Systems ...... 11

3.1 Tools Used to Simulate Energy Storage Value......................................................................... 11

3.2 Previous Analysis of Energy Storage Value in California Using the LTPP Model Database ....... 14

4 Modeling Framework and Implementation of Energy Storage .................................................. 17

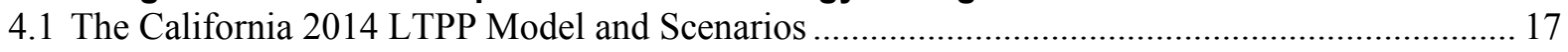

4.2 Representation and Operation of New Storage Resources in the LTPP Model........................... 23

4.3 Representation of Storage in Price-Taking Model................................................................... 26

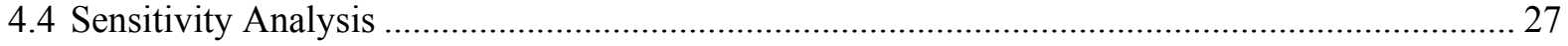

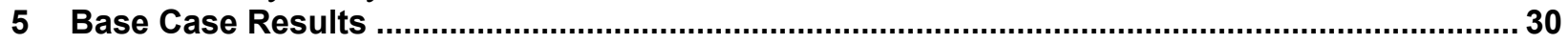

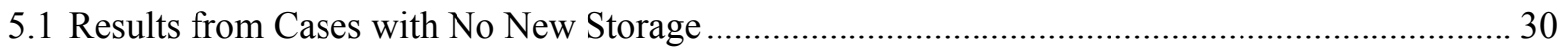

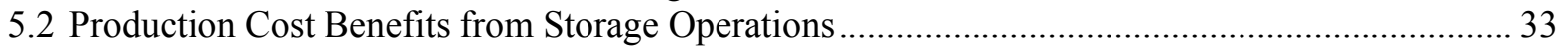

5.3 Changes to Emissions and Resource Utilization by Fuel Type ................................................. 44

5.4 Analysis of Historical and Future Energy and Ancillary Service Market Revenues .................... 48

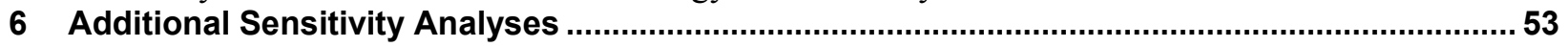

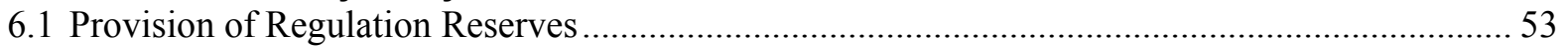

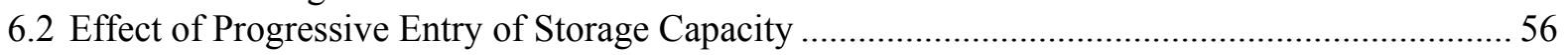

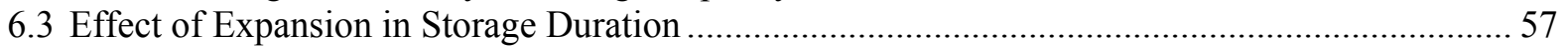

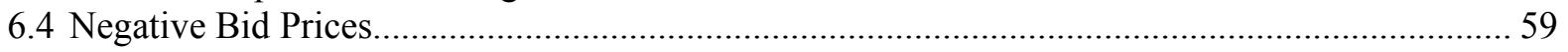

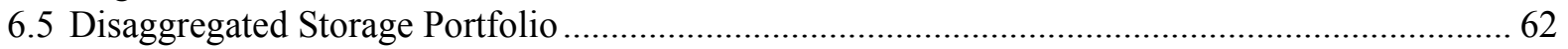

6.6 Regional Market Integration: Relaxation of Export Constraints ................................................ 63

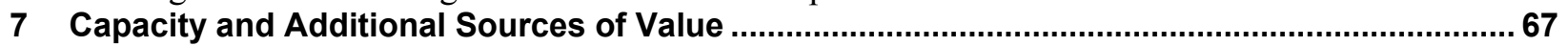

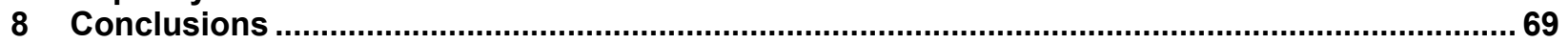

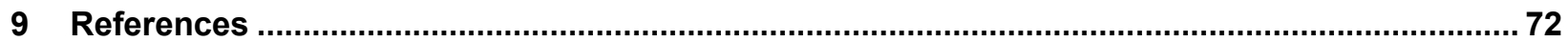

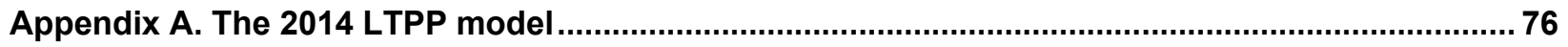

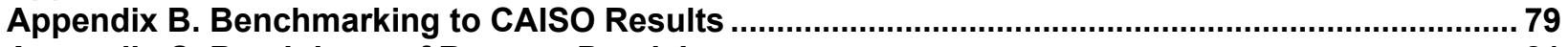

Appendix C. Breakdown of Reserve Provision .............................................................................. 81

Appendix D. Modelled Electricity Prices and Renewable Curtailment Details ................................ 83 


\section{List of Figures}

Figure 1: Fuel price inputs for LTPP model including range .......................................................... 20

Figure 2: Comparison of base case total system load, net load, and renewable generation for each season in California

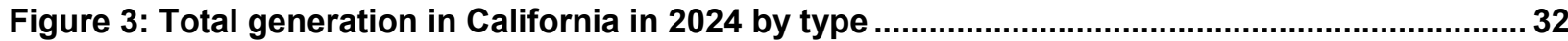

Figure 4: Total WECC-wide generation in 2024 by type............................................................. 32

Figure 5: Total production cost for $33 \%$ and $40 \%$ scenarios for both WECC and California without

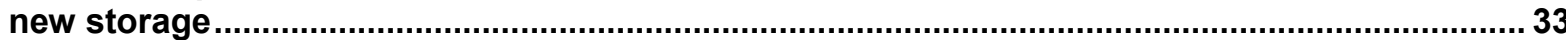

Figure 6: Production cost reduction with storage for $33 \%$ and $40 \%$ scenarios for all of WECC...... 34

Figure 7: Operational value of storage comparison for $33 \%$ and $40 \%$ scenarios for all of WECC... 34

Figure 8: Energy price for CAISO 2013 and 2014 market prices (SCE LAP) and modeled prices for

$33 \%$ and $40 \%$ scenarios without storage ............................................................................ 36

Figure 9: Average storage charging and discharging patterns by hour of day for each season..... 38

Figure 10: Summary of curtailment for $33 \%$ and $40 \%$ base scenarios.......................................... 39

Figure 11: Curtailment of RPS eligible wind and solar on March 23 .............................................. 40

Figure 12: Scatter plot of renewable curtailment for $33 \%$ and $40 \%$ ene\&res scenarios ................... 40

Figure 13: Total storage portfolio utilization factor........................................................................... 42

Figure 14: Total number of capacity-weighted unit starts for the Western Interconnect ................. 43

Figure 15: Total startup costs by generation type for the Western Interconnect ............................. 44

Figure 16: Change in yearly generation mixture for $33 \%$ scenarios with storage for all of WECC.. 45

Figure 17: Change in yearly generation mixture for $40 \%$ scenarios with storage for all of WECC.. 46

Figure 18: Change in emissions for the core $33 \%$ and $40 \%$ scenarios with storage for California only

Figure 19: Change in emissions for the core $33 \%$ and $40 \%$ scenarios with storage for the Western

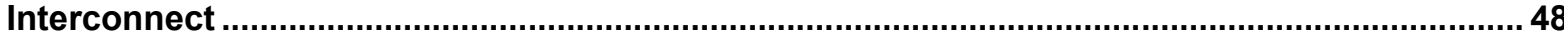

Figure 20: Average CAISO historical day-ahead energy and ancillary service prices by hour of day

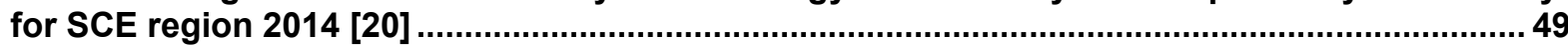

Figure 21: Storage revenues from a price-taker model using historical prices ..............................50

Figure 22: Average modeled ancillary service prices by hour of day from the LTPP model (33\%

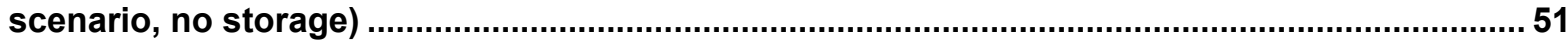

Figure 23: Comparison of storage revenues from the self-scheduled and system-optimized

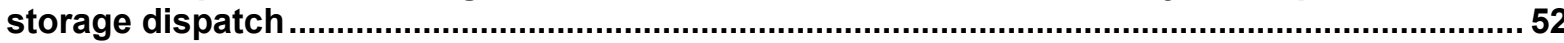

Figure 24: Provision of regulation up to meet California IOU's portion of reserves ........................54

Figure 25: Zero price hours for regulation compared to historical values ..................................... 55

Figure 26: Production cost reduction with storage providing both energy and reserves for three levels of installed capacity

Figure 27: Value of storage providing both energy and reserves per unit of capacity for three

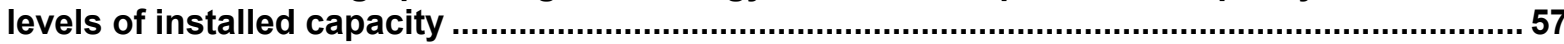

Figure 28: Production cost reduction in cases with longer duration storage ................................58

Figure 29: Value of storage in cases with longer duration storage .................................................59

Figure 30: Change in renewable energy curtailment for different renewable bid prices, without and with storage.

Figure 31: Change in production cost components moving from $\$ 0 / \mathrm{MWh}$ to $-\$ 300 / \mathrm{MWh}$ bid floor 61

Figure 32: Arbitrage revenue from a price-taker model using historical and modeled prices (values under the renewable penetration scenarios are the maximum value of avoided curtailment).. 62

Figure 33: Aggregate storage revenues for energy arbitrage using a price-taker model as a

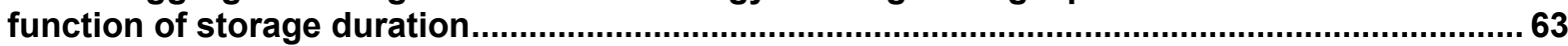

Figure 34: Curtailment values from relaxing California export limitations.........................................64

Figure 35: Yearly net import into California for zero net and relaxed export scenarios ...................64

Figure 36: Production cost reduction from relaxing California export limitations ..........................65

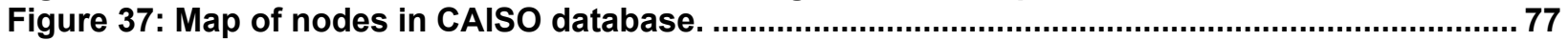

Figure 38: Reserve provision for California IOUs by resource type for $33 \%$ no-storage scenario.. 81

Figure 39: Reserve provision for California IOUs by resource type for $33 \%$ ene\&res storage scenario. 
Figure 40: Scatter plot of energy prices for $33 \%$ and $40 \%$ ene\&res scenarios $(-\$ 300 / \mathrm{MWh}$ bid floor).

Figure 41: Price duration curve for $33 \%$ and $40 \%$ ene\&res scenarios.

\section{List of Tables}

Table 1. Cumulative Energy Storage Capacity Procurement Targets (MW) for California................. 7

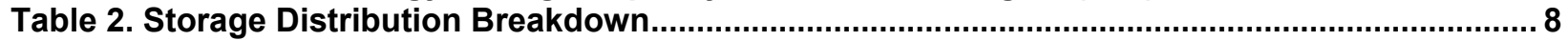

Table 3. Storage Services Identified in the California Storage Policy and Corresponding Representation in Procurement Protocols, Wholesale Markets, and the LTPP Simulation Model

Table 4. Comparison of Methods Used to Calculate Storage Value and Corresponding Models Used in This Paper

Table 5. Model Types Used in This Study, by Section and Application..

Table 6. Comparison of Key Features of Recent California Studies Modeling Storage with Production Cost Models

Table 7. Renewable Generation Mix for the $33 \%$ and $40 \%$ Scenarios Used in This Study... 19

Table 8. Day-Ahead CAISO Reserve Procurement (MW): Historical and Forecast, Represented Annually....

Table 9. Existing and Planned California Storage Modelled .......................................................2 23

Table 10. Storage Operational Attributes in 2024 from CPUC R.13-12-010 .................................... 24

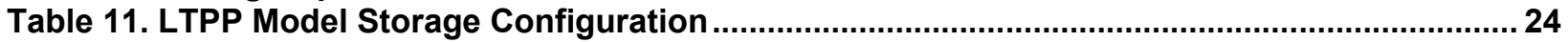

Table 12. List of Base Storage Scenarios and Alternative Applications........................................ 25

Table 13. Comparison of Storage Assumptions in Production Cost and Price-Taker Models.......... 26

Table 14. List of Storage Sensitivity Scenarios ........................................................................... 29

Table 15. Summary Statistics for Historical and Modeled California Energy Prices ......................... 37

Table 16. Storage Generic Capacity Ratings under Current CPUC Rules ........................................67

Table 17. Comparison of 2014 LTPP Deterministic Model Results for CAISO and NREL................. 80 


\section{Introduction and Overview}

Several regions in the United States have begun to develop policies and regulations for development and deployment of energy storage technologies, primarily to support technology innovation and address potential emerging operational issues on the electric power grid associated with renewable integration. ${ }^{1}$ Notably, in 2013, in compliance with California state legislative directives, the California Public Utilities Commission (CPUC) established storage procurement targets, along with other guidelines for utility procurement, for the three large California investor-owned utilities (IOUs): Pacific Gas and Electric (PG\&E), Southern California Edison (SCE), and San Diego Gas and Electric (SDG\&E) [5]. These utilities, which comprise about $80 \%$ of California electricity demand, are required to procure at least 1,325 megawatts (MW) of new energy storage by 2020, with full compliance by 2024 .

Calculating the value and opportunities provided by energy storage deployment is challenging due to several factors. Many studies point to the multiple benefit streams that storage can provide $[2,6,7]$. These benefits can be complicated to simulate, especially considering the regulatory and market barriers to realizing the benefits jointly [8]. Moreover, California is experiencing rapid changes to its power system resource mix due to a combination of policies and market factors, notably high penetration of solar and wind resources and, more recently, regional market expansion. Storage value will be highly contingent on system conditions resulting from rapid renewable penetration and evolving operational requirements, such as additional operating reserves, that are associated with renewable integration.

\section{Study Objectives}

This study has five goals:

1) Provide an overview of the CPUC storage mandate, highlighting opportunities for research to clarify operational and market implications of new storage deployment (Section 2)

2) Discuss the various applications or "use cases" of energy storage (Section 2.2) and how the value of these applications can be assessed using standard grid simulation tools, such as production cost models, as well as models that calculate wholesale market revenues (Section 3.1 and 4)

3) Review previous work relevant to storage valuation on the California grid (Section 3.2)

4) Analyze the potential operational value of energy storage using several modeling approaches and considering a range of sensitivities (Sections 5-6)

5) Suggest next steps for model development and research (Section 8)

\footnotetext{
${ }^{1}$ The potential role of storage in renewable integration has been explored in the literature $[1,2,3,4]$.
} 


\section{Modeling Approaches}

The study uses a regional power system simulation model developed by the CPUC, the California ISO (CAISO), ${ }^{2}$ and the California Energy Commission (CEC) for the CPUC's longterm procurement plan (LTPP) proceeding. The study complements other recent research into storage valuation in California using the same basic model framework [6, 9, 10, 11]. Among the particular contributions of this study is the use of the 2014 LTPP planning assumptions and scenarios for 2024 [12], which include both $33 \%$ and $40 \%$ renewable energy scenarios and a baseline representation of the investor owned utility (IOU) storage portfolio. Henceforth, these are called the $33 \%$ and $40 \%$ scenarios. The CPUC storage portfolio consists of a combination of storage resources with 2-hour, 4-hour and 6-hour durations, assumed to be located in the utility service territories and assigned to particular applications. We call these assumptions, scenarios, and accompanying databases the "LTPP model." Section 4 provides details of this model.

The study also uses two types of market revenue simulations: (1) a "self-scheduled" storage plant that is optimized as a price-taker by a hypothetical storage plant operator against historical or forecast wholesale market prices; ${ }^{3}$ and (2) a "system-optimized" storage plant that is optimized by the system operator within market operations. These approaches are explained in Sections 3 and 4.3 , and are further discussed in the results sections.

The applications for the storage portfolio examined using these models and methods include energy arbitrage only, combinations of operating reserves, and co-optimization among energy and operating reserves. In addition, the paper examines several sensitivities relevant to storage value, including different durations of the storage portfolio, more flexible utilization of the portfolio, alternative "negative bid" assumptions for renewable curtailment, and improved regional market integration. Sections 3 and 4 provide the details on these applications and sensitivities, and there is further discussion in the results sections.

\section{Selected Study Results}

The study calculates two measures of storage value when providing energy and ancillary services: (1) avoided production costs, defined as fuel costs, start-up costs and variable operations and maintenance (VO\&M) costs and (2) market revenues, defined as the market clearing prices for the operational services supplied multiplied by the quantity of the services provided, and subtracting the cost of charging to supply those services. ${ }^{4}$ Both types of results can be expressed in annual dollar $(\$)$ terms and as value per unit of installed storage capacity $(\$ / \mathrm{kW}$ year). Unless otherwise noted, we use the full storage portfolio with the same capacity and operational attributes in all simulations, and production cost results are for one year of the full WECC region.

\footnotetext{
${ }^{2}$ We use the term independent system operator (ISO) as a general reference to both the CAISO and other U.S. organized wholesale markets.

${ }^{3}$ A storage self-schedule is a fixed schedule of hourly charging and discharging submitted by a market participant which the ISO must follow; self-schedules are financially settled in the markets as "price-takers." While the selfscheduled optimization in this study assumes perfect foresight, in actual market scheduling, the plant operator would face uncertainty about day-ahead or real-time wholesale market prices. We describe this further in Section 3.

${ }^{4}$ The optimization model is maximizing market profits (revenues minus costs), but we use the term market revenues to refer to profits, which is common in storage valuation studies.
} 
Key results are that, across the base-case LTPP scenarios, the operational value of storage measured as avoided production costs is between $\$ 36 / \mathrm{kW}$-year and $\$ 59 / \mathrm{kW}$-year for the 33\% scenario and is between $\$ 62 / \mathrm{kW}$-year and $\$ 109 / \mathrm{kW}$-year for the $40 \%$ scenario. This range reflects different assumptions about storage applications, which are discussed in Sections 5 and 6 . The upper value represents a reduction in WECC production costs of $\$ 78$ million per year in the 33\% scenario and $\$ 144$ million per year in the $40 \%$ scenario. Consistent with the findings of other production cost studies [13,14], a large percentage of these avoided costs are due to avoided generator startup costs and provision of ancillary services. These findings highlight that under the scenarios modeled, storage value is contingent on components of electric power markets that are relatively small contributors to aggregate market costs.

Another measure of storage value is wholesale market revenues. Under CPUC requirements, the IOUs are required to use multi-year forecasts of market revenues when conducting storage valuation for contract terms that could be 10-20 years in duration [15]. We model market revenues from energy and ancillary services using the actual 2013-2014 prices from the CAISO markets and the simulated hourly marginal costs or prices in 2024 using the LTPP models.

Using 2014 market data, our "self-scheduled" price-taker model estimates an energy arbitrage market revenue of $\$ 25 / \mathrm{kW}$-year and a co-optimized energy and ancillary services revenue of $\$ 58 / \mathrm{kW}$-year (Section 5.4). These revenues are for a "marginal" storage resource that, for purposes of comparison, has the attributes of the future portfolio. ${ }^{5}$ By 2024 , market prices are expected to be quite different, reflecting a very different resource mix and operating conditions. In the LTPP model results, there are greater differences between the daily low and high energy prices when compared to 2014, due to an increased frequency of low or negative prices during periods of high solar production and, to a lesser extent, an increased frequency of price spikes coincident with the higher system ramps. This leads to greater storage revenues from energy arbitrage when compared to those calculated from recent market prices. These price results in the model are in part due to modeling assumptions, notably the assumed level of negative bids assumed for renewable curtailment and the penalties for reserve shortages that can affect the price spikes.

Assuming a bid price of zero for renewable energy curtailment in 2024, the value of energy arbitrage alone roughly doubles between 2014 and 2024 under the 33\% renewable scenario (to $\$ 51 / \mathrm{kW}$-year using the self-scheduled price-taker model), and it triples in the $40 \%$ scenario (to $\$ 77 / \mathrm{kW}$-year). If energy prices become more significantly negative (from renewable generators bidding negative costs for production), there is the potential for much greater value, because storage would then earn positive revenue when charging as well as when discharging. To investigate the effect of negative bids on storage value, we examined cases where the cost of renewable curtailment is modeled as $-\$ 150 / \mathrm{MWh}$ (the current CAISO energy market "bid floor") and again when it is modeled as $-\$ 300 / \mathrm{MWh}$ (the future bid floor). The full range of these results is in Section 6.5.

\footnotetext{
${ }^{5}$ That is, the incremental resource has the same proportions of capacity and duration as the full storage portfolio, which is shown in Table 11. In Section 5.4, the components of the portfolio with 2-hour, 4-hour, and 6-hour durations are optimized separately against the historical and simulated future energy prices to examine how they differ.
} 
Many other factors will affect storage revenue, including competition from other resources both within and external to California for supplying operational flexibility. For example, the frequency of overgeneration conditions and resulting negative prices will depend greatly on the ability of California to export surplus renewable generation to neighboring states. The modeled results suggest that the value of storage will decrease if California is able to export curtailed renewable energy (Section 6.6).

While ancillary services are expected to represent a large fraction of potential revenues for energy storage, it is more difficult to use the LTPP model to estimate these revenues due to limitations in how reserves prices are modeled (see discussion in Section 5.4). However, this study does explore the value of storage primarily providing ancillary services in reducing production costs. Generally, the scenarios where storage is dedicated to providing reserves provide about $90 \%$ of the production cost reductions compared to the scenarios where storage provides both energy and reserves. Sensitivity analyses also confirm the expectation that if sufficient storage enters the CAISO regulation market, value and prices will be reduced. We also note that part of the avoided production costs associated with provision of regulating reserves are avoided generator start-up costs, which are not reflected in current operating reserves market prices.

\section{Other Findings}

In the market revenue simulations of 2024, we found that the self-scheduled optimization of storage operation against the future energy market prices yields systematically higher energy revenues across different scenarios than the system-optimized results. This appears to be due to several factors. First, the self-scheduled optimization is not affected by power system constraints - transmission and generation unit constraints - and the storage portfolio operates at a higher utilization in our simulations than the system-optimized result. A second factor could be that the production cost results show a large percentage of the storage value is due to avoided generator start-up costs, which are included in the least-cost unit commitment and dispatch but are not reflected directly in the resulting energy market prices. Hence, because of this factor, the system operator could develop a storage dispatch that minimizes production costs but does not maximize market revenues for a storage plant that earns only market revenues, under the current rules (i.e., a merchant plant). These findings are discussed in Section 5.4.

In addition to providing operational benefits, under the CPUC Resource Adequacy program, storage has capacity value both as generic capacity, and flexible capacity (the capability to address system ramps and possibly other operational needs). Most of the storage portfolio that we model under LTPP assumptions is eligible to provide either of these types of capacity because of the duration (hours of storage capacity) of the resources. This capacity value could be higher than the operational value, assuming new capacity is needed for resource adequacy. Utilizing a commonly used estimate for the cost of a new combustion turbine in California of $\$ 190 / \mathrm{kW}$-year [16] provides a value of new capacity that is substantially higher than the operational values of storage. At the same time, utility procurement costs for new capacity may be lower than this estimate depending on the contract term, and 1-3 year-ahead capacity prices from existing resources in California are typically much lower. Overall, the storage portfolio will obtain some capacity value in the time frame being modeled (2024), but we did not examine this value directly from a either a reliability or operational perspective. In addition, other sources of 
storage value are not addressed here, including other ancillary services, transmission and distribution upgrade deferral, and retail rate reductions.

\section{Model Improvements and Research Needs}

Finally, this paper identifies several challenges in developing and interpreting valuation results from production cost models. Throughout this study, we provide observations on the advantages and disadvantages of the LTPP models as currently structured for conducting valuation. This includes a discussion of how the current model assigns ancillary services to storage technologies and calculates ancillary service hourly marginal costs. Despite these current limitations, the study results provide useful insights into drivers of storage value and are suggestive of directions for further work. This could include additional capabilities within the deterministic model to reflect the day-ahead to real-time operational sequence and additional network representation for improved locational valuation (Section 8). 


\section{California's Energy Storage Policy and Related Policies}

California's energy storage policy was instituted by the state legislature in 2010 [17] and requires California utilities and all other load-serving entities to evaluate storage procurement targets. The policy has multiple objectives, including "market transformation" for storage technologies and support for the larger set of energy and environmental policies and programs developed to achieve the state's policy objectives, notably integration of an expanding portfolio of wind and solar resources procured under the RPS and the mandated reduction in carbon emissions [17]. In addition, storage is expected to support grid operations generally and maintain long-term reliability requirements, such as the state's Resource Adequacy (RA) requirement. The development of storage portfolios by the California utilities will thus be responsive over time to these policy objectives, as well as evidence of operational impact and wholesale market value. This section briefly describes these policies and programs, as background for the modeling methodology and the storage scenarios that are examined.

While all California load-serving entities have obligations to evaluate storage procurement, how they comply differs depending on the type of regulatory oversight. ${ }^{6}$ In October 2013 , the CPUC issued a final decision on the requirements for the investor-owned utilities $[5,17]$. In particular, this decision defined the timelines and targets for storage procurement (Table 1), the eligible technologies, and the key procedural requirements. The utilities may also exceed these targets if deemed cost-effective to meet other resource planning and operational requirements. In 2014, each of these utilities filed detailed storage procurement plans that document the set of

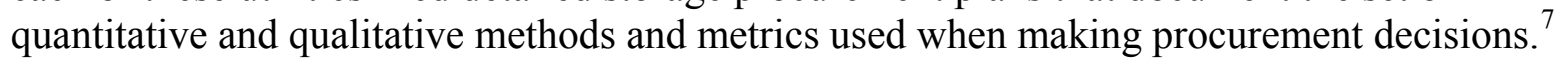
These include methods for economic valuation, as discussed in this study. CPUC provided final approval of these plans in late 2014 and the procurements have begun. There are several overlapping resource procurement processes underway ${ }^{8}$ that may include storage; hence the storage-specific procurements may only procure residual projects to fulfill the mandate.

\subsection{CPUC Storage Procurement Targets and Eligible Technologies}

Table 1 summarizes the CPUC storage procurement targets including the timing and minimum quantity of procurement by utility, and where the storage is located by type of connection (called the domain). The utilities must demonstrate that they have procured sufficient storage projects to meet the minimum targeted requirements for each procurement cycle, net of existing or otherwise contracted projects that qualify, or provide justification for deferring procurement until later cycles ([5]: pg. 16). Subsequently, the utilities will continue to procure each additional target, with final compliance required by 2024.

\footnotetext{
${ }^{6}$ The publicly owned (municipal and co-operative) utilities (POUs) in California are also legislatively required to evaluate procurement of energy storage, with reporting requirements to the California Energy Commission (CEC). This paper does not examine value of new POU storage plans.

${ }^{7}$ The IOU applications and CPUC orders can be found on or via the CPUC storage webpage [18].

${ }^{8}$ The most notable of these concurrent procurements was the decision by SCE to propose approximately $260 \mathrm{MW}$ of storage under its authorization to procure resources to meet local area requirements.
} 
The decision divides the procurement targets into transmission-connected, distributionconnected, and customer-side energy storage domains, but leaves some flexibility to shift up to $80 \%$ of procurement between the transmission and distribution categories ([5]: pg. 39). However, the decision does not allow for shifting between the customer-sited requirements and the other domains.

Table 1. Cumulative Energy Storage Capacity Procurement Targets (MW) for California

\begin{tabular}{|l|cccc|c|}
$\begin{array}{l}\text { Storage Grid Domain Point of } \\
\text { Interconnection }\end{array}$ & 2014 & 2016 & 2018 & 2020 & $\begin{array}{c}\text { Total by } \\
2024\end{array}$ \\
\hline $\begin{array}{l}\text { Southern California Edison } \\
\text { Transmission }\end{array}$ & 50 & 65 & 85 & 110 & 310 \\
\hline Distribution & 30 & 40 & 50 & 65 & 185 \\
\hline Customer & 10 & 15 & 25 & 35 & 85 \\
\hline Cumulative Subtotal SCE & 90 & 120 & 160 & 210 & 580 \\
Pacific Gas \& Electric & 50 & 65 & 85 & 110 & 310 \\
\hline Transmission & 30 & 40 & 50 & 65 & 185 \\
\hline Distribution & 10 & 15 & 25 & 35 & 85 \\
\hline Customer & 90 & 120 & 160 & 210 & 580 \\
\hline Cumulative Subtotal PG\&E & 10 & 15 & 22 & 33 & 80 \\
\hline San Diego Gas \& Electric & 7 & 10 & 15 & 23 & 55 \\
\hline Transmission & 3 & 5 & 8 & 14 & 30 \\
\hline Distribution & 20 & 30 & 45 & 70 & 165 \\
\hline Customer & 200 & 270 & 365 & 490 & 1,325 \\
\hline Cumulative Subtotal SDG\&E & & & & & \\
\hline Total - all 3 utilities & & &
\end{tabular}

Source: CPUC [5]: pg. 15.

The CPUC has also determined the eligibility of storage technologies under the mandate. Most notably, the mandate does not extend to pumped storage plants greater than $50 \mathrm{MW}$ capacity. For storage co-located with a generator, such as concentrating solar power with thermal energy storage (CSP-TES), only the storage component of the project counts toward the mandate.

\subsection{Application Specifications}

The CPUC decision establishes the procurement targets in MW to allow the investor-owned utilities to determine the desirable mix of other attributes. In a later decision on planning assumptions in the 2014 LTPP proceeding [12], specific operational requirements were identified for analysis in the LTPP model, including the services that storage should provide - in categories of operational flexibility and resource adequacy capacity - and a breakdown of different aggregate power capacities and energy capacities for the storage resources. Operational flexibility refers to energy, load-following and ancillary services. These are shown in Table 2, below, with additional breakdown by utility and applications in Table 10 and Table 11, in Section 4.2. At the transmission level, all the capacity is assumed to be providing operational flexibility, as well as being eligible for resource adequacy capacity; transmission-sited storage is not assumed to provide transmission deferral. At the distribution level, half of the capacity is assumed to be fully dedicated to distribution deferral and, hence, is not otherwise available for operational flexibility or capacity. Customer-sited storage is assumed not to be utilized for operational benefits. In Section 3, we review how these attributes and others are being modeled 
in recent and ongoing studies of storage on the California grid, while in Section 4, we develop variations on these attributes within the LTPP modeling framework.

Table 2. Storage Distribution Breakdown

\begin{tabular}{|lccc|}
\hline Values are MW in $\mathbf{2 0 2 4}$ & $\begin{array}{c}\text { Transmission- } \\
\text { connected }\end{array}$ & $\begin{array}{c}\text { Distribution- } \\
\text { connected }\end{array}$ & $\begin{array}{c}\text { Customer- } \\
\text { sited }\end{array}$ \\
\hline Total Installed Capacity & 700 & 425 & 200 \\
\hline Amount providing capacity and flexibility & 700 & 212.5 & 0 \\
\hline Amount with 2 hours of storage & 280 & 170 & 100 \\
\hline Amount with 4 hours of storage & 280 & 170 & 100 \\
\hline Amount with 6 hours of storage & 140 & 85 & 0 \\
\hline
\end{tabular}

Source: CPUC [19]: pg. 22.

Under the CPUC's rules, both existing storage projects and those already in planning and development are potentially qualified to meet utility requirements. ${ }^{9}$ By the utilities' estimates, these include $93 \mathrm{MW}$ of projects prior to any subsequent procurement, which consists of the 40 MW pumped storage plant being planned by SDG\&E and other smaller demonstration projects and micro-grids. ${ }^{10}$

\subsection{Storage Valuation}

The CPUC order requires jurisdictional load-serving entities to procure "viable and costeffective" energy storage systems, while meeting the requirements to promote storage technologies. The guidance includes identification of a set of storage services for consideration, including energy (including congestion and losses), ancillary services, RA capacity, effect on carbon emissions, and deferral of transmission and distribution investments. When evaluating storage offers, the utilities are required to use certain common pricing assumptions and reporting metrics under a Consistent Evaluation Protocol [5], with results denominated in levelized $\$ / \mathrm{kW}$. However, the utilities are also provided with latitude to utilize their own proprietary methods and models. Project selection requires using both quantitative and qualitative metrics.

Table 3 lists a set of the primary operational services and benefits provided by storage and how they are represented in the CPUC storage valuation requirements and the CAISO wholesale market. The final column of the table explains whether and how these services are represented in the LTPP model as currently configured. Additional discussion of these services is provided in Section 4.1 and in the results sections. Capacity value and other storage services are discussed further in Section 7.

The CAISO markets have a set of current products and pricing methods, as well as new products and pricing revisions in development. The current products include day-ahead and real-time energy, regulation up, regulation down, spinning reserves, and non-spinning reserves. The regulation market provides an option for limited energy non-generation resources called "regulation energy management." The CAISO plans to deploy a flexible ramping product in 2016, to be procured on an as-needed forecast basis in real-time operations and possibly in subsequent years in the day-ahead market. There may be yet other new market products, notably

\footnotetext{
${ }^{9}$ Detailed descriptions of these projects can be found in the 2014 utility storage procurement applications.

${ }^{10}$ The status of IOU procurement can be reviewed via the utility links on the CPUC storage webpage [18].
} 
a frequency responsive reserve. The average hourly quantities and prices for existing market products are available through a public website [20], and the past 2 years of ancillary service price and quantity data are summarized in Table 8 and Figure 20 below. The CAISO historical market prices are important as benchmarks for any simulated future prices, but it is also recognized that the increasing quantities of zero- or negative-priced renewable energy may significantly alter market prices in the future. ${ }^{11}$ These factors are evaluated further in this study.

In their procurement plan applications [18], each of the utilities outlined their internal valuation methods (these are also discussed in other regulatory documents). Generally, for the operational benefits analyzed in this study, the utilities utilize both proprietary and commercial models to develop long-term forecasts of wholesale locational energy prices, ancillary service prices, and RA capacity costs. These may then be modeled within an optimization framework, similar to the models used here, to derive joint operational benefits for storage. In addition, newer and planned services, such as ramping reserves, frequency responsive reserves, and flexible capacity, are also mentioned, although long-term price curves for these products are not yet available. Some of the utilities indicate that the effect of the penetration of storage technologies on market prices will be accounted for when valuing incremental storage resources.

\footnotetext{
${ }^{11}$ Additional insights would be gained from analysis of the sensitivity of energy storage value to natural gas price and carbon costs or constraints.
} 
Table 3. Storage Services Identified in the California Storage Policy and Corresponding Representation in Procurement Protocols, Wholesale Markets, and the LTPP Simulation Model

\begin{tabular}{|c|c|c|c|}
\hline $\begin{array}{c}\text { Storage } \\
\text { Operational } \\
\text { Services and } \\
\text { Benefits }\end{array}$ & $\begin{array}{l}\text { CPUC Consistent } \\
\text { Evaluation } \\
\text { Protocol/Other } \\
\text { Directives }\end{array}$ & $\begin{array}{c}\text { CAISO Wholesale } \\
\text { Market }\end{array}$ & LTPP Model \\
\hline \multicolumn{4}{|c|}{ Energy and Ramping Reserves } \\
\hline $\begin{array}{l}\text { Avoided start-up } \\
\text { costs }\end{array}$ & $\begin{array}{l}\text { Not discussed as a } \\
\text { component of energy or } \\
\text { ancillary services value }\end{array}$ & $\begin{array}{l}\text { Resource start-up and } \\
\text { minimum load costs are } \\
\text { bid into the markets and } \\
\text { compensated separately } \\
\text { for any residual such costs } \\
\text { that are not recovered } \\
\text { through market price } \\
\text { revenues. In the CAISO } \\
\text { markets, this is called Bid } \\
\text { Cost Uplift or Bid Cost } \\
\text { Recovery. These costs are } \\
\text { reported in CAISO reports } \\
\text { on an aggregated basis. }\end{array}$ & $\begin{array}{l}\text { Calculated as component of } \\
\text { production costs }\end{array}$ \\
\hline $\begin{array}{l}\text { Day-ahead } \\
\text { energy }\end{array}$ & \multirow{2}{*}{$\begin{array}{l}\text { Requires calculation of net } \\
\text { energy value; CPUC does not } \\
\text { distinguish day-ahead or } \\
\text { real-time energy value; } \\
\text { utilities may conduct } \\
\text { valuation of these markets } \\
\text { separately }\end{array}$} & $\begin{array}{l}\text { Hourly market with } \\
\text { locational marginal prices }\end{array}$ & \multirow{2}{*}{$\begin{array}{l}\text { LTPP model reflects both day- } \\
\text { ahead and real-time market } \\
\text { attributes (load-following) } \\
\text { using an hourly time-step. } \\
\text { Energy value can be } \\
\text { calculated as avoided } \\
\text { production costs or market } \\
\text { revenues. }\end{array}$} \\
\hline $\begin{array}{l}\text { Real-time } \\
\text { energy }\end{array}$ & & $\begin{array}{l}15 \text {-minute and } 5 \text {-minute } \\
\text { markets with locational } \\
\text { marginal prices }\end{array}$ & \\
\hline $\begin{array}{l}\text { Ramping } \\
\text { reserves }\end{array}$ & Not mentioned & $\begin{array}{l}\text { Flexible ramping constraint } \\
\text { implemented (real-time); } \\
\text { flexible ramping product } \\
\text { scheduled to be deployed } \\
\text { in } 2016\end{array}$ & $\begin{array}{l}\text { Load-following Up and Load- } \\
\text { following Down capacity } \\
\text { reservation in model reflects a } \\
\text { combination of ramping } \\
\text { reserves and economic } \\
\text { dispatch. Load following value } \\
\text { can be calculated as avoided } \\
\text { production costs or market } \\
\text { revenues. }\end{array}$ \\
\hline \multicolumn{4}{|c|}{ Ancillary services } \\
\hline $\begin{array}{l}\text { Regulation (up } \\
\text { and down) }\end{array}$ & \multirow{3}{*}{$\begin{array}{l}\text { Requires calculation of } \\
\text { market value }\end{array}$} & \multirow{3}{*}{$\begin{array}{l}\text { Hourly day-ahead and real- } \\
\text { time markets with zonal } \\
\text { clearing prices }\end{array}$} & \multirow{3}{*}{$\begin{array}{l}\text { All of these ancillary services } \\
\text { are represented as reserve } \\
\text { capacity, subject to resource } \\
\text { eligibility. Ancillary service } \\
\text { value can be calculated as } \\
\text { avoided production costs or } \\
\text { market revenues. }\end{array}$} \\
\hline Spinning reserve & & & \\
\hline $\begin{array}{l}\text { Non-spinning } \\
\text { Reserve }\end{array}$ & & & \\
\hline Voltage support & $\begin{array}{l}\text { Identified, but not required } \\
\text { to be quantified }\end{array}$ & Tariff-based rate & Not evaluated \\
\hline Blackstart & $\begin{array}{l}\text { Identified, but not required } \\
\text { to be quantified }\end{array}$ & Tariff-based rate & Not evaluated \\
\hline
\end{tabular}




\section{Research on Valuation of Energy Storage in California and Western U.S. Power Systems}

\subsection{Tools Used to Simulate Energy Storage Value}

Analysis of the value of energy storage is complicated because of the wide range of potential services (many of which can be jointly provided [7]), how those services are defined and procured in different regions, and the different types of models and tools used to analyze provision of those services. This study evaluates two types of value, which are most commonly calculated in simulations of storage operations: (1) reduction in aggregate production costs; and (2) wholesale market revenues. Each of these categories can be calculated using several approaches, including those summarized in Table 4.

Table 4. Comparison of Methods Used to Calculate Storage Value and Corresponding Models Used in This Paper

\begin{tabular}{|cccc|}
$\begin{array}{c}\text { Type of } \\
\text { Storage } \\
\text { Value }\end{array}$ & Model Used & $\begin{array}{c}\text { Where Prices } \\
\text { Come From }\end{array}$ & Description \\
$\begin{array}{c}\text { Reduction } \\
\text { in } \\
\text { production } \\
\text { cost }\end{array}$ & $\begin{array}{c}\text { Power system } \\
\text { model }\end{array}$ & N/A & $\begin{array}{c}\text { Establishes the value of storage measured by } \\
\text { reduction in operating costs between two model } \\
\text { runs: with and without storage. Storage dispatch is } \\
\text { optimized to minimize production costs. }\end{array}$ \\
\hline & $\begin{array}{c}\text { Power system } \\
\text { model, "system } \\
\text { optimized" }\end{array}$ & $\begin{array}{c}\text { Power system } \\
\text { model }\end{array}$ & $\begin{array}{c}\text { Revenue to storage plant(s) when storage is } \\
\text { optimized in a power system model. Storage } \\
\text { revenue is calculated by multiplying storage } \\
\text { dispatch by marginal prices for the services } \\
\text { provided. }\end{array}$ \\
\cline { 2 - 4 } Market & $\begin{array}{c}\text { Price-taker } \\
\text { model, } \\
\text { revenue }\end{array}$ & $\begin{array}{c}\text { Actual historical } \\
\text { markets or } \\
\text { power system } \\
\text { model }\end{array}$ & $\begin{array}{c}\text { Incremental storage resource is optimized to } \\
\text { maximize revenues against either historical } \\
\text { marginal prices OR prices generated from power } \\
\text { system models for each service provided. }\end{array}$ \\
\hline
\end{tabular}

\section{Models Used to Calculate Reduction in Production Cost (Regional Power System Models)}

Power system operational models simulate the interaction of supply and demand for electric power services subject to resource operating characteristics and transmission network constraints. These models are used to conduct long-term planning studies and examine system operations in an interconnected region, a wholesale market that comprises part of that region, or a utility or load-serving entity.

The most common type of models used to examine future operational impacts are production cost models, which use forecasts of fuel prices and generator heat rates to estimate the average and marginal cost of generation. A production cost model simulates a least-cost unit commitment and dispatch over a period of time to establish which resources - generators, storage, or demand response - are required to be online to meet the electricity demand and supply reserves for operational reliability, and satisfy other system constraints. Variable energy resources are generally added as fixed production profiles, and may consider a penalty cost for curtailment. Further details on these penalties and on storage representation are found in Section 4, below. 
Production cost models produce a variety of outputs including unit-level operations, total production costs, marginal costs of providing energy and reserves, and emissions.

Production cost models can be used to estimate the savings in operational costs that result from the introduction of new storage resources in an existing system. This method requires two model runs: a base case without the new storage and a case with the new storage. The resulting difference in production costs represents the operational value of the new storage resources.

\section{Models Used to Calculate Market Revenue}

As noted in Section 2, for projects in a wholesale market region, storage valuation can use historical market prices and forecasts of future prices to simulate future market revenues. Table 4, above, shows two methods to calculate storage revenue: (1) a storage plant optimized within a power system model; and (2) a price-taker model to calculate storage revenues using either historical or future simulated prices. These two methods are basically analogous to the two methods that storage operators could have for plant optimization within an ISO market: ISO optimization and self-scheduling.

\section{(1) System-optimized Market Revenues}

The first approach we define here is to calculate the market revenue for a system-optimized storage resource using the prices and storage dispatch determined by the power system model. Similar to an actual wholesale market, this method assumes that the storage resource is used to minimize total system production costs, including costs of start-up and fuel. ${ }^{12}$ In this case, the market revenue calculation is based on the simulated marginal prices for the wholesale services supplied by the storage resource. ${ }^{13}$ Because this approach uses a power system model, it considers the interaction of storage with all other resources and constraints in the power system and can be used to evaluate the impact of storage penetration on market prices and corresponding changes to storage revenue. The result shown in this study is the average revenue to the storage portfolio; to calculate the value of additions to the storage portfolio would require additional simulations. Production cost models can also simultaneously calculate the value of avoided startup costs, which are not credited to the storage plants under current wholesale market rules. We discuss this further in the next section.

\section{(2) Price-taker, Self-scheduled Market Revenues}

The second approach to calculate market storage revenue uses a separate optimization model, sometimes referred to as a price-taking model. This type of model calculates storage revenue using fixed historical or simulated future wholesale market prices or avoided utility marginal fuel costs. ${ }^{14}$ Unlike many power system models, these types of models can include very detailed

\footnotetext{
${ }^{12}$ In the actual markets operated by ISOs the cost minimization is based on bids submitted by the market participants and includes more bid components than are represented in the production cost models.

${ }^{13}$ The mathematical formulation of this calculation is to sum $p^{\prime} \times q^{\prime}$ for each interval $t$, where $p^{\prime}$ is the marginal price for the service (such as energy or ancillary services) and $q^{\prime}$ is the fixed quantity of services provided by storage as determined in each interval by the power system model. In other words, we are simply cross-multiplying outputs from the production cost model and not re-optimizing the use of the storage device.

${ }^{14}$ The basic formulation of this model is to maximize $p^{\prime} \times q$ subject to multiple storage specific and system constraints over a certain period of time, where $p^{\prime}$ is a vector of fixed prices for each service being analyzed and $q$ is a vector of variables for the quantity of services optimized in each interval.
} 
operational parameters and constraints of particular storage technologies. They co-optimize the storage resource's net revenues across multiple market products while respecting constraints imposed due to other uses of the resource, including those established to meet RA capacity requirements or support transmission and distribution deferral (e.g., [21]). This approach is the easiest method to estimate storage revenue, and as a result, most storage valuation studies to date have used variants on such price-taking models.

When used to model storage in competitive wholesale markets, such as the CAISO markets, we label these models as "self-scheduled" price-taker models, to distinguish them from the systemoptimized approach. Self-scheduling is an option in the wholesale markets by which the owner/operator provides the ISO with fixed schedules - in the case of storage, for both charging and discharging - which the ISO must utilize unless these schedules cause an operational infeasibility. We use this term for the price-taker models because they assume that the storage resource is used to maximize market revenues for the owner/operator, without consideration of how storage operations affect the operations of other resources as discussed further below.

Such price-taker models have been used to conduct cost-benefit analysis of CAISO market revenues and other applications for storage technologies across a variety of use-cases relevant to the CPUC storage policy [21]. A number of studies have found that the highest value applications of storage resources based on current market prices (in both the CAISO and other ISOs) are in the ancillary service markets, particularly regulation [21]. We show some additional estimates using historical CAISO prices in Section 5.4.

There are several major limitations of price-taking models. The first is that they do not evaluate how the operation or penetration of storage resources affects wholesale market prices or costs of power system operations not captured in market prices such as generator start-up costs. Under current CAISO rules, generators are compensated for these costs, if necessary, through additional out-of-market payments called "bid cost recovery" or "uplift." A merchant storage operator would not be directly compensated for avoiding generator start-up costs and regardless, they cannot be evaluated using a price-taker model. As a result, these models can only calculate the revenue of an "incremental" amount of energy storage, as significant penetration of storage would likely change market prices.

A second limitation is that most such models, including the one used in this study, have assumed perfect foresight of market prices across the optimization horizon. This results in higher storage revenues than would be the case in actual operations, where the entity self-scheduling would encounter forecast uncertainty. Some studies attempt to calculate the impact of forecast uncertainty within the optimization horizon of a price-taker model [22].

Other limitations include that, depending on the assumed storage operational constraints, the storage dispatch calculated by price-taker models may be highly responsive to small changes in market product prices between pricing intervals (typically on hourly time-steps). The cooptimized result for the individual resource may thus differ from the dispatch established by a system operator undertaking unit commitment and dispatch of all resources simultaneously.

As discussed in Section 5.4, these limitations of price-taker models could be particularly problematic for storage valuation under the new conditions emerging on the California power 
grid. In contrast, the system-optimized market revenue calculation would respect all system operational constraints. Results of these different approaches are discussed in Sections 5 and 6.

\section{Models Used in this Study by Application and Section}

This study utilizes all three of the approaches described in Table 4 above. This allows for a more detailed comparison of results for particular scenarios, and a more comprehensive perspective on storage value. Table 5 summarizes the application of each model type in results sections.

Table 5. Model Types Used in This Study, by Section and Application

\begin{tabular}{|c|c|c|c|c|c|}
\hline \multirow{3}{*}{ Section } & \multirow{3}{*}{ Use-Cases - Sensitivities } & \multirow{3}{*}{$\begin{array}{l}\text { Reduction } \\
\text { in } \\
\text { Production } \\
\text { Cost (2024) }\end{array}$} & \multicolumn{3}{|c|}{ Market Revenue } \\
\hline & & & \multicolumn{2}{|c|}{$\begin{array}{l}\text { Self- scheduled, } \\
\text { price-taker }\end{array}$} & \multirow{2}{*}{$\begin{array}{c}\text { System optimized } \\
\begin{array}{c}\text { forecast } 2024 \\
\text { prices }\end{array}\end{array}$} \\
\hline & & & $\begin{array}{l}\text { historical CAISO } \\
\text { prices from } \\
2013-14\end{array}$ & $\begin{array}{c}\text { forecast } 2024 \\
\text { prices }\end{array}$ & \\
\hline 5.1 & Pre-storage baseline & $\checkmark$ & & & \\
\hline 5.2 & $\begin{array}{l}\text { Energy arbitrage, } \\
\text { Reserves, } \\
\text { Co-opt. energy and reserves }\end{array}$ & $\checkmark$ & & & \\
\hline 5.4 & Energy arbitrage & & $\checkmark$ & $\checkmark$ & $\checkmark$ \\
\hline 5.4 & Co-opt energy and reserves & & $\checkmark$ & & \\
\hline 5.4 & Reserves-only & $\checkmark$ & & & \\
\hline 6.1 & Regulation-only & $\checkmark$ & & & \\
\hline 6.2 & $\begin{array}{l}\text { Co-opt. energy and reserves } \\
\text { - penetration by capacity }\end{array}$ & $\checkmark$ & & & \\
\hline 6.3 & $\begin{array}{l}\text { Co-opt. energy and reserves } \\
\text { - increased duration }\end{array}$ & $\checkmark$ & & & \\
\hline 6.4 & $\begin{array}{l}\text { Energy arbitrage } \\
\text { - negative bid sensitivities }\end{array}$ & $\checkmark$ & $\checkmark$ & $\checkmark$ & $\checkmark$ \\
\hline 6.5 & Disaggregated Portfolio & & $\checkmark$ & $\checkmark$ & \\
\hline 6.6 & $\begin{array}{l}\text { Co-opt. energy and reserves } \\
\text { - relaxed export constraints }\end{array}$ & $\checkmark$ & & & \\
\hline
\end{tabular}

\subsection{Previous Analysis of Energy Storage Value in California Using the LTPP Model Database}

Several of the recent studies of California storage benefits have utilized versions of the LTPP databases along with the PLEXOS production cost model (or other production cost models). More details on these models are provided in the next section and Appendix A. Several of these studies are listed in Table 6 below. The LTPP scenarios provide the starting point for analysis of storage impacts, typically modified to include additional storage resources for comparative valuation. The term "LTPP services" refers to the set of services represented in the LTPP model and listed in Table 3. 
Table 6. Comparison of Key Features of Recent California Studies Modeling Storage with Production Cost Models

\begin{tabular}{|c|c|c|c|c|}
\hline $\begin{array}{l}\text { Studyl } \\
\text { publication } \\
\text { year }\end{array}$ & $\begin{array}{l}\text { California LTPP } \\
\text { scenarios or other } \\
\text { scenarios }\end{array}$ & $\begin{array}{l}\text { Types of new } \\
\text { storage }\end{array}$ & $\begin{array}{l}\text { Storage } \\
\text { services } \\
\text { modeled }\end{array}$ & New storage scenarios \\
\hline $\begin{array}{l}\text { CAISO } \\
2014 \text { LTPP } \\
\text { models } \\
(2014)\end{array}$ & $\begin{array}{l}\text { All } 33 \% \text { and } 40 \% \\
\text { LTPP scenarios } \\
(2014)\end{array}$ & $\begin{array}{c}\text { Generic electrical } \\
\text { storage, CSP- } \\
\text { TES }\end{array}$ & $\begin{array}{l}\text { LTPP services } \\
\quad(\text { Table } 3)\end{array}$ & $\begin{array}{l}\text { Storage mandate portfolio } \\
\text { shown in Table } 10 \\
\text { assumed within scenarios }\end{array}$ \\
\hline $\begin{array}{l}\text { Lawrence } \\
\text { Livermore } \\
\text { National } \\
\text { Lab (LLNL) } \\
(2014) \\
2012 \text { LTPP } \\
\text { models [10] }\end{array}$ & $\begin{array}{l}\text { CPUC } 33 \% \text { RPS } \\
\text { trajectory scenario } \\
\qquad(2012)\end{array}$ & $\begin{array}{l}\text { Lithium ion } \\
\text { batteries, flow } \\
\text { batteries, CAES, } \\
\text { pumped hydro }\end{array}$ & $\begin{array}{l}\text { LTPP services } \\
\text { (Table 3) plus } \\
\text { subhourly } \\
\text { regulation } \\
\text { dispatch }\end{array}$ & $\begin{array}{c}\text { Multiple storage } \\
\text { scenarios showing } \\
\text { incremental additions and } \\
\text { variations in attributes, up } \\
\text { to } 1,700 \mathrm{MW} \text { of new } \\
\text { storage capacity }\end{array}$ \\
\hline $\begin{array}{l}\text { DNV-GL } \\
(2014) \\
2012 \text { LTPP } \\
\text { models [6] }\end{array}$ & $\begin{array}{l}\text { CPUC } 33 \% \text { RPS } \\
\text { trajectory scenario } \\
(2012)\end{array}$ & $\begin{array}{l}\text { Lithium ion } \\
\text { batteries, flow } \\
\text { batteries, CAES }\end{array}$ & $\begin{array}{l}\text { LTPP services } \\
\text { (Table 3) plus } \\
\text { subhourly } \\
\text { regulation } \\
\text { dispatch }\end{array}$ & Storage mandate portfolio \\
\hline $\begin{array}{l}\text { Argonne } \\
\text { Natl Lab } \\
(2013)[14]\end{array}$ & $\begin{array}{l}14 \% \text { and } 33 \% \\
\text { renewable Western } \\
\text { Interconnection } \\
\text { scenarios }\end{array}$ & Pumped storage & $\begin{array}{l}\text { LTPP services } \\
\text { (Table 3) plus } \\
\text { day-ahead to } \\
\text { real-time } \\
\text { commitment } \\
\text { and dispatch }\end{array}$ & $\begin{array}{l}\text { Planned and proposed } \\
\text { pumped storage plants }\end{array}$ \\
\hline $\begin{array}{l}\text { Jorgenson } \\
\text { et al., } 2014 \\
\text { (NREL) } \\
2012 \text { LTPP } \\
\text { models [11] }\end{array}$ & $\begin{array}{c}\text { CPUC 33\% RPS } \\
\text { trajectory scenario } \\
(2012) ; 40 \% \\
\text { California renewable } \\
\text { energy scenario } \\
\text { (developed for the } \\
\text { study) }\end{array}$ & $\begin{array}{c}\text { CSP-TES, } \\
\text { generic electrical } \\
\text { storage }\end{array}$ & $\begin{array}{l}\text { LTPP services } \\
\quad(\text { Table 3) }\end{array}$ & $\begin{array}{l}\text { Incremental CSP with } \\
\text { thermal storage }\end{array}$ \\
\hline $\begin{array}{l}\text { Denholm et } \\
\text { al., } 2013 \\
\text { (NREL) } \\
2012 \text { LTPP } \\
\text { models [9] }\end{array}$ & $\begin{array}{c}\text { CPUC 33\% RPS } \\
\text { trajectory scenario } \\
(2012)\end{array}$ & CSP-TES & $\begin{array}{l}\text { LTPP services } \\
\quad(\text { Table 3) }\end{array}$ & $\begin{array}{l}\text { Incremental CSP with } \\
\text { thermal storage }\end{array}$ \\
\hline
\end{tabular}

While starting from the LTPP databases, there are some differences in the model structure in these studies. Most studies, including this one, use a "deterministic" model framework, which assumes perfect foresight across the optimization horizon and a single forecast of load and renewable production for the target year being modeled; others have developed types of stochastic production simulation, which require much greater computation (e.g., [10] [23]). Most studies have used a single commitment and dispatch. In the actual CAISO markets, the dayahead markets clear in the prior day, and, therefore, have greater forecast uncertainty than is represented in these models, especially with increasing production by variable energy resources; real-time markets conduct a residual economic dispatch to meet actual load net of actual renewable production. To provide a more realistic approach to system operations, some storage simulation studies using variants on the LTPP model (e.g., $[10,14])$ also replicate the multiple 
steps of the day-ahead to real-time economic dispatch. This approach that could affect storage valuation, but is not evaluated in this study.

Some previous studies consider an array of storage technologies and applications. The LLNL study [10] evaluates a number of different storage technologies including lithium ion batteries, flow batteries, compressed air energy storage (CAES), and pumped hydro, with a wide range of assumptions and sensitivities. In addition, [10] examines the effect of storage penetration on value (which we also examine in Section 6 of this study); the simulations shows net revenue for the first unit of storage ranging from $\$ 20 / \mathrm{kW}$-year to $\$ 100 / \mathrm{kW}$-year of installed storage depending on the technology selected and the type of services provided. In addition to market revenues, changes in production costs were calculated. For a storage resource providing regulation, the reduction in production cost was $\$ 70$ million per year for $200 \mathrm{MW}$ of storage, which is $\$ 350 / \mathrm{kW}$-year. The LLNL study also finds a significant decline in revenue per unit of storage capacity as a function of storage penetration.

Some studies find that storage benefits increase with increasing renewable penetration. The Argonne study [14] evaluates both reduction in production cost and revenue associated with the addition of $1.8 \mathrm{GW}$ of new, flexible pumped storage plants in California. The study finds a low value of energy arbitrage in a base (14\% renewable) scenario, which increases substantially in a $33 \%$ renewable scenario. The study also demonstrates the ability of new storage to reduce curtailment and overall emissions under increased penetration of wind.

While diverse in methods and results, the literature to date on storage benefits on the California system is suggestive of a few key findings. First, storage benefits could increase with increasing renewable penetration. Second, some storage benefits, particularly from supply of ancillary services, are likely to decrease with increasing penetration of storage resources; however, this effect may be offset by the increased benefits from mitigation of other factors increasing with renewable penetration, such as over-generation. 


\section{Modeling Framework and Implementation of Energy Storage}

This section provides additional details on the modeling framework, including the production cost models and the market revenue models, and the scenarios which were developed to evaluate storage operations and value. As noted above, the CPUC's long-term procurement planning (LTPP) proceeding has developed a process for implementation of a regional power system model to evaluate the long-term (10 years ahead) operational impacts of different resource portfolios. In each LTPP cycle, the participating agencies develop a set of assumptions and scenarios for resource and transmission planning [19]; additional scenarios may also be developed [24]. This study uses the 2014 version of the database, which models the year 2024 and is publicly available. ${ }^{15}$ Henceforth, all references to the LTPP database or model refer to this version. The CAISO maintains the database and conducts the modeling for the proceeding.

The current CAISO modeling framework uses a three-step procedure, in which the first step is development of a single annual point forecast of 1-minute load and wind and solar profiles for the target year (2024). The second step is the calculation of hourly regulation and load-following requirements using a statistical model, and the third step is use of a production cost model (the PLEXOS software package) for the simulation of system operations under each scenario modeled [25]. The CAISO simulations are intended primarily to identify operational requirements in the target year. The results are not used for valuation, at least in this proceeding.

\subsection{The California 2014 LTPP Model and Scenarios}

This section discusses key assumptions and scenarios in the LTPP model.

\section{Modeling Methodology}

The LTPP model contains detailed generator, demand, and reserve requirement information along with transmission system properties and system constraints (e.g., local generation requirement for California, no net export from California, and a carbon tax). The model seeks to minimize production cost while satisfying all system constraints The LTPP model presently runs a medium-term commitment first to establish monthly hydroelectric targets at daily resolution, then runs a day-ahead unit commitment and economic dispatch with hourly resolution using one day of look-ahead. The model includes a full chronological year of modeled data on which to perform deterministic simulations. Additional details can be found in Appendix A.

\section{Thirty-Three Percent and Forty Percent Renewable Energy Portfolios}

The state's renewable portfolio standard (RPS) program sets both long-term and annual incremental targets and procedures for renewable procurement, including the valuation of

\footnotetext{
${ }^{15}$ The LTPP database contains several $33 \%$ and $40 \%$ renewable penetration scenarios: Trajectory, Trajectory without Diablo Canyon, High-load, Expanded preferred resources, and 40\% renewable energy in 2024. Each of those scenarios can also be run under two conditions: (1) "need", which is used to explore potential capacity shortfalls; and (2) "prodcost" (production cost), which is used to look at normal operations. The difference between the "need" and "prodcost" models are related to the load-following and regulation requirements, which are higher in the former than in the latter. For this study we utilize the " $33 \%$ Trajectory ProdCost" and " $40 \%$ RPS ProdCost" scenarios from the 2014 LTPP model.
} 
alternative renewable technologies. ${ }^{16}$ The RPS is currently set at $50 \%$ of annual retail electricity sales by 2030 [26]; the prior RPS targets (33\% RPS by 2020) and commercial expectations suggest that the range by 2024 should be between $33 \%$ - 40\% renewable energy. Hence, for LTPP and other planning purposes, the CPUC prepares a set of 2024 scenarios for its jurisdictional load-serving entities and for transmission planning of the remaining RPS energy requirements, currently including several alternative $33 \%$ and $40 \%$ renewable energy portfolios [19]. The methodology for developing these portfolios is based on a combination of existing contracts and the use of environmental and economic criteria to develop alternative additions to the existing portfolio.

The two LTPP scenarios for 2024 modeled in this study are summarized in Table 7 below. The $33 \%$ scenario includes $33.2 \mathrm{GW}$ of renewable capacity dedicated to serving load of the California IOUs, of which about $84 \%$ is located within California and the remainder in other parts of the WECC. Notably, of the resources added to the $33 \%$ scenario to get to the $40 \%$ scenario, all are located in California ("In-State"). Moreover, most of the additional renewable energy is expected to be solar PV. Specifically, the $40 \%$ scenario modeled here adds 7,659 MW of $\mathrm{PV}$ to the solar portfolio of $14,453 \mathrm{MW}$ in the $33 \%$ scenario. There is also an additional 1,043 MW of wind in the $40 \%$ scenario, added to $11,146 \mathrm{MW}$ of wind in the $33 \%$ scenario. As such, the scenarios provide some insight into the interaction of increased solar production and storage valuation, which is seen in the results sections and discussed further in the conclusions. The $40 \%$ renewable scenario could be fulfilled by a different mix of renewable resources, which would then have different impacts on storage value.

\footnotetext{
${ }^{16}$ The renewable technologies eligible for the California RPS include wind, solar, geothermal, biofuels, and small hydro, but exclude large-scale hydro.
} 
Table 7. Renewable Generation Mix for the $33 \%$ and $40 \%$ Scenarios Used in This Study

\begin{tabular}{|c|c|c|c|c|c|c|c|c|}
\hline & Biomass & Geothermal & $\begin{array}{l}\text { Small } \\
\text { Hydro }\end{array}$ & $\begin{array}{l}\text { Large } \\
\text { Solar } \\
\text { PV }\end{array}$ & $\begin{array}{l}\text { Small } \\
\text { Solar } \\
\text { PV }\end{array}$ & $\begin{array}{l}\text { Solar } \\
\text { Thermal }\end{array}$ & Wind & Total \\
\hline \multicolumn{9}{|c|}{ Trajectory $33 \%$ Renewable Energy Scenario } \\
\hline $\begin{array}{l}\text { Capacity } \\
\text { (MW) }\end{array}$ & 1,623 & 2,999 & 3,017 & 9,087 & 3,564 & 1,802 & 11,146 & 33,239 \\
\hline $\begin{array}{l}\text { Energy } \\
\text { (GWh) }\end{array}$ & 10,096 & 15,003 & 5,334 & 21,091 & 7,312 & 4,322 & 24,899 & 88,056 \\
\hline $\begin{array}{l}\text { In-state } \\
\text { energy }\end{array}$ & 9,534 & 13,645 & 5,294 & 17,787 & 7,312 & 4,322 & 15,701 & 73,595 \\
\hline $\begin{array}{c}\text { Out-state } \\
\text { energy }\end{array}$ & 562 & 1,358 & 40 & 3,304 & 0 & 0 & 9,198 & 14,461 \\
\hline \multicolumn{9}{|c|}{ 40\% Renewable Energy in 2024 Scenario } \\
\hline $\begin{array}{l}\text { Capacity } \\
\text { (MW) }\end{array}$ & 1,626 & 2,999 & 3,017 & 11,195 & 9,115 & 1,802 & 12,189 & 41,943 \\
\hline $\begin{array}{l}\text { Energy } \\
\text { (GWh) }\end{array}$ & 10,117 & 15,003 & 5,334 & 25,597 & 18,518 & 4,322 & 27,844 & 106,734 \\
\hline $\begin{array}{l}\text { In-state } \\
\text { energy }\end{array}$ & 9,555 & 13,645 & 5,294 & 22,293 & 18,518 & 4,322 & 18,646 & 92,273 \\
\hline $\begin{array}{c}\text { Out-state } \\
\text { energy }\end{array}$ & 562 & 1,358 & 40 & 3,304 & 0 & 0 & 9,198 & 14,461 \\
\hline
\end{tabular}

Source: CPUC [19]

\section{Geographical Scope}

In the LTPP model, the full Western Interconnection is represented by 43 zones, illustrated in Appendix A. The model is solved as a single region. Historically, California has been a net importer in each hour, and accurate modeling of the California grid requires consideration of how California will interact with the rest of the WECC. The database has constraints set on transmission between zones; however, these constraints represent an aggregation of transmission lines, and therefore the modeled results cannot evaluate the role of storage in relieving local transmission congestion or in deferring new transmission investments.

There are two additional factors that constrain interchange between California and the rest of the West. The first is a carbon cost on imports, which is described further below. The second is a "net zero export constraint," which does not allow for net export of energy generated in California. In other words, California must remain a net importer in all hours. However, with the growing supply of renewable generation within the state, the potential for exports of surplus energy are being forecasted. Hence, this restriction is also examined in Section 6.6.

\section{Fuel Prices}

Figure 1 shows the forecasts of prices for each type of fuel in the LTPP model. The error bars represent the range of fuel prices, which can vary across region and even monthly for natural gas. 


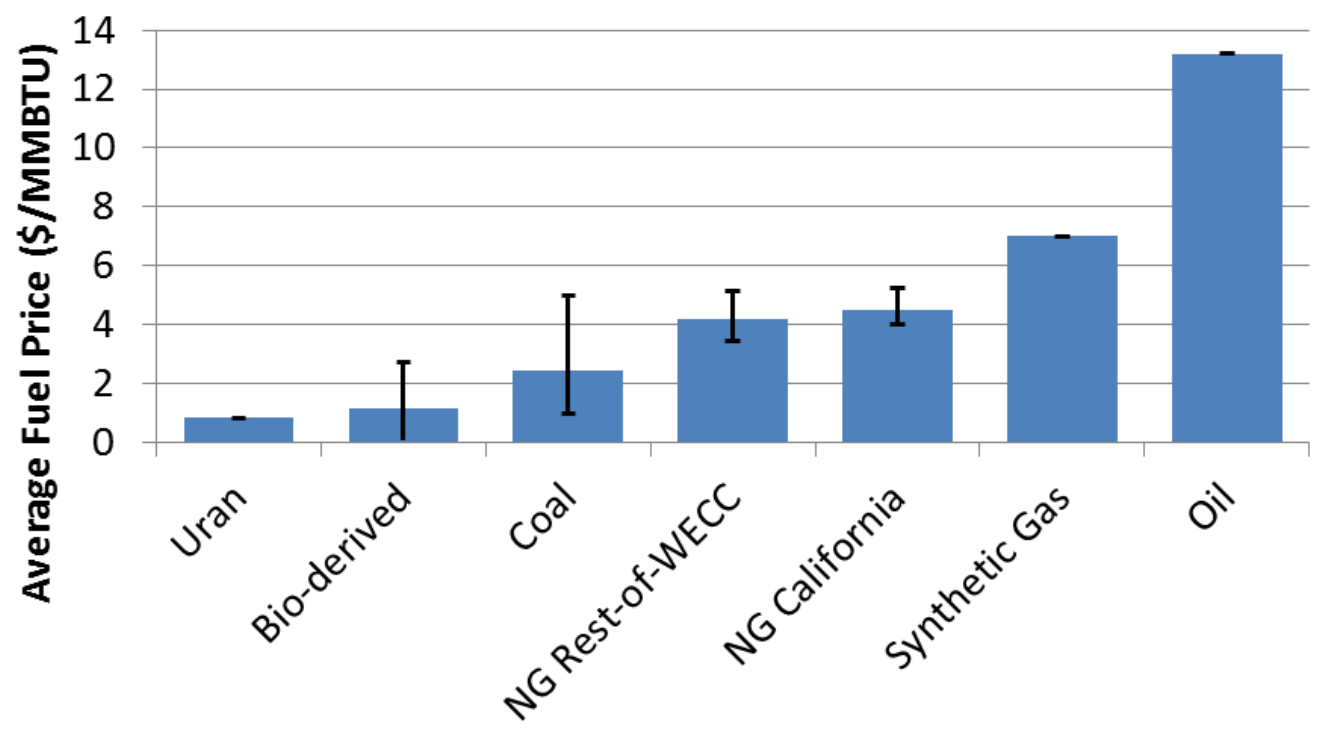

Figure 1: Fuel price inputs for LTPP model including range

\section{Ancillary Service and Load-Following Requirements}

The LTPP model simulates six reserve products: load-following up, load-following down, regulation up, regulation down, spinning reserve, and non-spinning reserve. Table 8 provides basic statistics on the reserve requirements in the CAISO markets in 2013 and 2014, and the simulated increase in reserves needed by 2024 incorporated in the LTPP model for future renewable integration.

The actual reserve requirements needed in 2024 could have a significant impact on storage value, because storage resources can offer reserves at low incremental cost, and could in principle reduce regulation requirements by providing faster response and higher performance than most thermal generators (which is not examined in this study). Reserve requirements for loadfollowing and regulation are constructed for the entire state and then proportionally split between IOUs (85.6\%) and POUs (14.4\%). The CAISO's current statistical model (called the "Step 1" model in the LTPP framework) suggests that average hourly regulation requirements will increase by about $13 \%$ for regulation up and $23 \%$ for regulation down in the $33 \%$ scenario. Notably, the model suggests only a subsequent $3 \%$ increase in average regulation up requirements and a $5 \%$ increase in regulation down between the $33 \%$ and $40 \%$ scenarios. This is in part because the additional solar energy is spatially distributed and does not significantly increase the 1-minute variability on the system. However, the maximum hourly regulation requirements, which are also the highest cost intervals, do increase more significantly between the two scenarios-about $27 \%-28 \%$-reflecting the increase in the net load system ramps.

The load-following reserve does not currently have a direct analogue in the actual CAISO markets, where the load-following function is conducted by the real-time dispatch augmented by a flexible ramping constraint to maintain additional ramping capability. In the future, the CAISO will implement a flexible ramping product. In the LTPP model this reserve similarly functions as a proxy for the real-time energy dispatch range, including any required flexible ramping 
reserves, which should be held in the hourly production cost model. ${ }^{17}$ Between the $33 \%$ and $40 \%$ scenarios, the average increase in hourly load-following increases by about $10 \%$ for loadfollowing up and 9\% for load-following down, but the maximum requirements, which are the highest cost intervals, increase by $37 \%$ and $32 \%$, respectively. Spinning and non-spinning reserves are not forecast to change from current levels as renewable energy does not affect system contingency events (associated with large power plant or transmission line failures). In the LTPP model, spinning and non-spinning reserve requirements are set as $3 \%$ of the load (each) for a total of $6 \%$. Storage resources will be eligible for participation in these reserve markets as long as they can meet the required operational capabilities.

Table 8. Day-Ahead CAISO Reserve Procurement (MW): Historical and Forecast, Represented Annually

\begin{tabular}{|c|c|c|c|c|c|c|c|c|}
\hline & \multirow[t]{2}{*}{$\begin{array}{l}2013 \text { [16] } \\
\text { Avg. }\end{array}$} & \multirow[t]{2}{*}{$\begin{array}{l}2014 \text { [16] } \\
\text { Avg. }\end{array}$} & \multicolumn{3}{|c|}{$2024-33 \%$ Scenario } & \multicolumn{2}{|c|}{$\begin{array}{l}2024-40 \% \\
\text { Scenario }\end{array}$} & \multirow[b]{2}{*}{ Min } \\
\hline & & & Avg. & Max. & Min & Avg. & Max. & \\
\hline \multicolumn{9}{|l|}{ Current ancillary services } \\
\hline Regulation up & 338 & 341 & 385 & 803 & 0 & 397 & 1026 & 0 \\
\hline Regulation down & 325 & 326 & 401 & 1109 & 62 & 422 & 1412 & 0 \\
\hline Spinning reserve & $\sim 871$ & $\sim 849$ & 850 & 1588 & 559 & 850 & 1588 & 559 \\
\hline Non-spinning reserve & $\sim 846$ & $\sim 853$ & 850 & 1588 & 559 & 850 & 1588 & 559 \\
\hline \multicolumn{9}{|l|}{ Load-following provision } \\
\hline Load-following up & N/A & N/A & 1279 & 2573 & 471 & 1412 & 3532 & 467 \\
\hline Load-following down & $\mathrm{N} / \mathrm{A}$ & N/A & 1256 & 2669 & 520 & 1373 & 3529 & 491 \\
\hline
\end{tabular}

Sources: CAISO historical data from OASIS website; 2024 data for IOUs from LTPP databases.

\section{Negative Bids from Renewable Generation}

In the wholesale markets, overgeneration conditions generally result in negative market prices for energy, signaling that generators that prefer to remain online will have to pay for all energy produced, while demand (including storage charging) in those intervals would be paid to consume. Negative prices are generally caused by negative bids that clear the energy market [16]. For generation with constraints on starts and stops, negative bids are related to the willingness to pay to avoid costs and potential lost market revenues from shutting down for the period of negative prices and starting up afterwards. For variable energy resources, negative bids are a function of the potential lost non-wholesale market revenues due to curtailment of production, which could include lost financial incentives linked to energy production, renewable energy credits, and/or contracted payments under power purchase agreements [27].

In the CAISO markets, negative bids are currently limited by a $-\$ 150 / \mathrm{MWh}$ " bid floor," which will reach $-\$ 300 / \mathrm{MWh}$ before 2020 [28]. In 2014, most CAISO real-time market negative prices were between $\$ 0 / \mathrm{MWh}$ to $-\$ 30 / \mathrm{MWh}$, although they did reach $-\$ 150 / \mathrm{MWh}$ in some interval [16]. The LTPP model uses the $-\$ 300 / \mathrm{MWh}$ bid floor to bound the assumed negative bids of renewable energy in 2024 by setting their variable operations and maintenance (VO\&M) cost to $-\$ 300 / \mathrm{MWh}$. That is, this assumption establishes a maximum allowed price on renewable

\footnotetext{
${ }^{17}$ The Step 1 load-following reserve requirement is calculated with consideration of short-term forecast errors about load, wind, and solar within the operating hour; hence, it incorporates the type of additional reserve capability currently provided by the CAISO's flexible ramping constraint.
} 
curtailment (which is examined further in Section 6.4). However, because all (non-curtailed) renewable energy is then valued at this cost in the model solution, the CAISO removes all negatively priced energy in post-processing, and retains only the production costs of positive priced energy [25]. ${ }^{18}$ We use the same approach in our production cost runs. However, when calculating storage plant revenue, we consider a range of negative bids for renewables, discussed in Section 4.3.

\section{Carbon Cost}

Under legislation enacted in 2006 [29], California has a target to reduce greenhouse gas emissions in 2020 to 1990 levels, in part using a cap-and-trade system to establish efficient reductions between and across the affected sectors. The cap-and-trade system is source based, requiring all in-state fossil generation to obtain emissions permits. California also assigns a carbon tax on power imported into the state. For purposes of power system modeling, the LTPP model assumes a carbon tax of $\$ 21.88 /$ ton in 2024 for in-state fossil generation and a cost adder assessed to imports from external resources. The cost adder for imports from Bonneville Power Administration (BPA) is $\$ 2.02 / \mathrm{MWh}$, due to the prevalence of hydro and wind in the resource mix, while for every other region outside of California it is $\$ 10.12 / \mathrm{MWh}$. In this way, all fossilfuel power produced in California or imported is assessed a charge for carbon. However, as the LTPP model allows for the entire West to re-dispatch, this carbon tax does not prevent storage located in California from effectively charging from lower-cost coal generation outside California if the charging cost is sufficiently low to reduce overall production cost. This effect is examined in more detail in Section 5.

\section{Existing and Planned Pumped Storage}

California has an existing stock of approximately $3.1 \mathrm{GW}$ of pumped storage plants, including IOU and POU plants, and the LTPP model assumes that another $390 \mathrm{MW}$ is deployed by 2024 outside the CAISO, as indicated in Table 9. The pumped storage plants, as modeled, are able to provide energy arbitrage and the reserve services listed in the table below. Pumped storage in the model is not limited to specific hours but rather is responsive to grid needs and can generate or pump at any hour of the day. The LTPP model assumes that the Lake Hodges plant (40 MW) counts toward the 1,325 MW storage mandate; therefore, it is considered "new" storage in the next subsection.

\footnotetext{
${ }^{18}$ An example of how the model accounts for two different types of energy - renewable and fossil fuel - can help to illustrate this method. Consider a hypothetical $200 \mathrm{MW}$ of energy demand from some interval being modeled: 100 MW is generate by renewable energy and $100 \mathrm{MW}$ is produced by a fossil generator. The renewable energy has no fuel cost but a VO\&M cost of $-\$ 300 / \mathrm{MWh}$. The fossil generator has an assumed cost of $\$ 50 / \mathrm{MWh}$. The aggregate "production cost" of this hypothetical $200 \mathrm{MW}$ of energy is $(100 \mathrm{MW} \times-\$ 300 / \mathrm{MWh})+(100 \mathrm{MW} \times \$ 50 / \mathrm{MWh})=-$ $\$ 30,000+\$ 5,000=-\$ 25,000$. The negative-priced renewable energy is then removed in post-processing, leaving a positive additional production cost of $\$ 5,000$, reflecting operations of the fossil generator. This procedure applies to all energy dispatched in the model. All results in this paper are also processed in this fashion.
} 
Table 9. Existing and Planned California Storage Modelled

\begin{tabular}{|lccc|}
\hline Plant Name & Location & Capacity (MW) & $\begin{array}{c}\text { Reserve Services } \\
\text { Provided }\end{array}$ \\
\hline Castaic & LADWP & 1,271 & $\begin{array}{c}\text { All } \\
\text { (but assigned to LADWP) }\end{array}$ \\
\hline Eastwood & SCE & 199 & None \\
\hline Helms & PG\&E Valley & 1,218 & All \\
\hline lowa Hill & SMUD (planned) & 390 & $\begin{array}{c}\text { All } \\
\text { (but assigned to SMUD) }\end{array}$ \\
\hline Lake Hodges & SDG\&E (planned) & 40 & $\begin{array}{c}\text { Load following, } \\
\text { nonspinning }\end{array}$ \\
\hline $\begin{array}{l}\text { SN LS PP 8 } \\
\text { (William R. Gianelli } \\
\text { hydroelectric plant) }\end{array}$ & PG\&E Valley & 374 & \begin{tabular}{c} 
Nonspinning \\
\hline Total
\end{tabular} \\
\hline
\end{tabular}

\subsection{Representation and Operation of New Storage Resources in the LTPP Model}

This section describes the further development of storage scenarios examined in this study.

\section{Reference "No Storage" Scenario}

The primary performance metric evaluated in this study is the change in production costs associated with the addition of new storage. Because the LTPP model includes the 1,325 MW of new storage in its portfolio, and the operation of this portfolio in its modeled results [25], we begin by removing this new storage and recalculating production costs. No other adjustments were made to the resource portfolios. We evaluate both $33 \%$ and $40 \%$ scenarios in this fashion.

\section{Base Storage Scenarios}

The base storage scenarios include the original LTPP portfolios with storage, as well as variants described in this subsection.

The CPUC storage procurement targets as modeled in the original LTPP database are divided over the three investor-owned utilities by location (i.e., utility footprint), type of connection, and capacity, illustrated in Table 10. The LTPP model has sufficient transmission detail to allow for storage projects to be modeled by transmission zones corresponding to these utilities, although they do not reflect the boundaries of all local capacity areas or any other sub-zonal locational value (for example, deferral of distribution-investment). Following the LTPP model assumptions, storage resources assigned by the CPUC to the investor-owned utilities are located in the zones corresponding to each utility. ${ }^{19}$

\footnotetext{
${ }^{19}$ PG\&E comprises two sub-regions: PG\&E Valley and PG\&E Bay. The storage portfolio is split between the two regions (i.e., $62 \%$ for the Valley and $38 \%$ for the Bay).
} 
The CPUC storage decision in 2013 [5] established only MW targets for the storage portfolio. However, the 2014 LTPP assumptions included preliminary assumptions about the storage attributes for each IOU, as shown in Table 10. The Lake Hodges pumped storage plant is not included in the table, but represents $40 \mathrm{MW}$ of transmission-connected storage allocated to SDG\&E. Inclusion of Lake Hodges brings the total installed capacity of new storage to 1,325 MW.

Table 10. Storage Operational Attributes in 2024 from CPUC R.13-12-010

\begin{tabular}{|lccccccccccc|} 
& \multicolumn{1}{c}{ PG\&E Capacity (MW) } & \multicolumn{4}{c}{$\begin{array}{c}\text { SCE Capacity } \\
\text { (MW) }\end{array}$} & \multicolumn{4}{c}{$\begin{array}{c}\text { SDG\&E Capacity } \\
\text { (MW) }\end{array}$} & $\begin{array}{c}\text { Total } \\
\text { (MW) }\end{array}$ \\
\hline Duration (hours) & 2 & 4 & 6 & 2 & 4 & 6 & 2 & 4 & 6 & \\
& hours & hours & hours & hours & hours & hours & hours & hours & hours \\
\hline Transmission & 124 & 124 & 62 & 124 & 124 & 62 & 32 & 32 & 0 & 660 \\
\hline Distribution & 74 & 74 & 37 & 74 & 74 & 37 & 22 & 22 & 11 & 425 \\
\hline Customer & 43 & 43 & 0 & 43 & 43 & 0 & 15 & 15 & 0 & 200 \\
\hline Total & 241 & 241 & 99 & 241 & 241 & 99 & 69 & 69 & 11 & 1,285 \\
\hline
\end{tabular}

Source: CAISO Testimony to the CPUC (Table 13) [25]

In addition, the 2014 LTPP assumptions include a number of constraints on how storage resources are operated to provide operational flexibility (defined here as energy shifting and all reserves) and capacity to the CAISO, reflecting both the expected mix of applications and current regulatory rules at both federal and state levels. These initial assumptions are that all transmission-connected, and $50 \%$ of distribution-connected storage is capable of providing operational flexibility. This is represented in the LTPP model by assuming that the system operator can optimally dispatch these resources and provide any combination of energy and reserves that minimizes system-wide production cost. The new storage can only provide reserves for the IOU portion of the total reserve requirement in California. The remaining $50 \%$ of distribution-connected storage and all customer-sited storage are not expected to provide such flexibility. This is modeled by representing this storage as energy-shifting-only resources, dispatched optimally to minimize system-wide production costs. As a result, the only difference in the operation of any storage resource is whether or not it can provide reserves. Table 11 provides a more accurate representation of how the storage listed in Table 10 is actually modeled in the LTPP database.

Table 11. LTPP Model Storage Configuration

\begin{tabular}{|c|c|c|c|c|c|c|c|c|c|c|}
\hline \multirow[b]{2}{*}{ Storage type } & \multicolumn{3}{|c|}{$\begin{array}{l}\text { PG\&E Capacity } \\
\text { (MW) }\end{array}$} & \multicolumn{3}{|c|}{ SCE Capacity (MW) } & \multicolumn{3}{|c|}{$\begin{array}{c}\text { SDG\&E Capacity } \\
\text { (MW) }\end{array}$} & \multirow[t]{2}{*}{$\begin{array}{l}\text { Total } \\
\text { (MW) }\end{array}$} \\
\hline & $\begin{array}{c}2 \\
\text { hours }\end{array}$ & $\begin{array}{c}4 \\
\text { hours }\end{array}$ & $\begin{array}{c}6 \\
\text { hours }\end{array}$ & $\begin{array}{c}2 \\
\text { hours }\end{array}$ & $\begin{array}{c}4 \\
\text { hours }\end{array}$ & $\begin{array}{c}6 \\
\text { hours }\end{array}$ & $\begin{array}{c}2 \\
\text { hours }\end{array}$ & $\begin{array}{c}4 \\
\text { hours }\end{array}$ & $\begin{array}{c}6 \\
\text { hours }\end{array}$ & \\
\hline $\begin{array}{l}\text { All services (energy + } \\
\text { reserves) }\end{array}$ & 161 & 161 & 80.5 & 161 & 161 & 80.5 & 43 & 19 & 5.5 & 872.5 \\
\hline $\begin{array}{l}\text { Energy (load shifting) } \\
\text { only }\end{array}$ & 79.5 & 79.5 & 18 & 79 & 79 & 18 & 26 & 26 & 5.5 & 412.5 \\
\hline Total & 240.5 & 240.5 & 99 & 240.5 & 240.5 & 99 & 69 & 45 & 11 & 1,285 \\
\hline
\end{tabular}


Before conducting sensitivities, we evaluate the no storage scenario and four "base" storage scenarios, summarized in Table $12 .{ }^{20}$ The first storage scenario most closely resembles the storage mandate, where most storage can provide energy and reserves, with the exceptions described in the previous paragraph. (We use the abbreviation "ene\&res" for this scenario in many of the figures). The other three storage scenarios limit the services that storage can provide (energy-only, eligible reserves and reserves-only) and thus help determine the source of the value for the storage portfolio. For the energy-only scenario, storage provides exclusively energy arbitrage. The last two scenarios are used to represent different capabilities to provide reserves. The "eligible reserves" scenario increases reserve participation to the maximum level eligible under the 2014 LTPP assumptions (i.e., 50\% of distribution-connected and all of transmissionconnected storage can provide operating reserves), which results in $912.5 \mathrm{MW}$ providing reserves-only and the remaining $412.5 \mathrm{MW}$ provides energy-only. This limitation is based on current expectations about the use-cases for storage at the distribution level and current technical and regulatory limitations on customer-sited storage providing wholesale market services. However, in the future, it may be possible that a larger part of the storage portfolio may be able to provide ancillary services. To examine a bounding case where all storage provides only reserves, we also consider a "reserves-only" scenario.

Table 12. List of Base Storage Scenarios and Alternative Applications

\begin{tabular}{|c|c|c|c|c|}
\hline \multirow[b]{2}{*}{$\begin{array}{l}\text { Scenario } \\
\text { Name }\end{array}$} & \multicolumn{3}{|c|}{$\begin{array}{l}\text { Storage Capacity (MW) } \\
\text { By Service Provided }\end{array}$} & \multirow[b]{2}{*}{ Additional Description } \\
\hline & 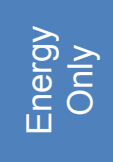 & 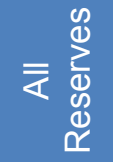 & 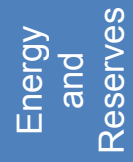 & \\
\hline $\begin{array}{l}\text { LTPP no } \\
\text { storage } \\
\text { "No Storage" }\end{array}$ & None & None & None & $\begin{array}{l}2014 \text { LTPP } 33 \% \text { and } 40 \% \text { scenarios with new storage } \\
\text { removed. }\end{array}$ \\
\hline $\begin{array}{l}\text { Base (Energy+ } \\
\text { Reserves) } \\
\text { "ene\&res" }\end{array}$ & 412.5 & & 912.5 & $\begin{array}{l}33 \% \text { and } 40 \% \text { scenarios with CPUC storage portfolio included } \\
\text { [19]. Several adjustments to LTPP assumptions are described } \\
\text { in Appendix B. }\end{array}$ \\
\hline $\begin{array}{l}\text { Energy only } \\
\text { "ene only" }\end{array}$ & 1325 & & & $\begin{array}{l}\text { Same as Base storage scenario above, but all resources } \\
\text { provide only energy time-shift or arbitrage. }\end{array}$ \\
\hline $\begin{array}{l}\text { Eligible } \\
\text { reserves } \\
\text { "eligible res" }\end{array}$ & 412.5 & 912.5 & & $\begin{array}{l}\text { Same as Base storage scenario above, but most resources } \\
\text { provide only operating reserves within the limits on storage } \\
\text { utilization prescribed in the } 2014 \text { LTPP assumptions [19]. }\end{array}$ \\
\hline $\begin{array}{l}\text { Reserves only } \\
\text { "res only" }\end{array}$ & & 1,325 & & $\begin{array}{l}\text { Same as Base storage scenario above, but all storage } \\
\text { resources provide only operating reserves. }\end{array}$ \\
\hline
\end{tabular}

Storage resources are modeled in the production simulation using methods implemented in previous NREL analyses $[2,11,13]$. Storage properties include maximum generation and charging capacity (MW), efficiency (\%), and energy capacity (MWh). Storage is assumed to be able to ramp very quickly, so can use all capacity not used for provision of energy for operating reserves. The LTPP model assumes that the storage portfolio must begin and end the day at a

\footnotetext{
${ }^{20}$ In all cases, "no storage" actually means no new storage, as all scenarios include the existing pumped storage in California.
} 
$50 \%$ state of charge. The LTPP model does not model a specific energy storage technology; instead it represents a "generic" storage resource with an assumption of $83.3 \%$ round-trip efficiency.

All scheduling and operation of the storage resources is optimized by the production cost model, and in scenarios where multiple services are jointly analyzed the model performs a cooptimization. This means that the actual provision of services is not an input to the model, but is determined by the model, selecting the set of services to minimize the overall cost of production in any given period of time.

The production cost model explicitly tracks energy shifted in time for energy arbitrage, accounting for efficiency losses. However the LTPP model does not consider the actual energy cycled through storage when providing regulation or load-following reserves. Inclusion of this would tend to decrease the value of energy storage; however, the LTPP model also does not consider many of the avoided costs associated with providing regulation and load-following with energy storage. These include the costs associated with thermal plants rapidly changing output when providing reserves. This issue and its impact on storage value are discussed in Sections 5.4 and 6.1 .

\subsection{Representation of Storage in Price-Taking Model}

In addition to the production cost model, this study used a price-taker optimization model developed by NREL [30]. As described in Section 2, this model uses historical or simulated future prices as fixed inputs to maximize the profit earned by the resource, subject to its operational constraints. The model can be adjusted to examine different storage capacity and duration.

To maximize consistency between the simulated results, similar parameters are used for representing storage in both the production cost and price-taker models (Table 13). The parameters are identical except for the optimization window, which is shorter for the production cost model than for the price-taker model.

Table 13. Comparison of Storage Assumptions in Production Cost and Price-Taker Models

\begin{tabular}{|lcc|}
\hline Storage Parameters & Production Cost Model & Price-Taker \\
\hline Efficiency & $83.3 \%$ & $83.3 \%$ \\
\hline Duration & 2,4, and 6 hours & 2,4, and 6 hours \\
\hline $\begin{array}{l}\text { Total installed capacity (composed of } \\
\text { several resources across four } \\
\text { regions) }\end{array}$ & $1,325 \mathrm{MW}$ & $1,325 \mathrm{MW}$ \\
\hline Ramp rate & $\begin{array}{c}\text { unconstrained } \\
\text { 24 hours }\end{array}$ & Unconstrained \\
\hline Optimization window & $\begin{array}{c}\text { (Starts and ends the day } \\
\text { at the same SOC) }\end{array}$ & 8784 hours \\
\hline State of charge assumptions & No minimum SOC & No minimum SOC \\
\hline Minimum part-load operation & 0 & $0 \%$ \\
\hline
\end{tabular}




\subsection{Sensitivity Analysis}

In addition to the initial (base) storage scenarios, we examine six sensitivity scenarios which help address key questions of interest in California regarding how storage value is affected by the penetration of storage into different market products, decisions on the composition of the storage portfolio, and the interaction of storage operations with other market factors and policies intended to support renewable integration. Each of these sensitivities is explained briefly here, with more description and results in Section 6.

\section{Value of Storage Providing Regulation Reserves}

Regulation is currently the highest value ancillary service in the CAISO markets, and is the service most attractive to certain types of storage resources, such as batteries and flywheels [21]. The LTPP model does not explicitly represent regulation dispatch or regulation performance payments, but can evaluate the impact of storage in meeting regulation capacity reserve requirements (i.e., the range of regulation capability (MW) reserved on eligible resources for real-time operations). We examine a scenario where all the storage eligible to provide ancillary services (which we have called "eligible res" in the prior section) can provide only regulation up and regulation down services and evaluate the effects on production costs and the operations of other resources providing this service. This helps identify the potential for market saturation. This section also examines in detail the challenges of modeling reserve prices and limitations of using the LTPP model for ancillary service revenue estimates.

\section{Effect of Storage Penetration}

Several studies have established that storage value changes with the penetration of storage resources because of various factors, such as the reduction in energy arbitrage opportunities and the small quantity of ancillary services procurement $[2,10]$. A key question is whether declining marginal value of additional storage is affected by increasing renewable penetration. We examine the value of different storage power capacities (MW) with scenarios of half and quarter of the full capacity of storage on avoided production costs across both of the renewable portfolio scenarios.

\section{Effect of Storage Energy Capacity (Hours of Storage)}

The value of energy arbitrage depends in part on the number of hours of storage energy capacity, also called "duration." We examine the effect on avoided production costs of increased energy capacity in scenarios where an additional 1 and 4 hours of capacity are added to all storage resources in the portfolio.

\section{Negative Bids}

As noted in Section 4.1, the LTPP model incorporates an assumption that all renewable energy has a negative bid price of $-\$ 300 / \mathrm{MWh}$, reflecting the future CAISO bid floor. This has a major impact on the resulting production costs and on the marginal energy prices in the modeled scenarios. In actual market operations, negative bids from renewables could be anywhere between $\$ 0$ and the bid floor, and it is not possible to accurately predict how negative they will become due to lack of public information about the RPS contract prices and the financial incentives of the different parties with renewable contracts. To examine the impact of negative bids and negative prices on storage value, we modeled the avoided production costs and energy 
arbitrage market revenues across a range of bid floors, including $\$ 0 / \mathrm{MWh},-\$ 150 / \mathrm{MWh}$, and the $-\$ 300 /$ MWh value used in the LTPP model.

\section{Disaggregated Portfolio}

Through the paper, we provide results for the entire portfolio (aggregated results). To provide insight in to the relative value of the individual storage resources, we examine how duration affects the value of different components of the modeled portfolio, by disaggregating the energy arbitrage market revenue results for units with 2 hours, 4 hours, and 6 hours of duration.

\section{Export Constraints and Regional Market Integration}

The relaxation of the "net zero export constraint" described above has been previously studied [31], with the finding that renewable curtailment was completely relieved and, as a result, regional greenhouse gas emissions reduced. To examine the effect on storage benefits, we also relaxed this constraint, allowing for measurement of the resulting effects on avoided production costs from the no-storage scenario and the various storage application scenarios.

\section{Summary of Sensitivity Analysis}

Table 14 summarizes the individual storage sensitivity scenarios. Each scenario is evaluated for both the $33 \%$ and $40 \%$ scenarios. In addition several of the sensitivities include no storage scenarios (e.g., negative bid floor and no export limit scenarios are performed with and without storage). 
Table 14. List of Storage Sensitivity Scenarios

\begin{tabular}{|c|c|c|c|c|}
\hline \multirow[b]{2}{*}{ Scenario Name } & \multicolumn{3}{|c|}{$\begin{array}{l}\text { Storage Capacity (MW) } \\
\text { By Service Provided }\end{array}$} & \multirow[b]{2}{*}{$\begin{array}{l}\text { Additional Description - All scenarios are modifications } \\
\text { of the base storage scenario in Table } 12 \text { and evaluated } \\
\text { for both } 33 \% \text { and } 40 \% \text { scenarios }\end{array}$} \\
\hline & 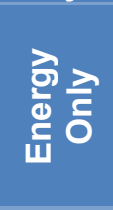 & 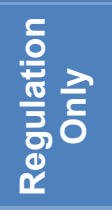 & 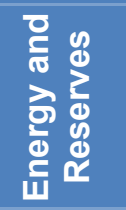 & \\
\hline Regulation only & 412.5 & 912.5 & & $\begin{array}{l}\text { Most resources provide only regulation reserves and other } \\
\text { resources provide energy only, within the limits on storage } \\
\text { utilization prescribed in the } 2014 \text { LTPP assumptions [19] }\end{array}$ \\
\hline +1 hour storage & 412.5 & & 912.5 & $\begin{array}{l}\text { All resources have } 1 \text { additional hour of capacity (so a mix of } \\
3,5 \text {, and } 7 \text { hours) }\end{array}$ \\
\hline +4 hours storage & 412.5 & & 912.5 & $\begin{array}{l}\text { All resources have } 4 \text { additional hours of capacity (so a mix } \\
\text { of } 6,8 \text {, and } 10 \text { hours) }\end{array}$ \\
\hline $\begin{array}{l}-\$ 150 / \mathrm{MWh} \\
\text { bid floor }\end{array}$ & 412.5 & & 912.5 & $\begin{array}{l}\text { RPS renewables curtailment cost set at }-\$ 150 / \mathrm{MWh} \\
\text { "bid floor" (case with and without full storage portfolio) }\end{array}$ \\
\hline $\begin{array}{l}\$ 0 / \mathrm{MWh} \\
\text { bid floor }\end{array}$ & 412.5 & & 912.5 & $\begin{array}{l}\text { RPS renewables curtailment cost set at \$0/MWh } \\
\text { "bid floor" (case with and without full storage portfolio) }\end{array}$ \\
\hline $\begin{array}{l}\text { Disaggregated } \\
\text { Portfolio }\end{array}$ & 1325 & & & $\begin{array}{l}\text { Revenue for different storage durations within the entire } \\
\text { storage portfolio }\end{array}$ \\
\hline No export limit & 412.5 & & 912.5 & $\begin{array}{l}\text { Restrictions on exports in LTPP model removed (case with } \\
\text { and without full storage portfolio) }\end{array}$ \\
\hline $1 / 2$ capacity & 206.3 & & 456.3 & $\begin{array}{l}1 / 2 \text { power capacity (MW) of storage portfolio; co-optimized } \\
\text { energy and reserves }\end{array}$ \\
\hline $1 / 4$ capacity & 103.1 & & 228.1 & $\begin{array}{l}1 / 4 \text { power capacity (MW) of storage portfolio; co-optimized } \\
\text { energy and reserves }\end{array}$ \\
\hline
\end{tabular}




\section{Base Case Results}

This section describes the results for the storage base cases defined in Table $12 .{ }^{21}$ It also compares results from the LTPP simulations to those using historical CAISO prices to examine the impact of the increasing renewable mix on wholesale market price patterns. The model types used for each base-case are listed in Table 4 in Section 3.1.

This section begins with a review of some of the inputs and results from the "no storage" case. This helps to illustrate the forecasted system conditions in 2024 and describe the base-line generation output by fuel type and total production costs before introducing the storage portfolio into the model. Subsequently, we examine the effect on production costs, market revenues, generation by fuel type, and emissions resulting from the storage portfolio and different storage applications. We use two primary value metrics for this study: the total (absolute) dollar value and the value per unit of storage capacity. The total value (\$ million) is calculated as annual avoided production cost or annual market revenue, while the annual value per unit of storage $(\$ / \mathrm{kW})$ is calculated as the annual avoided production cost or market revenue divided by $1,325 \mathrm{MW}$.

\subsection{Results from Cases with No New Storage}

To measure the operational benefits of the CPUC storage portfolio, all storage cases are compared to a case without the addition of new storage. As discussed above, this "no storage" case is created by removing the new storage from the 2014 LTPP model and re-solving the model. This subsection shows key results from the no storage cases.

\section{Load and Net Loads}

Changes to net load are expected to be a major driver of new operational requirements on the California power system, and potentially of increased storage value. Net load is defined here as demand minus the production from variable renewables for each operational interval ( 1 hour in the LTPP model), and represents the residual portion of demand that must be met by conventional generation.

Figure 2 shows the forecast 2024 average hourly system load, net load, and the (postcurtailment) aggregated wind and solar production profiles for California, by season. ${ }^{22}$ Both the $33 \%$ and the $40 \%$ scenarios are shown. Generally, these scenarios result in a significant reduction in the net load during the hours of high solar production (including possible overgeneration), followed by net load system ramps of greater magnitude and duration than current load ramps, particularly in the late afternoon. Figure 8 in Section 5.2 shows how these net loads and ramps affect the simulated hourly energy prices. Of note, the lowest prices in the model are during the periods of lowest net load (due to high solar production), while the highest prices correspond to the net load ramps and remaining highest net loads.

\footnotetext{
${ }^{21}$ Note that the base-case analysis began with simulations to benchmark against the original CAISO model results. Appendix B provides details of the benchmarking exercise.

${ }^{22}$ The forecast peak IOU and POU load for California in 2024 is $65.8 \mathrm{GW}$, the minimum load is $23.1 \mathrm{GW}$, and the average load is $35.7 \mathrm{GW}$. The load calculation includes PG\&E, SCE, SDG\&E, SMUD, LADWP, IID, and TIDC.
} 

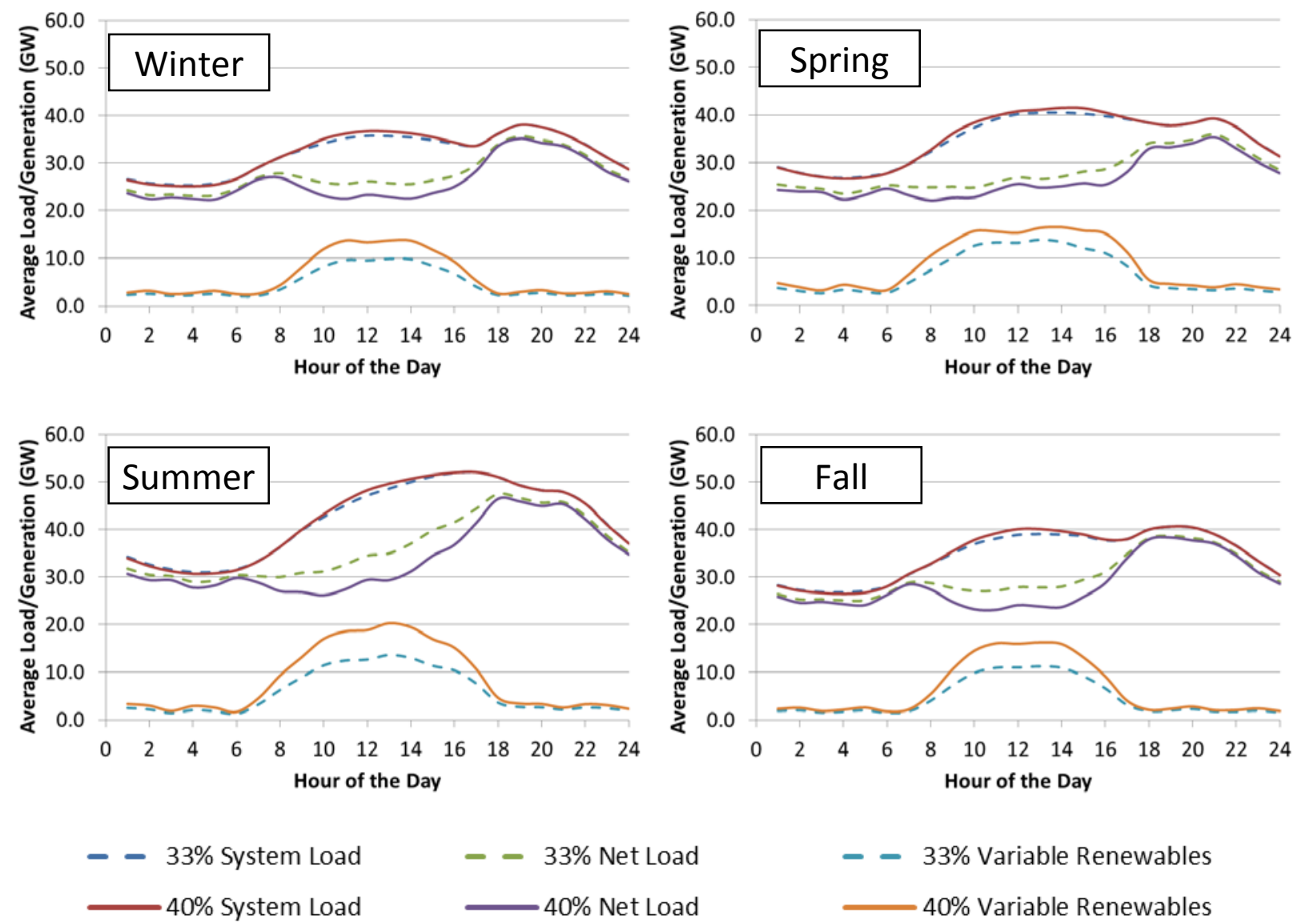

$-\quad 33 \%$ Variable Renewables
_ $40 \%$ Variable Renewables

Figure 2: Comparison of base case total system load, net load, and renewable generation for each season in California

\section{Pre-Storage Generation by Fuel Type in California and WECC}

Historically, storage energy arbitrage value has been highest when there is the greatest disparity in fuel costs between off-peak and peak periods. With the changes underway in the resource mix in California and the rest of the WECC, the resulting patterns of energy costs and prices could change opportunities for energy arbitrage. For example, within California, the prevalence of gasfired generation on the margin today at current low natural gas costs (2014) results in the relatively flat average prices across the day and limited value for arbitrage (see discussion in Section 5.4). However, as renewable energy displaces more fossil generation it increases price variability and potential for energy arbitrage value.

Figure 3 and Figure 4 summarize the base case generation by fuel type for the no storage 33\% and $40 \%$ simulations. Figure 3 summarizes the annual generation in California and Figure 4 provides the results for the entire Western Interconnection. Figure 16 and Figure 17 in Section 5.3 then show how storage changes utilization by resource fuel types and discusses the implications. 


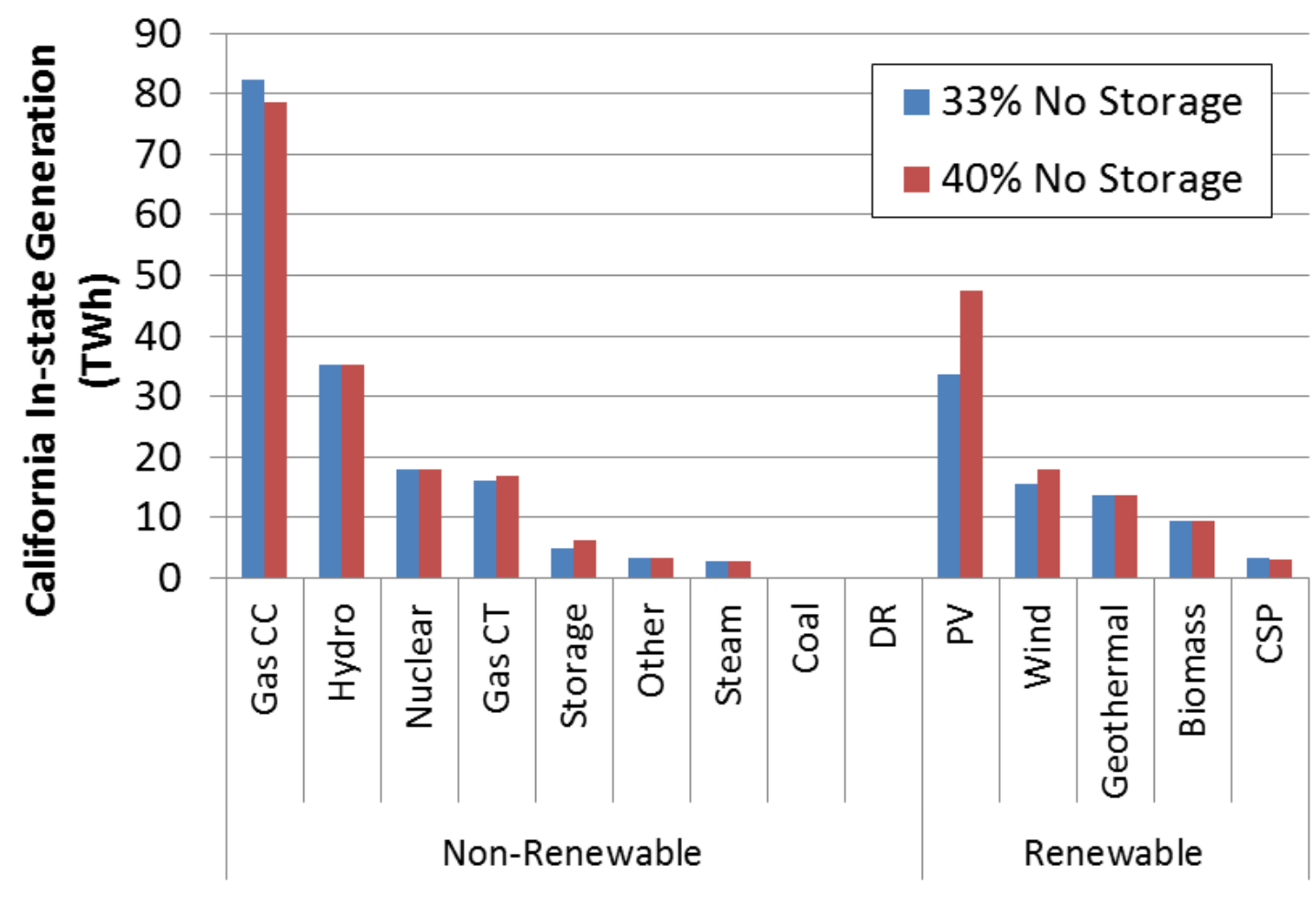

Figure 3: Total generation in California in 2024 by type

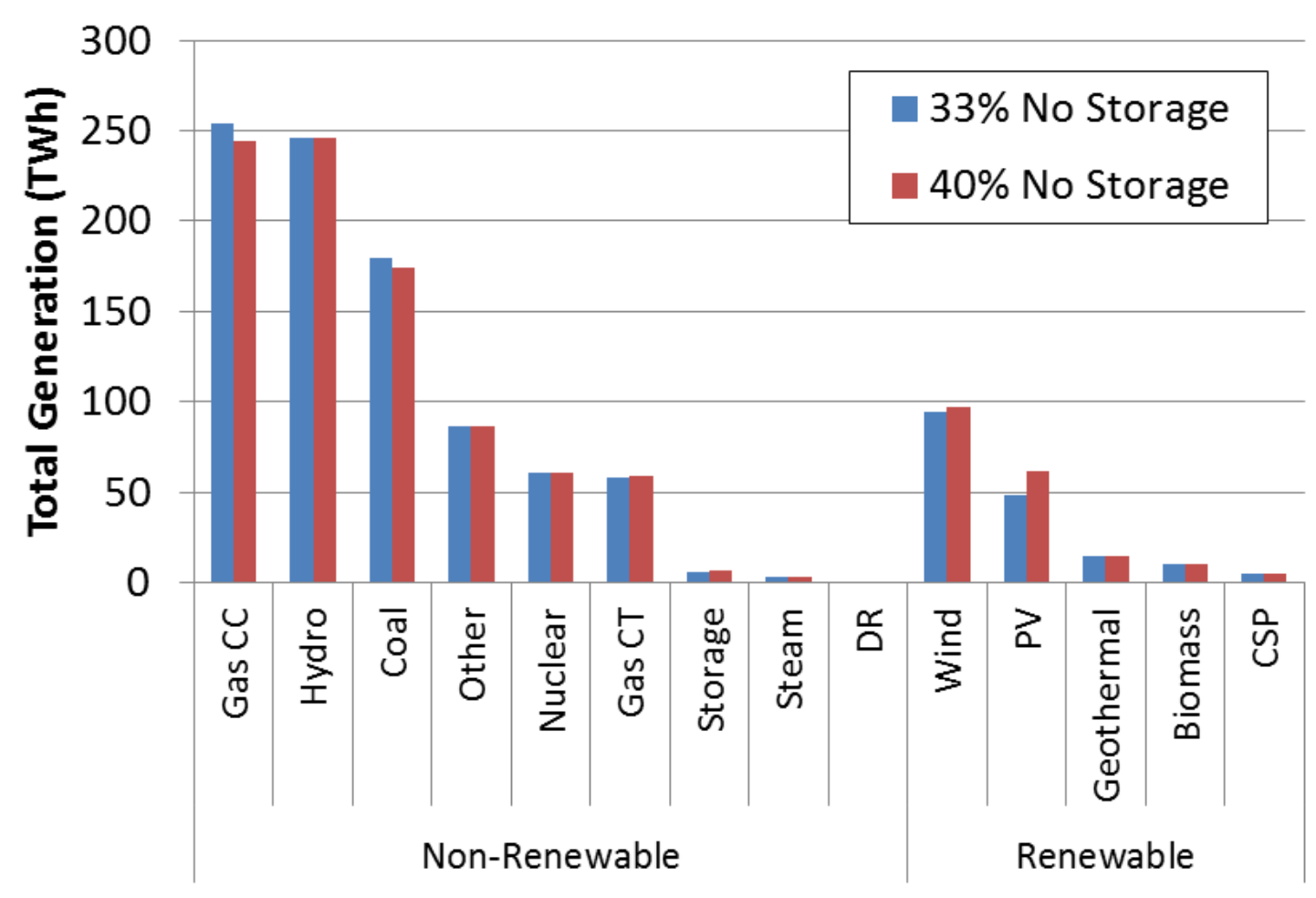

Figure 4: Total WECC-wide generation in 2024 by type 


\section{Pre-Storage Production Costs}

The cases with no new storage provide a baseline calculation of annual production costs $(\$$ billions), from which the cases with storage will be measured. Figure 5 illustrates the components of the production cost in the base system, including fuel costs, variable operation and maintenance (VO\&M) cost, and startup cost. In addition, the optimization considers emissions costs as described in Section 4.1; the CAISO did not include emissions costs when presenting the production cost results, so for consistency, they are not included below. For comparison, the removed emissions costs for CAISO (including the in-state carbon tax and import wheeling charge) represent $6.5 \%$ of the total system-wide production cost.

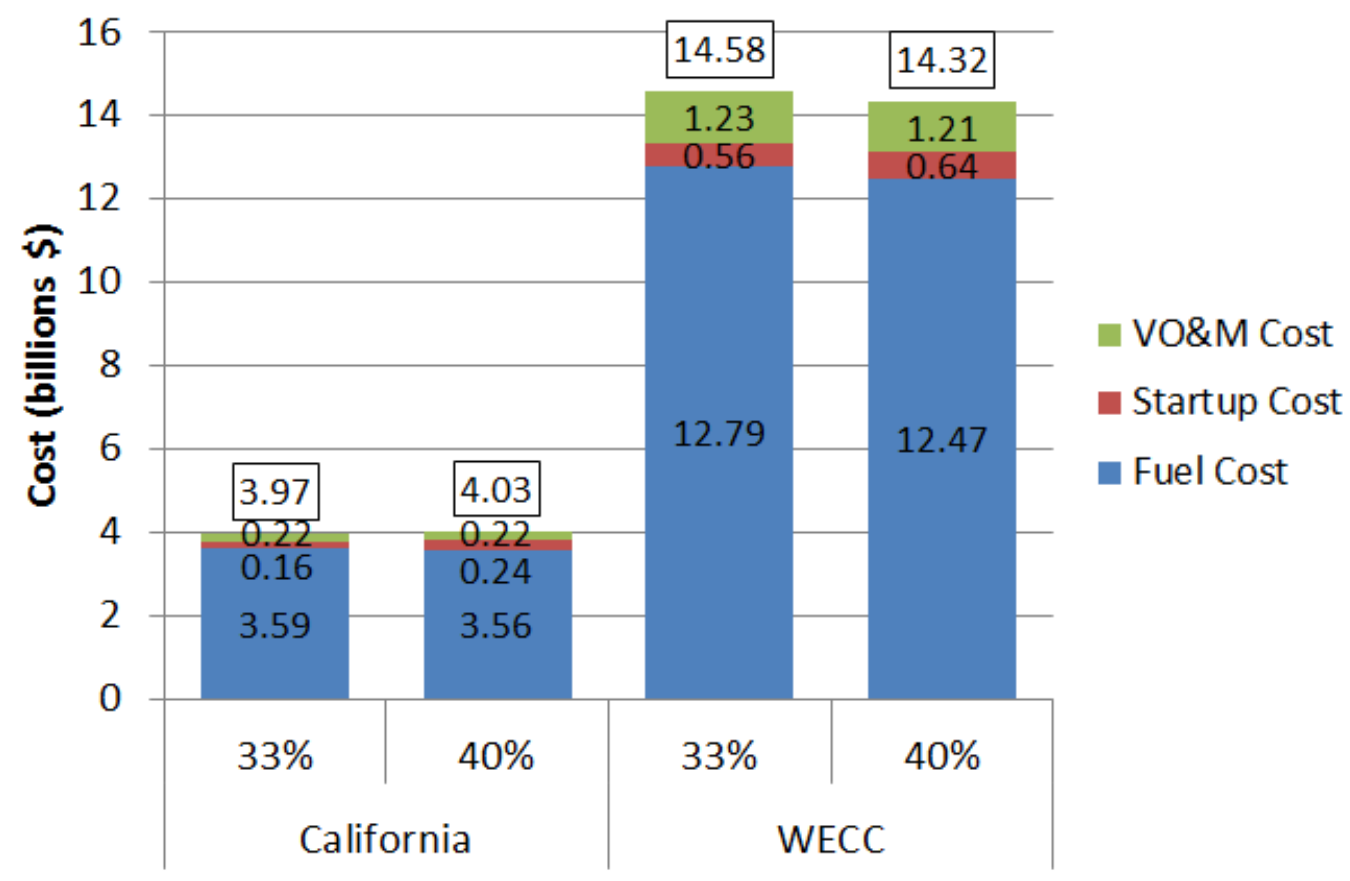

Figure 5: Total production cost for $33 \%$ and $40 \%$ scenarios for both WECC and California without new storage

Start-up costs are a very small component of the baseline production costs, but as shown in the next sections, provide a very large component of storage benefits measured as changes in production costs.

Another baseline finding is that the increase in renewable production between the $33 \%$ and $40 \%$ scenarios results in a slight increase in production costs in the CAISO footprint. As shown in Figure 5, this results from the combination of a small reduction in fuel costs and an increase in startup costs. However, in the full WECC, the increase in renewable production in California does result in an overall reduction in production cost. The interpretation is that the increase in renewable energy production primarily acts to reduce imports into California, which was observed in previous analysis [11].

\subsection{Production Cost Benefits from Storage Operations}

This section examines the storage cases presented in Table 12. Note that the cases with cooptimized energy and reserves correspond to how the storage portfolio is represented in the 
original LTPP model. Figure 6 and Figure 7 provide the results expressed in terms of the annual reductions in production cost (\$ millions), as well as these cost reductions per unit of installed storage capacity $(\$ / \mathrm{kW}$-year). In each scenario, the co-optimization of energy and ancillary services results in the greatest reduction in production cost. Providing energy arbitrage only achieves around $60 \%$ of the energy and reserves case, while the eligible reserves and reserves only cases achieve over $90 \%$ of the production cost reduction in the energy and reserve scenarios.

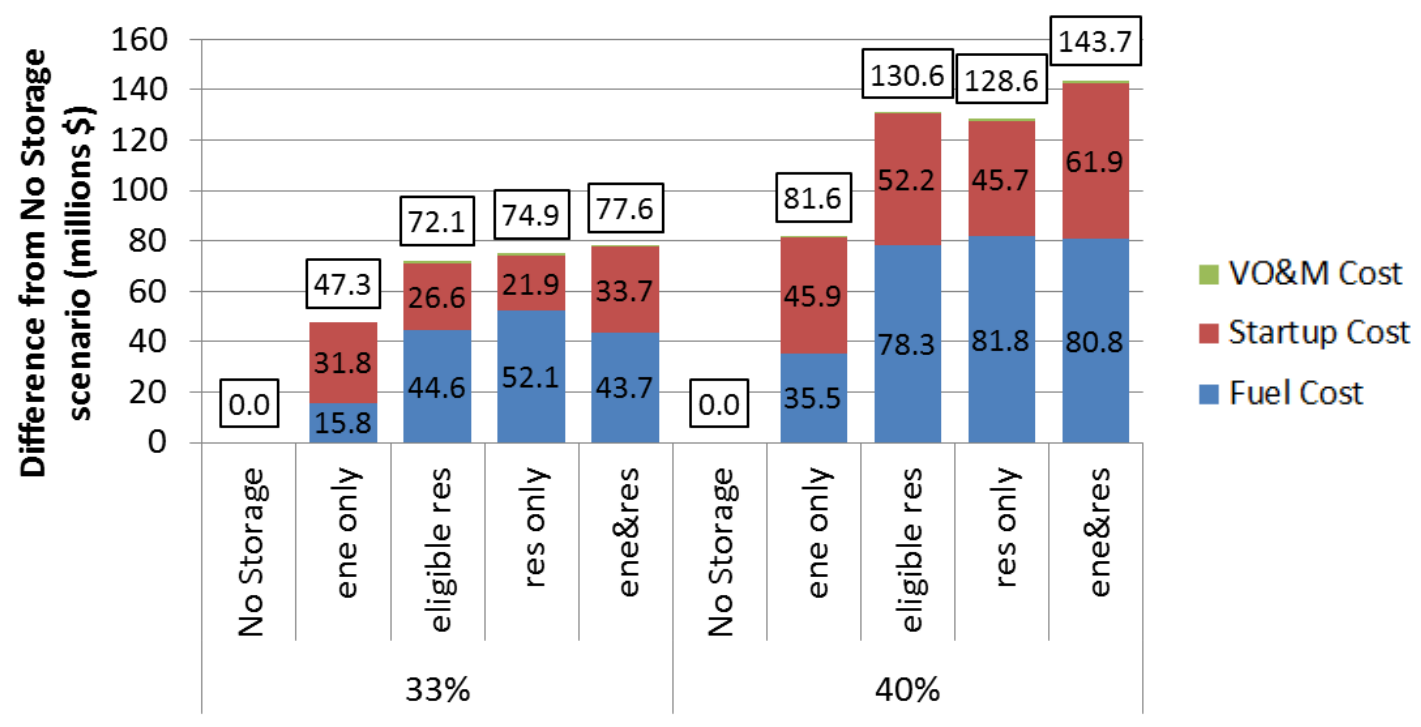

Figure 6: Production cost reduction with storage for $33 \%$ and $40 \%$ scenarios for all of WECC

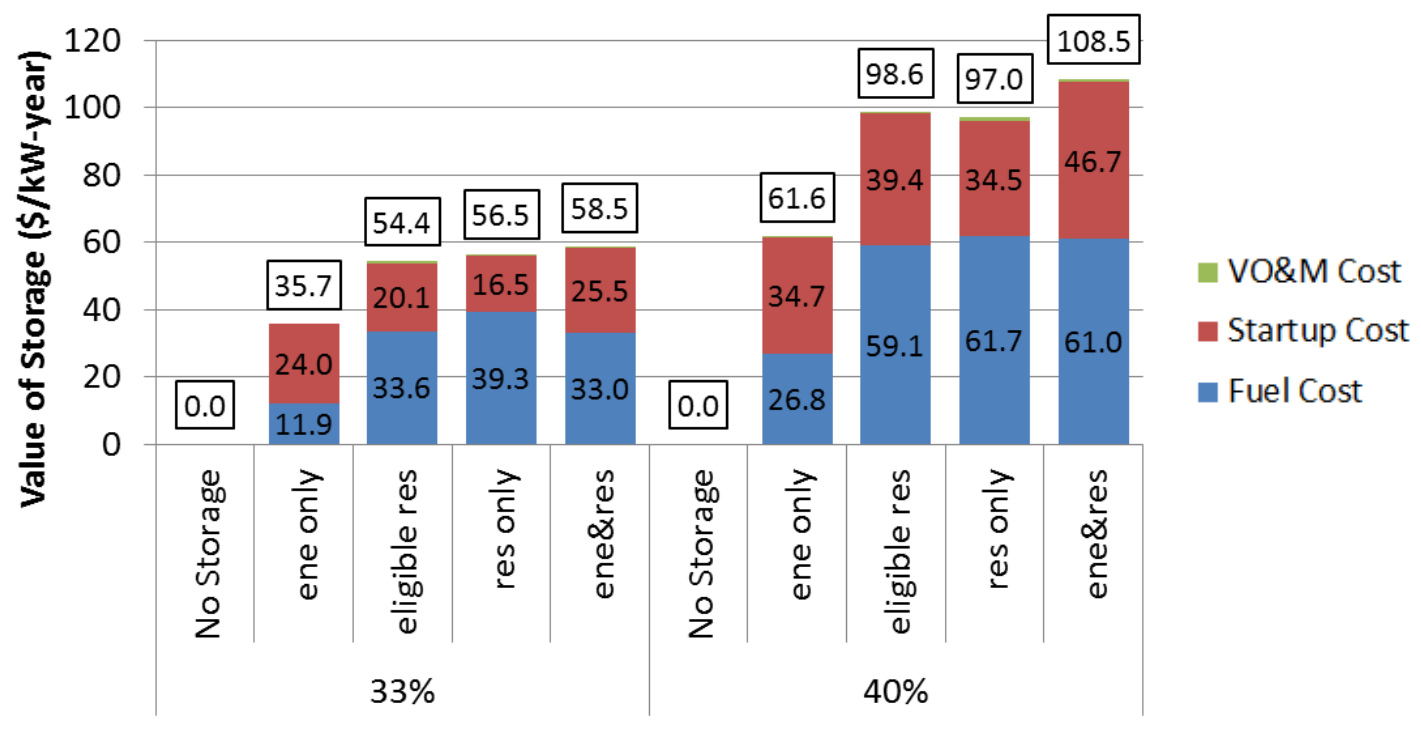

Figure 7: Operational value of storage comparison for $33 \%$ and $40 \%$ scenarios for all of WECC

Results in Figure 6 and Figure 7 show avoided production costs for all of WECC, but California regulators and utilities are primarily interested in the value of the storage portfolio within the state. From a modeling point of view, it is challenging to separate the production cost benefits 
assigned to California from the aggregate WECC benefits because of the integrated structure of the model and difficulties in disaggregating imports and exports. Some of the value comes from impacts that California's storage has on the rest of the West. For instance, $\$ 7$ million to $\$ 9$ million of the avoided startup costs due to storage operations in California take place outside of California. Additionally, in most hours when storage charges in California it also increases the import of lower cost generation into the state, but when it discharges it provides a net fuel cost reduction in the state. Therefore the net fuel cost in California decreases but the fuel cost for the rest of the West increases. The impacts of storage operations on generator utilization and imports are explored in more detail in later sections.

The addition of the CPUC storage portfolio is a relatively small resource addition to the WECC resource mix. Generally, the cases that we evaluated resulted in changes in production costs consistent with the findings in other studies. The results of these cases show two general trends: first, the value of energy storage is greater when able to provide multiple wholesale market services, and second, the value of storage in the $40 \%$ scenario is higher than in the $33 \%$ scenario. In the following sections we identify and discuss three primary drivers for energy storage value: (1) on-off peak price difference (reflecting the impact of added renewable generation), (2) increased utilization of storage capacity due to provision of reserves, and (3) avoided start costs.

\section{Energy Value Due To On/Off Peak Price Differences and Availability of Curtailed Energy}

The first application shown in Figure 6 and Figure 7 utilizes the full storage portfolio to conduct energy arbitrage (load-shifting). This is one of the most studied applications of storage in power systems, with value driven by on/off-peak price differences (i.e., the availability of low-cost generation during certain periods and the ability to displace higher-cost generation during other periods). This section examines some of the drivers of storage operations in the LTPP scenarios.

Historically, CAISO energy prices have been closely correlated with loads; as discussed above and illustrated here, prices in the future CAISO system will be correlated with net loads, the net load system ramps, and over-generation conditions. To illustrate this transition, Figure 8 shows the actual average hourly CAISO market energy prices in the day-ahead market by hour of day for each season of the year in 2013 and 2014, and the simulated energy prices in the no-storage scenarios for 2024 from the production cost model. ${ }^{23}$ In addition, several summary statistics for energy prices are shown in Table 15, with additional details provided in Appendix D. For the modeled scenarios, the maximum price cap is set at $\$ 2,000 / \mathrm{MWh}$, which occurs between 6 and 16 times in the $40 \%$ scenarios. The table also shows sensitivity results for different negative bid assumptions, which are explained in Section 6.4.

The simulated average hourly prices for many of the hours in the 2024 simulations are fairly similar to the current market prices. However, there is a significant difference in price patterns for the middle of the day in all scenarios, and for the peak period in summer afternoons. In the middle of the day, renewable energy production in the $40 \%$ scenario displaces enough thermal generation and imports to be on the margin for up to one-third of the day. This means energy

\footnotetext{
${ }^{23}$ The simulated prices are sometimes called "shadow prices" to reflect that they are calculated in the model as the marginal value of the modeled system constraints.
} 
prices are set by renewable energy, which has a cost of $-\$ 300 / \mathrm{MWh}$ in the LTPP model. As discussed in Section 4.3, this is the level of the CAISO bid floor expected in 2024. Variants on this negative bid cost are examined in Section 6.4. Figure 8 shows that the model also generates price spikes corresponding to the net load system ramps as solar output ramps down.

The LTPP model has several further features which affect energy price determination, and hence can strongly impact revenue results. At a general level, the LTPP model shares some limitations with most production cost models used for planning studies, which affect the simulated marginal prices. These limitations include a highly aggregated transmission network, generic data on the operational characteristics of resources, and the use of marginal fuel costs rather than market offers for energy and operating reserves. As a general matter, these approaches tend to result in lower hourly marginal prices.
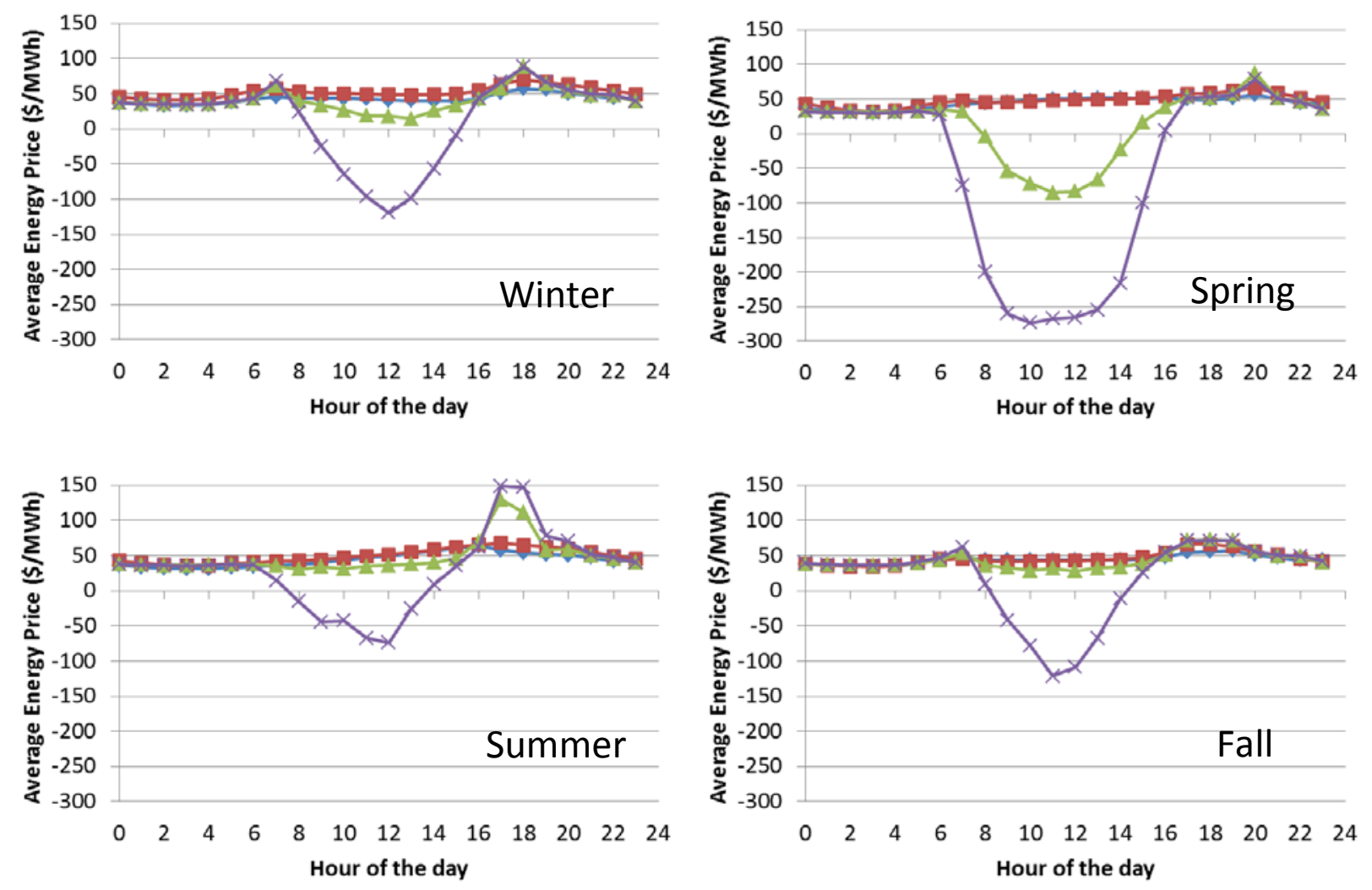

\section{$\rightarrow-2013 \rightarrow-2014 \rightarrow-33 \%$ No Storage $\leftarrow 40 \%$ No Storage}

Figure 8: Energy price for CAISO 2013 and 2014 market prices (SCE LAP) and modeled prices for $33 \%$ and $40 \%$ scenarios without storage 
Table 15. Summary Statistics for Historical and Modeled California Energy Prices

\begin{tabular}{|c|c|c|c|c|c|}
\hline \multicolumn{2}{|c|}{ Energy Price Statistics (\$/MWh) } & Max & Min & Average & Hours $\leq 0$ \\
\hline \multicolumn{2}{|l|}{2013} & 187.9 & 14.7 & 43.6 & 0 \\
\hline \multicolumn{2}{|l|}{2014} & 175.5 & 14.8 & 48.5 & 0 \\
\hline \multirow{3}{*}{$33 \%$ No storage } & $\$ 0 / \mathrm{MWh}$ & 2,000 & 0 & 43.9 & 215 \\
\hline & $-\$ 150 / M W h$ & 2,000 & -150 & 40.4 & 197 \\
\hline & $-\$ 300 / \mathrm{MWh}$ & 2,000 & -300 & 37.1 & 198 \\
\hline \multirow{3}{*}{$40 \%$ No storage } & $\$ 0 / \mathrm{MWh}$ & 2,000 & 0 & 40.5 & 1,334 \\
\hline & $-\$ 150 / \mathrm{MWh}$ & 2,000 & -150 & 21.6 & 1,198 \\
\hline & $-\$ 300 / M W h$ & 2,000 & -300 & 2.7 & 1,184 \\
\hline \multirow{3}{*}{$33 \%$ ene\&res } & $\$ 0 / \mathrm{MWh}$ & 2,000 & 0 & 43.1 & 139 \\
\hline & $-\$ 150 / M W h$ & 2,000 & -150 & 40.3 & 148 \\
\hline & $-\$ 300 / M W h$ & 2,000 & -300 & 38.1 & 146 \\
\hline \multirow{3}{*}{$40 \%$ ene $\&$ res } & $\$ 0 / \mathrm{MWh}$ & 2,000 & 0 & 39.1 & 1,058 \\
\hline & $-\$ 150 / M W h$ & 2,000 & -150 & 22.8 & 1,036 \\
\hline & $-\$ 300 / M W h$ & 2,000 & -300 & 7.0 & 1,019 \\
\hline
\end{tabular}

Corresponding to the energy price patterns shown above, storage resources in 2024 would have an inverse charging and discharging pattern to that experienced in historical CAISO conditions. Figure 9 shows the resulting charge and discharge patterns from the $33 \%$ and $40 \%$ energy-only storage cases. The storage operation patterns generally follow the price patterns in Figure 8, with substantial increase in charging during periods of extremely high negative prices. This discharge slightly changes the shape of the net load curves seen in Figure 2. (We do not show the new curves because of the relatively small change.)

A notable difference is in the spring, when Figure 9 shows that the total storage plant profile exhibits both charging and discharging during the middle of day. Under the model structure, no individual storage resource is allowed to simultaneously charge and discharge in a given hour; however, if a storage resource is fully charged and there are more hours of curtailment in its region, then the resource has an incentive to discharge at a loss and charge again. Hence, storage can take advantage of the roundtrip efficiency losses to dump energy during negative price intervals. For example, at $83.3 \%$ efficiency, $1 \mathrm{MW}$ charging results in only $0.833 \mathrm{MW}$ discharge. That means that during negative price hours, one hour of charge and one hour of discharge can reduce system costs by $0.167 \mathrm{MW}$ times the energy price. In other words, the model allows the plant to repeatedly charge and discharge in sequential hours, acting as a sink for otherwise curtailed energy, while not actually using this curtailed energy to displace fossil generation or otherwise provide actual benefits. This behavior has been noted previously for the LTPP model [4]. To test how this outcome affects model results, we examine sensitivities on other negative bid floors in Section 6.4, and demonstrate the impact on storage operation and value. 

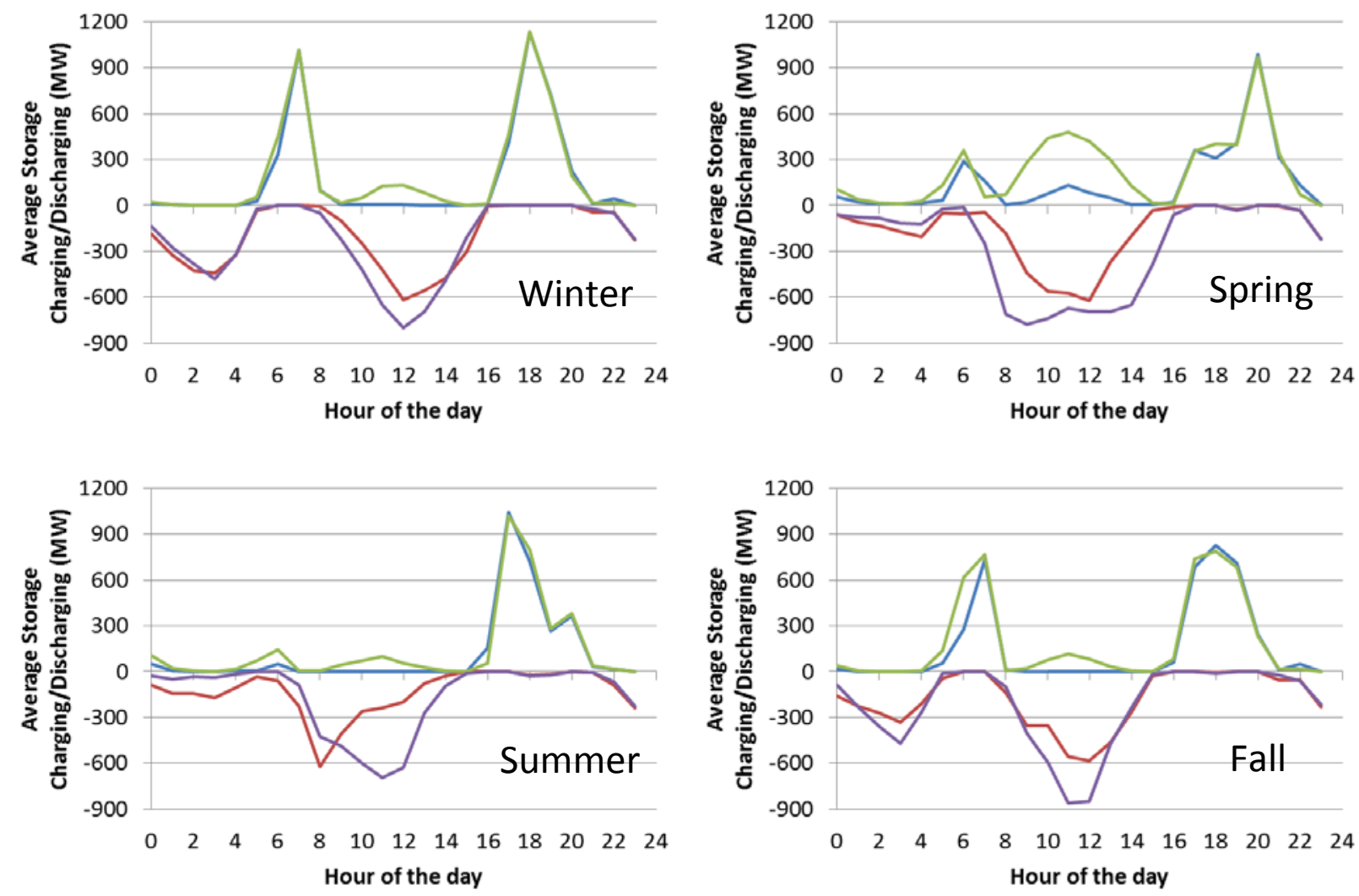

$33 \%$ ene only - Discharge

$40 \%$ ene only - Discharge

$33 \%$ ene only - Charge

$-40 \%$ ene only - Charge

Figure 9: Average storage charging and discharging patterns by hour of day for each season

Figure 10 shows the impact of added storage on curtailed energy in the various cases measured as $\%$ of annual renewable energy. In the $33 \%$ no-storage case, less than $0.5 \%$ of potential renewable generation is curtailed. This increases to about $4.7 \%$ in the $40 \%$ scenario no-storage case (note that for both scenarios California's existing pumped storage plants are operating). Above the figure, the quantity of curtailment in annual TWh is shown. 


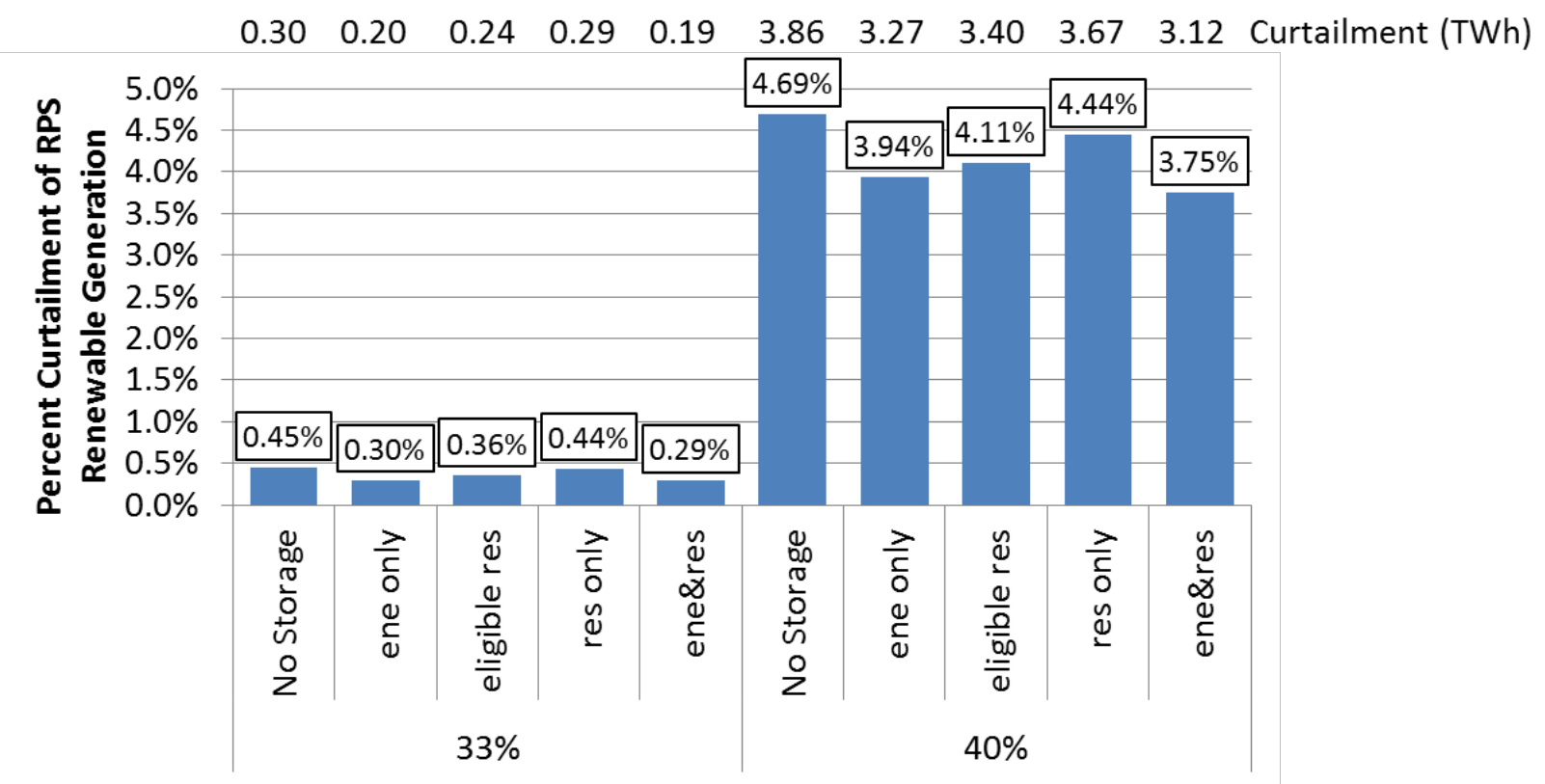

Figure 10: Summary of curtailment for $33 \%$ and $40 \%$ base scenarios

In the $40 \%$ scenario, the addition of the storage portfolio in California decreases renewable curtailment by about $20 \%$ compared to the "no storage" case. The additional storage is unable to eliminate curtailment due to the very high levels of curtailment that occur during periods of high solar output. Figure 11 illustrates how storage affects curtailment on a particular day. In the no storage case maximum curtailment on March 23 is as high as $6.1 \mathrm{GW}$, which significantly exceeds the additional storage capacity. Figure 12 shows all the remaining curtailment in both scenarios by curtailment event. In the $40 \%$ scenario, $27 \%$ of curtailment events are under 1.325 $\mathrm{GW}$ (the maximum charging limit of the storage portfolio), $45 \%$ are under $2.65 \mathrm{GW}$ (double the capacity of the planned storage portfolio), while the remainder are greater than that amount.

Storage eliminates $14 \%$ of the negative price instances in the $40 \%$ scenario, meaning that market prices could still be negative during the remaining periods under the assumptions and scenarios modeled. Notably, in each case, the highest value application - co-optimized energy and reserves - also results in the greatest reduction in curtailment.

Figure 10 also shows that the provision of reserves from storage can help reduce curtailment by changing the commitment and dispatch of thermal generators. This is possible by using storage to provide a portion of the reserves allowing the fleet to make better use of excess renewable generation and hence we see a small reduction in the curtailment even for the reserves-only scenario. 


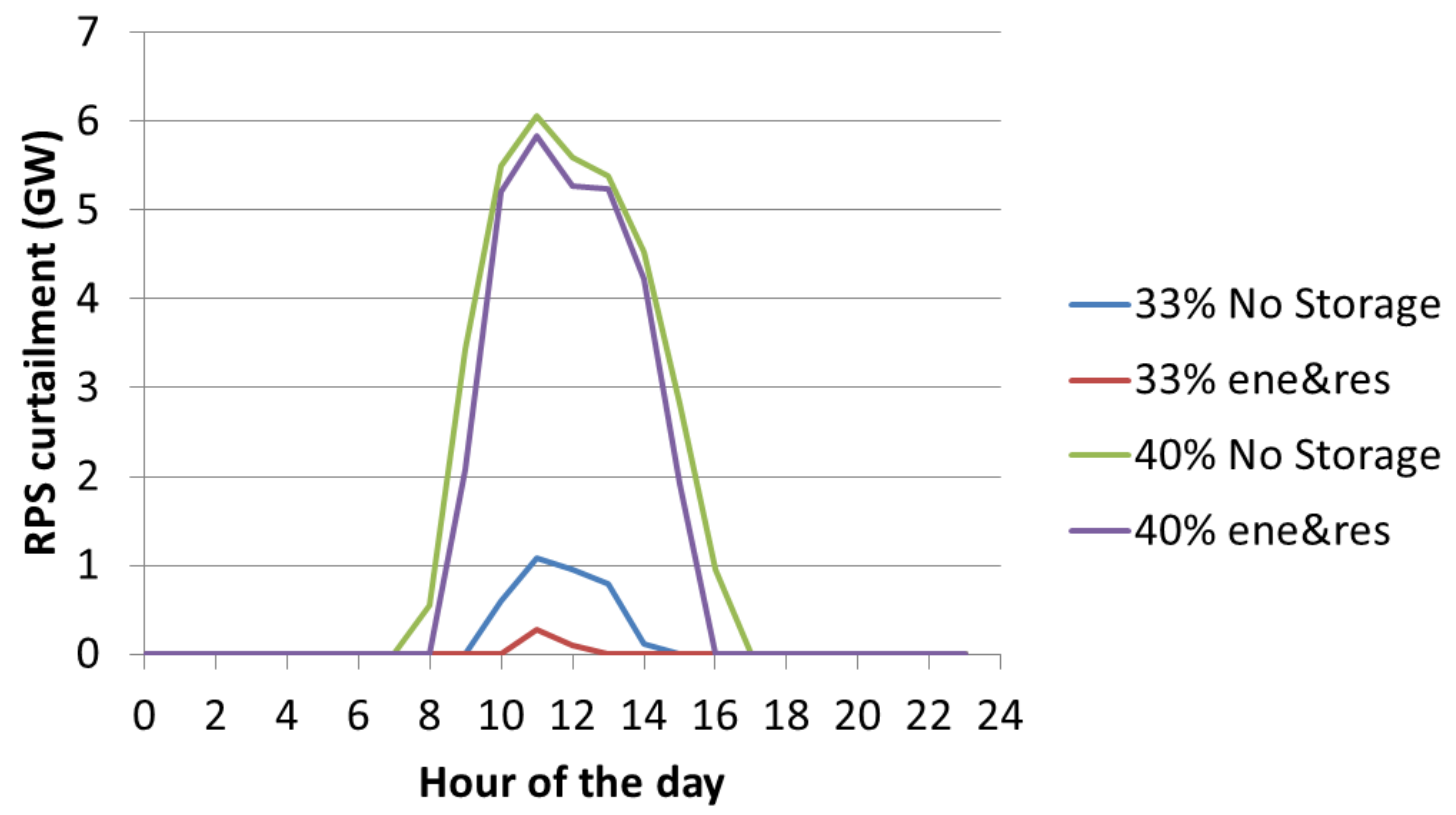

Figure 11: Curtailment of RPS eligible wind and solar on March 23

Figure 12 shows a scatter plot for the resulting curtailment during each hour of the day for cooptimized energy and reserves cases in the $33 \%$ and $40 \%$ scenarios.

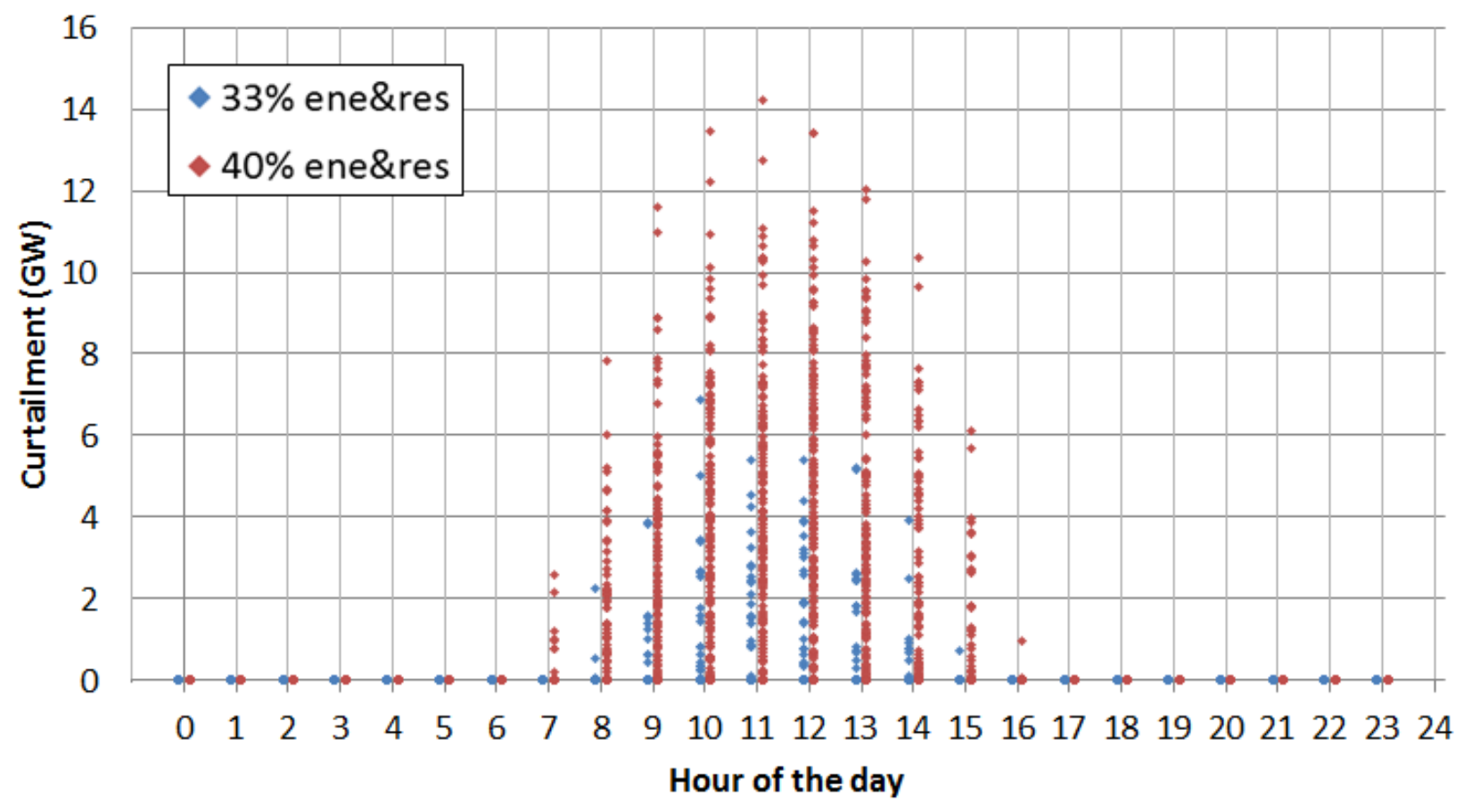

Figure 12: Scatter plot of renewable curtailment for $33 \%$ and $40 \%$ ene\&res scenarios 


\section{Effect of Storage Utilization and Reserves Provision on Value}

While reduction in renewable curtailment provides an opportunity for storage to provide high value energy arbitrage, even in the $40 \%$ scenario there are relatively few hours of curtailment, and storage will obtain much higher value from the provision of ancillary services during many hour of the year. Figure 6 and Figure 7 show the increasing value as storage provides additional services (moving from the energy-only scenario to the reserves scenarios, and then co-optimized for energy and reserves). The key driver of these value differences is the amount of time the resource is used. Storage utilization is lowest in the energy-arbitrage-only scenarios, and energyonly resources operate for relatively few hours of the year, with discharge capacity factors of $11 \%$ and $14 \%$ under $33 \%$ and $40 \%$ renewables, respectively. ${ }^{24}$ For a storage resource, the capacity factor is a function of the unit's round-trip efficiency and the daily price spread between hours. These factors typically result in 1 to 3 daily discharge cycles depending on the storage duration and net load shape.

Storage utilization is significantly greater when reserves can be provided because the storage resources can supply the full range of their capacity to provide the service with only minimal net additional charging costs. Storage providing reserves only operate essentially any time the price of any of the reserve products are greater than zero; the frequency of zero prices is discussed in more detail in Section 6.1. The utilization of the storage portfolio to provide reserves is as high as $80 \%$ with the maximum occurring in the reserves only scenario for $40 \%$ renewables.

Figure 13 shows the overall utilization of the storage resources including charging, discharging, and reserve provision. ${ }^{25}$ An important caveat when evaluating utilization in cases with reserves is that in the LTPP model, storage resources do not consume energy during reserve provision. This is most noticeable for the reserve only scenario where there is no charging or generating even though reserves will be called on occasionally during the year in case of contingency events or on a continuous basis for regulation. The calculation of make-up energy is discussed further in Section 6.1.

\footnotetext{
${ }^{24}$ Discharge capacity factor for energy operations is measured similarly to the capacity factor of a conventional generator: the total annual energy discharged $(\mathrm{MWh}) \div$ [unit upper operating limit $(\mathrm{MW}) \times 8784$ hours]. Note that the year 2024 has 8784 hours.

${ }^{25}$ Utilization is defined as the sum of energy charging and discharging (measured in MWh) plus reserves provision (measured in MW-h) divided by the product of the number of hours in the year (i.e., 8784 for 2024) and the storage capacity (i.e., 1,325 MW).
} 


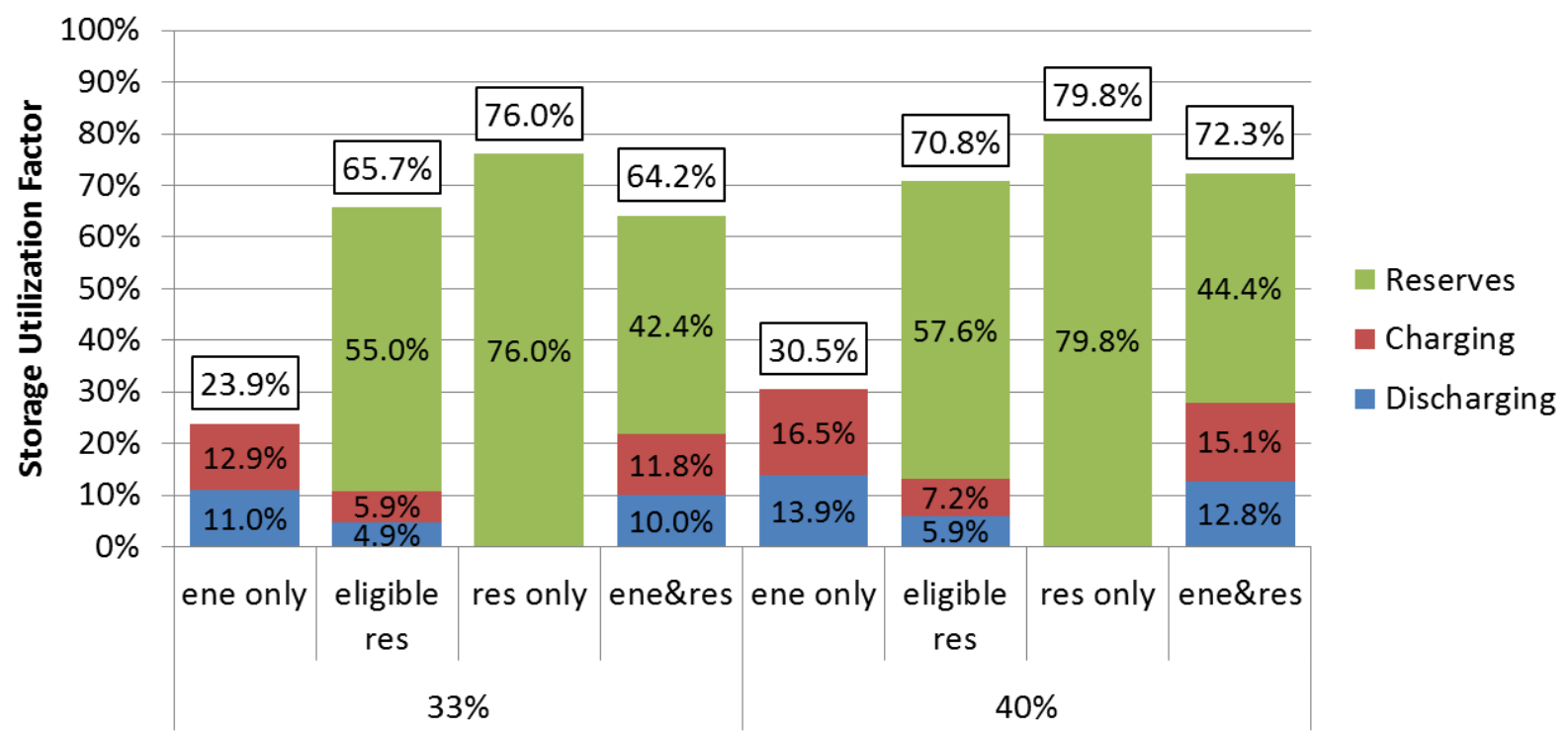

Figure 13: Total storage portfolio utilization factor

\section{Avoided Start-Up Costs}

In all the cases modeled, avoided start-up costs are a large component of storage benefits. This is consistent with other storage production cost studies $[2,14]$. While a range of startup costs are assumed in the model, typical values in the database are $\sim \$ 56,000 /$ start for coal, $\sim \$ 26,000 /$ start for combined cycle (CC), and $\sim \$ 3,000 /$ start for combustion turbines (CT). The existing pumped hydro storage can have start costs ranging from $\$ 1 /$ start to $\$ 6,000 /$ start (Helms). The LTPP model assumes that all new storage does not incur a start cost except for Lake Hodges, which has a start cost of $\$ 1 /$ start.

The model can optimize the system to frequently start and stop storage technologies to avoid thermal plant starts. In the energy-only cases, off-peak charging can increase loads and keep power plants online while avoiding starts of peaking capacity. When providing reserves, storage can avoid starting units needed to operate at part load to provide reserve capacity. Figure 14 shows the annual number of capacity-weighted starts for each generation type (equal to the number of starts for each unit multiplied by its installed capacity) that contributes to the startup cost. The cases that include storage show a large increase in capacity started for storage and a reduction in the capacity starts for all other generation types. 


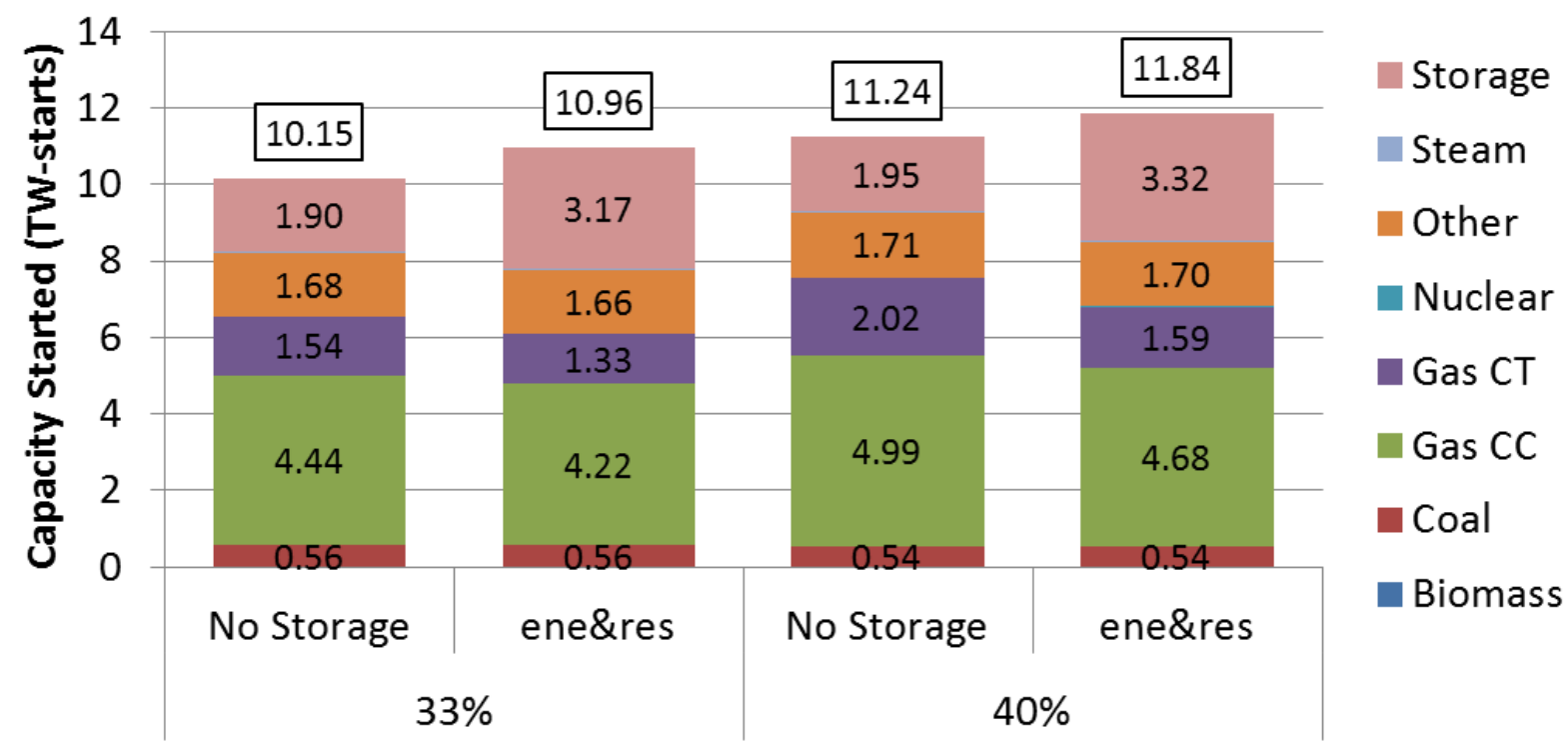

Figure 14: Total number of capacity-weighted unit starts for the Western Interconnect ${ }^{26}$

Figure 15 illustrates the annual value of the avoided starts by unit type. As noted in Section 3.1, reduction in these costs represents a system benefit that would be difficult to attribute to storage within the CAISO wholesale market under current rules, although there are pricing methods being evaluated in other markets that capture these costs in energy market prices. ${ }^{27}$ The possible incentives for bidding and scheduling of storage created by this market pricing rule are discussed further in Section 5.4.

\footnotetext{
${ }^{26}$ The figure does not include wind, PV, CSP, demand response, hydro, or geothermal because they do not have startup costs in the LTPP model.

${ }^{27}$ For additional discussion of capturing start costs in energy prices and proposed market mechanisms to address this issue see, e.g., "Extended Locational Marginal Pricing" www.misoenergy.org/Library/Repository/Communication\%20Material/Strategic\%20Initiatives/ELMP\%20FAQs.pdf
} 


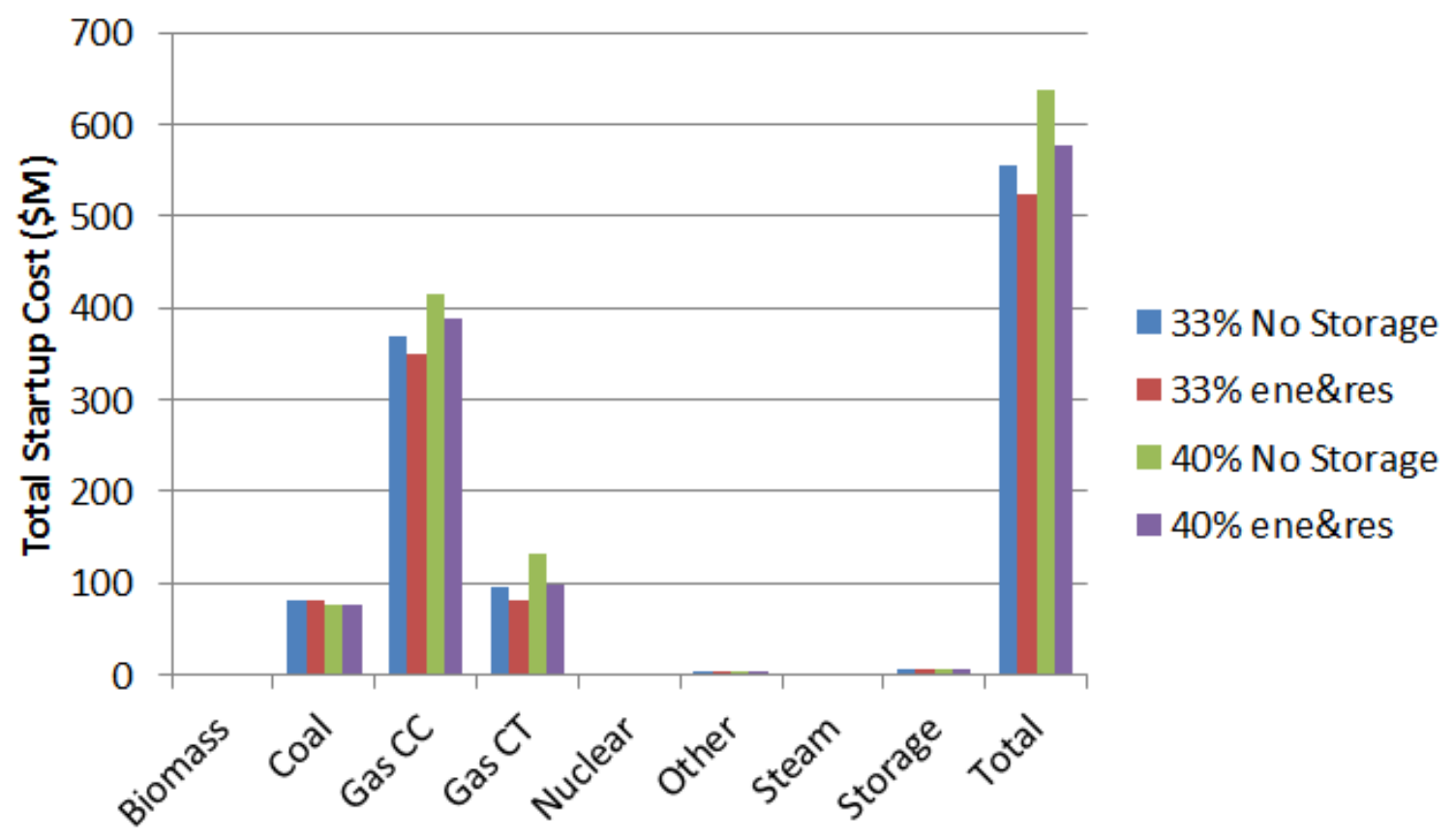

Figure 15: Total startup costs by generation type for the Western Interconnect

\subsection{Changes to Emissions and Resource Utilization by Fuel Type}

The storage portfolio in California is intended in part to support the transition to a low-carbon electric power sector. As such, it is expected that over the long-term, storage operations would reduce carbon emissions by enabling more energy from renewable resources. This section examines this question for the LTPP scenarios by first examining changes in all resource operations by fuel type across the WECC due to storage operations, then discussing the effect on aggregate generator emissions within California, and finally the aggregate emissions for the WECC region.

\section{Changes in Generation by Fuel Type}

One of the significant sources of value is energy storage charging with lower fuel cost plants and displacing higher fuel cost plants. In many regional simulations of hourly storage operations, the ability of storage to charge from lower fuel cost and high-emissions generation, such as coal plants, can lead to higher total emissions [2,14]. As described in Section 4, given the regional scope of the LTPP model, along with the attempt to reflect existing carbon policies, modeling the impact of storage on regional carbon emissions is complicated. Because there is no carbon tax outside California, the model tends to shift charging energy to the lowest cost plants, which are often coal-fired plants outside California, despite the inclusion of a carbon tax in the wheeling charge into California. ${ }^{28}$ Figure 16 and Figure 17 show the changes in generation from

\footnotetext{
${ }^{28}$ In the LTPP model, the wheeling charge for carbon emissions from imports into California is represented as a constant value and is independent of the generation mixture in the exporting region. As a result the wheeling charge does not send a clear incentive to import generation from a lower carbon source. See carbon cost in Section 4.1 for more details on the wheeling charge formulation.
} 
generators across WECC for the $33 \%$ and $40 \%$ scenarios. The addition of storage reduces curtailment, which increases generation from renewables. However, as discussed previously, there is very little curtailment in the $33 \%$ scenario and so little opportunity for increased renewable generation. This opportunity increases for the $40 \%$ scenario, and presumably would increase further at even higher RPS. Additionally, due to storage round-trip efficiency energy losses, there is an overall increase in generation for all cases except reserves only (which is due to that case not accounting for energy required to provide reserves). Much of the change in emissions is associated with how the added storage causes the thermal fleet to re-dispatch in order to minimize production cost.

As shown in the figure, the impact on different types of generation is related to the storage applications. When storage provides reserves, it allows for the greatest reductions in gas-fired generation from CCs but also the largest increases in out-of-state coal generation. Since the majority of operating reserves are provided by in-state CCs operating at part-load, storage providing reserves allows the system to reduce generation from CCs and increase lower cost imports, which include increases in coal generation. Conversely, if storage can only provide energy then it cannot displace in-state CCs, which are needed to provide reserves. More details about reserve provision can be found in Appendix C. In all cases, storage displaces generation from CTs as storage displaces peaking generation. There is also a change in existing storage generation for both the reserves scenarios and the energy and reserves scenarios. At 83.3\% efficiency, the proposed storage portfolio has higher efficiency and greater flexibility to provide reserves than existing storage. As a result, installing the proposed storage portfolio displaces a portion of the existing storage generation.

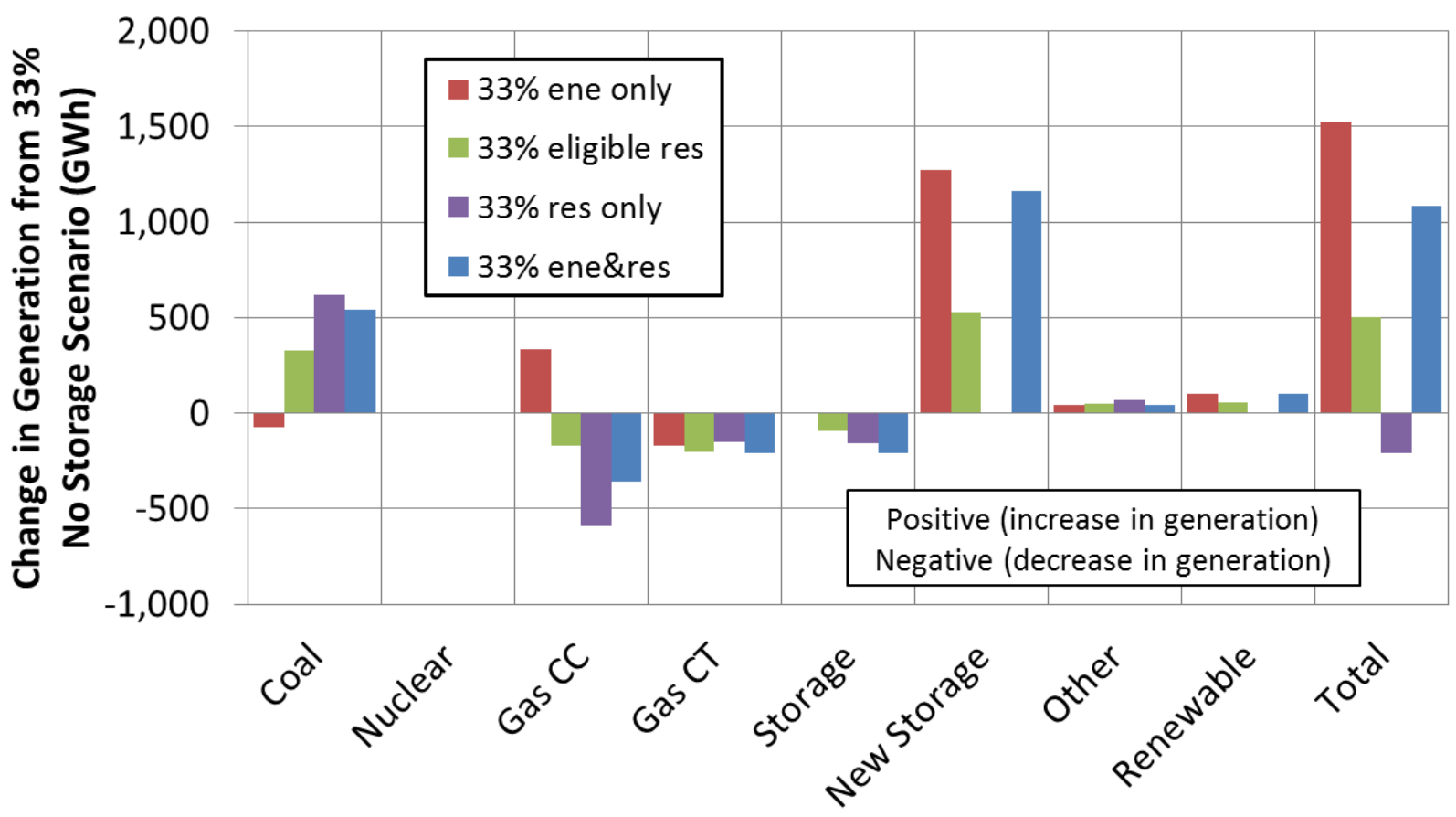

Figure 16: Change in yearly generation mixture for $33 \%$ scenarios with storage for all of WECC 


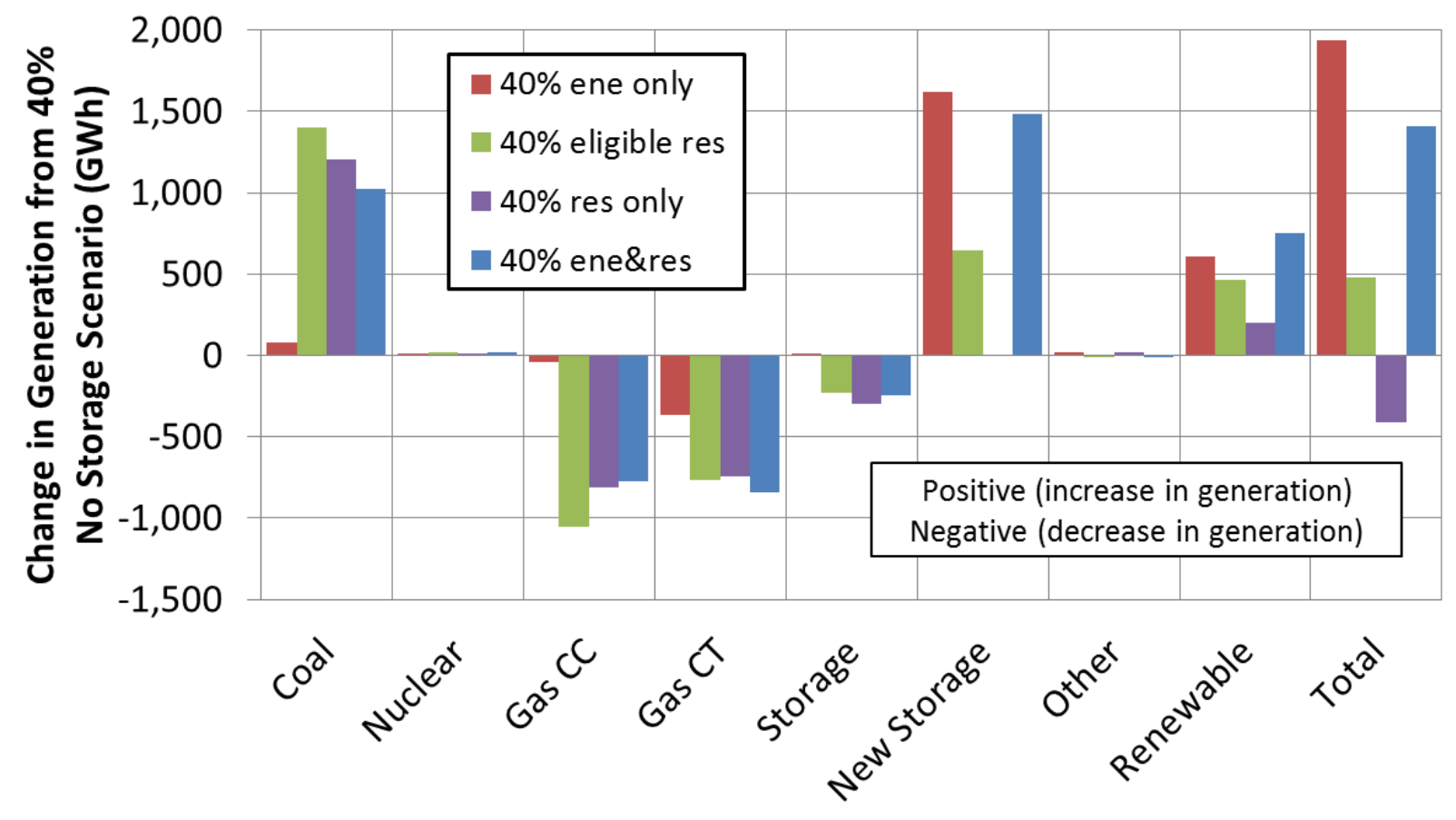

Figure 17: Change in yearly generation mixture for $40 \%$ scenarios with storage for all of WECC

\section{California Generation Emissions}

The model allows us to isolate emissions from in-state California generation. Generator emissions are calculated from normal operation as well as startup, based on individual plant fuel type and heat rate. Figure 18 shows the change in emissions within California due to storage operations. Annual California generator emissions are reduced in every case, and reductions range from 325,000 tons carbon dioxide $\left(\mathrm{CO}_{2}\right)$ to as high as 1.1 million tons $\mathrm{CO}_{2}$ in the $40 \%$ case. The largest emissions reduction is in the reserves only scenario, while providing arbitrage services only achieves around $40 \%$ of the maximum emissions reduction. 


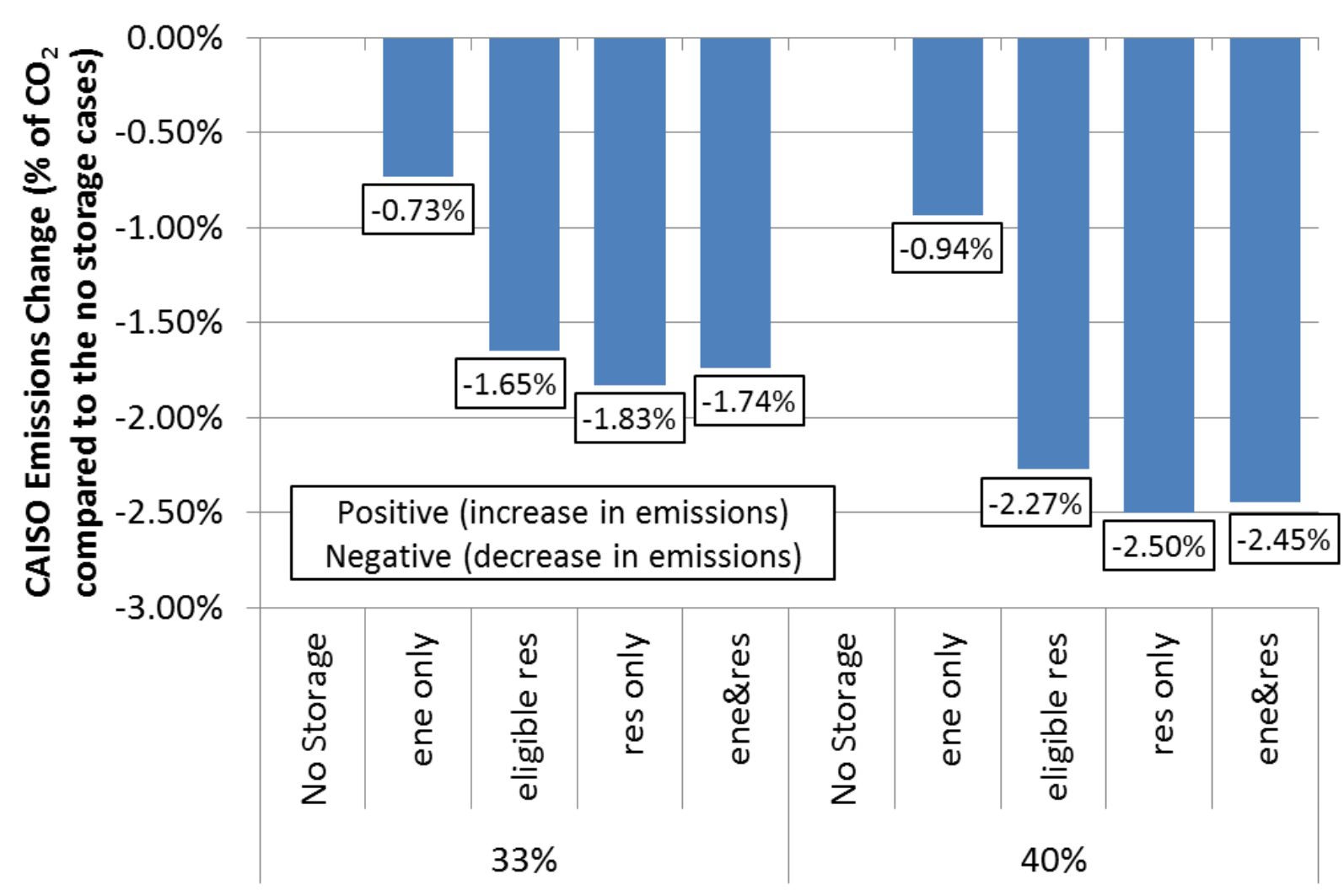

Figure 18: Change in emissions for the core $33 \%$ and $40 \%$ scenarios with storage for California only

\section{WECC Emissions}

When the changes in aggregate WECC emissions are evaluated for each of the use-cases, the results are mixed but also fairly small. In some cases, we find regional emissions increases due to increases in coal generation outside California discussed previously. Figure 19 shows these aggregate emissions, which are the sum of the changes in emissions for each resource type shown in Figure 16 and Figure 17. The overall annual impact on emissions is very small, ranging from a decrease of 275,000 tons to an increase of 223,000 tons. ${ }^{29}$ This can be compared to the total emissions for the WECC of 310 and 301 million tons of $\mathrm{CO}_{2}$, and 45 and 44 million tons for California (33\% and 40\%, respectively). It is important to note that these impacts do not consider the make-up energy requirements for storage providing regulation or load following (which would reduce the benefit of storage) or the avoided generator cycling (for example, when fast-responding storage provides frequency regulation which would increase the benefit of storage). These issues are discussed in more detail in Section 6.1 and [13].

\footnotetext{
${ }^{29}$ For the purposes of comparison, if the additional 1,325 MW of storage were to charge only with renewables, and displace the natural gas combined cycle (with a discharge capacity factor of $15 \%$ ), the avoided emissions would equal about 1.7 million tons of $\mathrm{CO}_{2}$. The lower values estimated here are largely due to the limited amount of curtailed energy.
} 


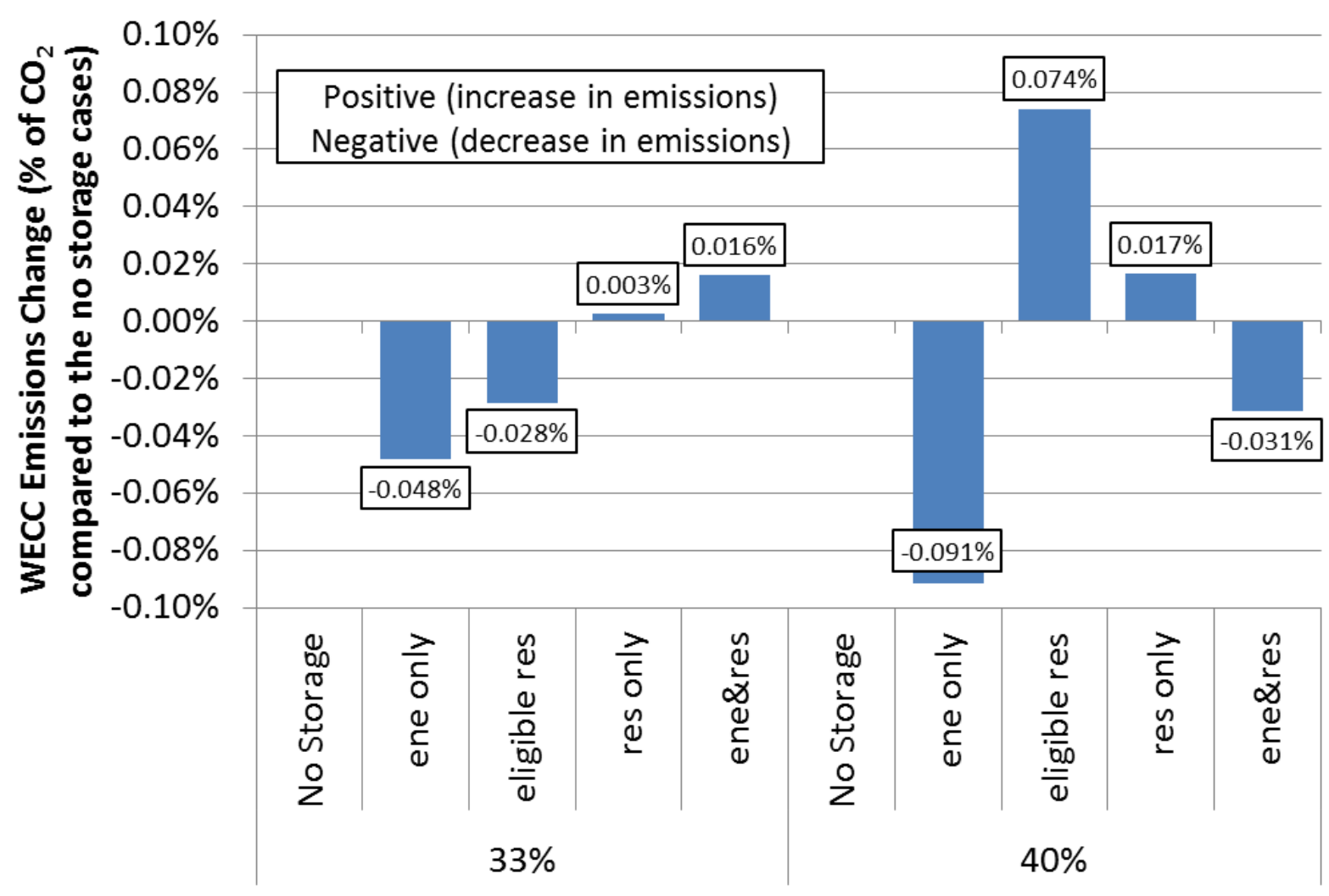

Figure 19: Change in emissions for the core $33 \%$ and $40 \%$ scenarios with storage for the Western Interconnect

In sum, the results for these scenarios suggest that storage operations will decrease in-state emissions, and also regional emissions for use-cases which shift more energy as renewable energy increases in the $40 \%$ scenario. There are a number of other factors that could affect the impact of storage on regional emissions in the timeframe of 2024, including Clean Power Plan regulations and other policies which could change the western resource mix and regional market integration. Regardless, the impact of the storage mandate on regional emissions will likely be relatively small over the coming decade when compared to other policies, such as increasing RPS. In addition, the ability of storage to reduce emissions will depend on both increased availability of low-carbon electricity for charging, as well as policies or other resource changes that reduce the opportunities for charging from the remaining coal generation in the West. Overall, these results suggest that as renewable penetration increases both in California and throughout the West, regional carbon emissions can be reduced by storage operations.

\subsection{Analysis of Historical and Future Energy and Ancillary Service Market Revenues}

As noted in Section 3, changes in production costs are one measure of storage operational value but do not necessarily reflect the wholesale market revenues of storage plants, especially in conditions with increased market price volatility due to negative prices or price spikes due to ramp events. To evaluate market revenue, this section provides results from models using both historical CAISO market prices and forecast 2024 marginal prices derived from the LTPP production cost model. The historical price simulations can only use a price-taker, "self- 
scheduled" model, since we cannot replicate a system-optimized storage dispatch for those periods. For the 2024 simulations, we show results from the two types of market revenue methods reviewed in Section 3.1.

\section{Historical Market Price Simulations}

Price simulations can be used to estimate historical market revenues, as a baseline for interpreting future changes in the markets. Figure 20 shows the hourly average day-ahead energy and ancillary service prices in 2014 in the SCE subregion of the CAISO market. ${ }^{30}$ Figure 20 shows that upward reserve - regulation up and spinning reserves - prices are closely correlated with energy prices on average. Downward reserve products - currently only regulation downhave lower prices for most of the day, as there is typically sufficient downward capacity available from conventional generators. Regulation up prices are generally \$2-3/MW higher than spinning reserve prices, reflecting factors such as the additional bid cost associated with thermal plants following a regulation signal.

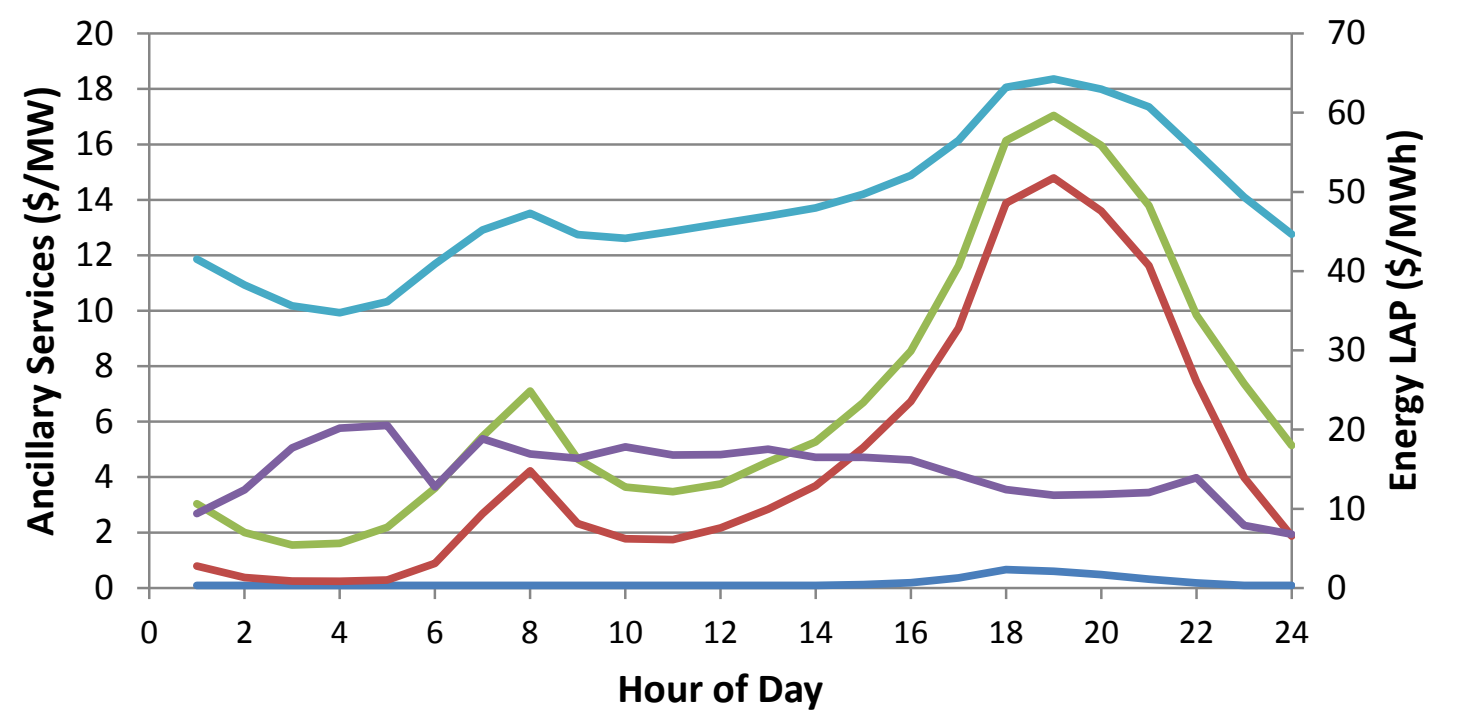

Won-spin $\longrightarrow$ Spinning Reg Up $\quad$ Reg Down $\longrightarrow$ SCE LAP

\section{Figure 20: Average CAISO historical day-ahead energy and ancillary service prices by hour of day} for SCE region 2014 [20]

Figure 21 shows the simulated net market revenues, by component, to the storage portfolio when optimized against 2013 and 2014 historical CAISO prices in the SCE LAP using a price-taker model [30]. Energy arbitrage alone has a value of $\$ 20 / \mathrm{kW}$-year in 2013 and $\$ 25 / \mathrm{kW}$-year in 2014. Energy co-optimized with ancillary services has a value of $\$ 51 / \mathrm{kW}$-year in 2013 and $\$ 58 / \mathrm{kW}$-year in 2014. These results need to be interpreted in light of the limitations of such models, as discussed in Section 3.1; generally, we expect such results to represent an upper bound on the actual revenues.

\footnotetext{
${ }^{30}$ This refers to the energy prices are for the SCE Load Aggregation Point (LAP). The ancillary service prices are for the expanded SP26 region.
} 


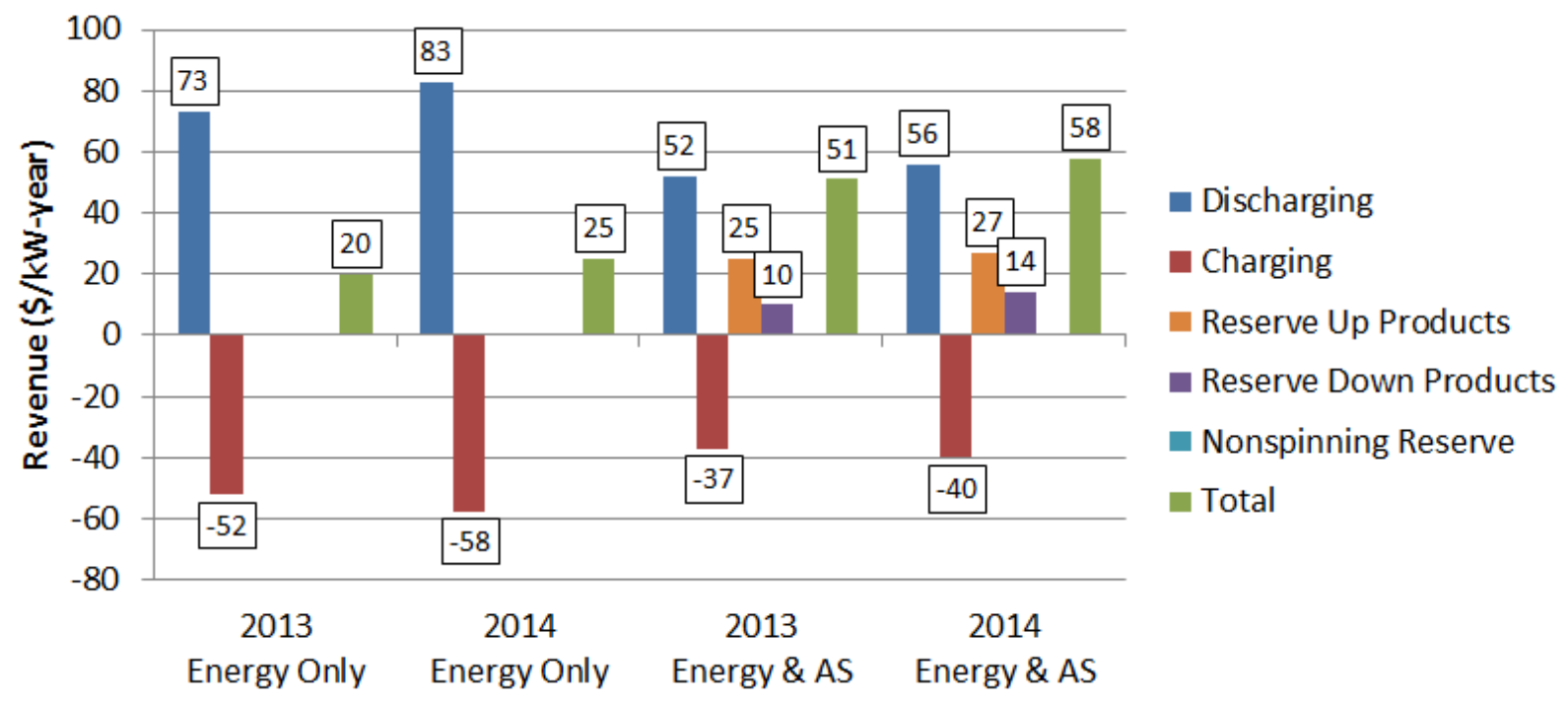

Figure 21: Storage revenues from a price-taker model using historical prices

\section{LTPP 2024 Market Price Simulations}

As conditions change on the CAISO system with higher renewable penetration, there will be significant changes in market prices. Because of their capability to model major structural changes to the resource mix and operational conditions, production cost models can be an important tool for market price forecasting, subject to careful analysis of their results. However, for a number of reasons discussed in this section, the LTPP model does not provide accurate price forecasts for the scenarios evaluated, particularly for ancillary services. This is in part because the model has not been developed, to date, as a tool for market price forecasting and resource valuation. Because ancillary services are expected to be a major component of storage revenues, this limits the ability to use the current model to forecast those revenues. However, results from the LTPP model can provide some indicators of potential market opportunities, as well as identify potential improvements in the LTPP model database.

\section{Challenges of Modeling Ancillary Service Prices and Revenue}

Figure 22 shows the average ancillary service marginal prices for the $33 \%$ scenario without storage. Generally, the simulated ancillary service prices are highly volatile: zero for most hours of the year and then ranging between very low and very high prices, with a much higher variance than the actual historical market prices. This can be seen by comparing the historical reserve prices (Figure 20) to average modeled reserve prices (Figure 22). The model without storage produces an average of 4,300 hours per year of zero prices for upward products, 5,200 hours for downward products and around 8,700 for non-spinning reserve. Challenges of modeling regulation prices in particular are discussed in greater detail in [32].

The shape of the modeled upward reserves price curves somewhat resembles the current market price curve for regulation and spinning reserves shown in Figure 20, and it is reasonable to assume that some of the difference is the more significant ramping that occurs due to the greater penetration of wind and solar generation. Zero prices occur when the normal system unit commitment results in spare capacity and no opportunity cost for committing additional capacity. 
This occurs to downward reserves in the early evening as generators ramp up to meet the increase in net load and can reduce output at no opportunity cost.

While the general shape of prices may provide some insight into the impact of added wind and solar generation to reserve prices, using the modeled ancillary service prices to determine expected revenue is of limited value, especially because of the identical prices for all upward products. Furthermore, the lack of bid prices for regulation (or other regulation-specific payments such as pay-for-performance) understates the potential revenue opportunities for storage providing this service.

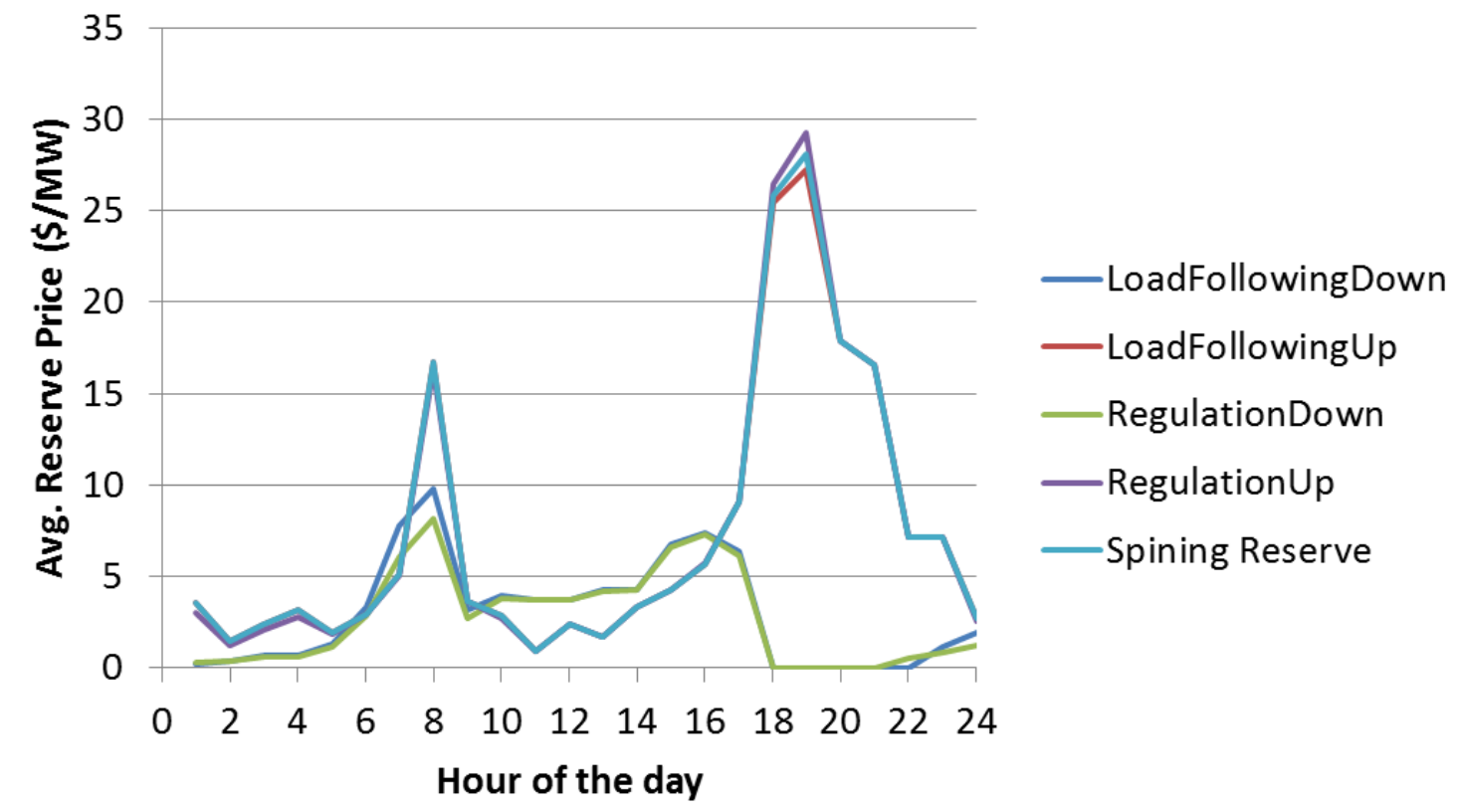

Figure 22: Average modeled ancillary service prices by hour of day from the LTPP model (33\% scenario, no storage)

In addition, because of the nearly identical prices, the model will have no significant preference for which services are provided by storage. This makes it difficult to evaluate how different reserve products will be affected by storage operations, and revenue calculations will be highly uncertain. However, the model does provide some indications of the challenges with revenue capture under increased penetration of storage, especially in the extreme case in which the majority of the storage portfolio is dedicated to provide regulation. These issues are discussed in Section 6.1.

\section{Comparison of Market Revenue Results When Using Different Models}

Section 3.1 defined two modeling approaches for estimates of market revenues, which we called (1) self-scheduled, or price-taker, and (2) system-optimized. All the prior results in this section were derived by using the price-taker model. However, as discussed above, much of the storage value in the production cost simulations was due to avoided starts and stops. Because these costs are not reflected in market prices, the optimal storage dispatch to the owner could be different depending on whether CAISO optimizes its operations within the day-ahead market, or it operates as a merchant plant self-scheduling. To test whether these alternative scheduling 
strategies affect market revenues using the models, we also calculated the system-optimized market revenues - that is, what the storage portfolio would obtain in energy market price revenues resulting from the dispatch obtained from the production cost model. Figure 23 compares the results for the two approaches.

Generally, we found that the self-scheduled price-taker model obtained higher revenues because the storage resources operates at higher charging levels and higher discharging levels and for longer durations than the system optimized resources. While the self-scheduled storage plants are operated in a less-constrained fashion, it is difficult to identify precisely the origins of the additional value associated with self-scheduling. It appears likely that the system optimized storage is operated frequently to avoid starts, which may provide significant value to the system (in terms of reducing production cost), but does not provide significant revenue.

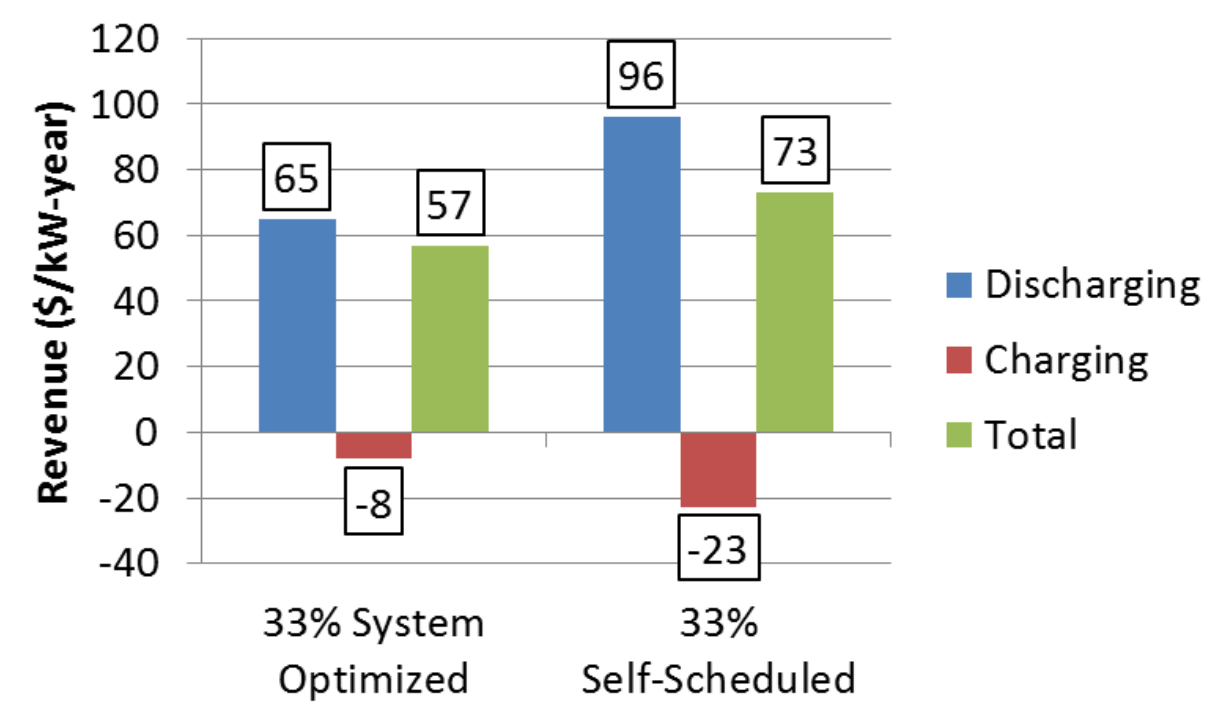

Figure 23: Comparison of storage revenues from the self-scheduled and system-optimized storage dispatch

The role of self-scheduling in storage plant operations, needs further analysis to determine the trade-offs between maximizing plant revenue and maximizing benefits to the system. This issue has been noted previously $[8,14]$. This analysis suggests that a merchant storage plant could have the incentive to attempt to earn higher revenues by self-scheduling, rather than allowing the CAISO to optimize it. Of course, if the merchant does so, the CAISO would have to re-dispatch the remaining resources with market bids, which could affect the prices, and possibly again change the storage owner's incentives. This situation could be much more complicated in actual operations, with many storage plants owned by both utilities and merchants. 


\section{Additional Sensitivity Analyses}

There are a large number of variables in the analysis of storage value within a regional power system, including the effect of the penetration of storage, decisions on the composition of the storage portfolio, and the effect on storage operations of other market factors and policies intended to support renewable integration. As outlined in Section 4.4, we explore a number of additional sensitivity scenarios within the LTPP model framework to explore these factors. The model types used for each sensitivity are listed in Table 4 in Section 3.1.

\subsection{Provision of Regulation Reserves}

Due to the storage policy, and potential participation from other new resources, such as demand response, there could be a large quantity of new, regulation-eligible capacity available over the coming decade. Regulation market prices could thus be highly susceptible to the effect of storage entry. CAISO procurement of regulation has remained fairly stable over the past few years. As noted in Table 8, CAISO currently procures on average about $340 \mathrm{MW}$ per hour of regulation up and $325 \mathrm{MW}$ of regulation down, with some variation from hour to hour and year to year. The regulation market also has the highest ancillary service prices (Figure 20) and includes performance payments which can benefit fast responding resources ([16], [21]). The CAISO models used to forecast regulation procurement in the LTPP scenarios predict the need for another 50-70 MW on average per hour of these services by 2024, again with hourly variation (Table 8).

As was noted in Section 5.4, the structure of the LTPP model currently does not allow the optimization to reflect the actual value of the different reserves. As such, for the cases where storage provides reserves, the impact on the regulation market is unclear. To gain further insight into the impact of storage operations on the regulation market, we evaluate bounding cases with high entry of storage into the regulation market, in which $912.5 \mathrm{MW}$ of the new storage provides only regulation reserves (as noted previously, this capacity is the maximum eligible to supply operational flexibility under the 2014 LTPP assumptions, with the remainder of the portfolio only eligible to provide energy shifting). Production cost model runs were performed for both the $33 \%$ and $40 \%$ scenarios. The production cost value of the added storage is very similar to the other high reserves cases, since the LTPP model groups upwards and downward reserves. The focus in this section is rather on changes to resource utilization and inferring the impact on regulation prices.

The storage capacity dedicated to regulation in these cases is greater than the combined upward and downward regulation requirement in almost all hours of the year. As a resource with no costs for providing regulation in the LTPP model (see further discussion below), storage displaces all other resource types and provides up to $90 \%$ of the CAISO requirement. Figure 24 shows the set of resources displaced from CAISO regulation up requirement. Gas-fired generation, which is forecast by the model to provide between 50-60\% of regulation up in 2024, is largely displaced, but also hydro and existing pumped storage resources (the operations of which could also be affected by the impact of the remaining storage portfolio on energy prices). 


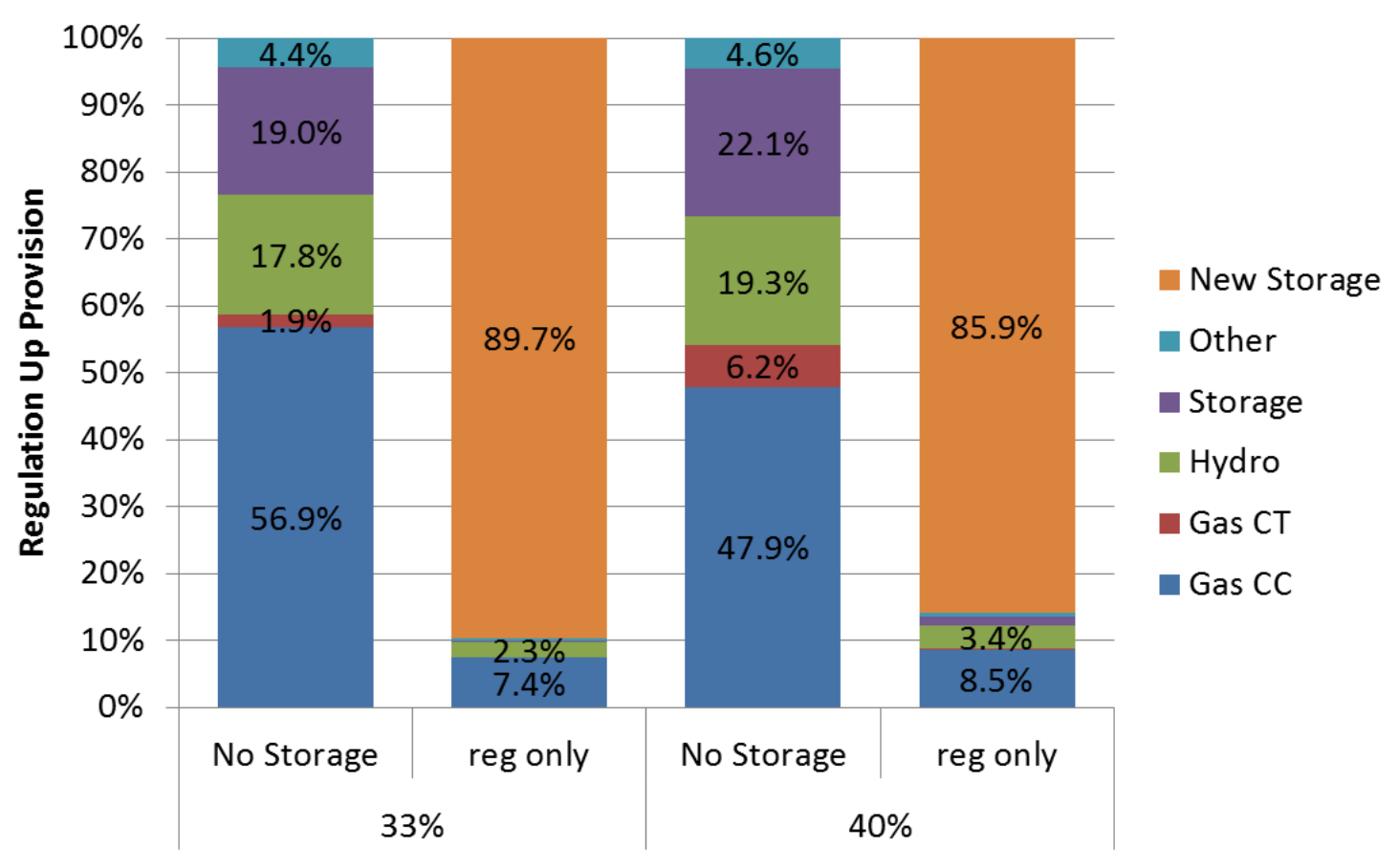

Figure 24: Provision of regulation up to meet California IOU's portion of reserves

While new types of storage may be more efficient at providing regulation, their entry into the market will also impact prices in the regulation market. As discussed in Section 5.4, the operating reserve marginal prices from the current LTPP models are of limited utility for forecasting regulation market prices. However, the model does measure saturation of the market by indicating with zero prices in particular hours when the marginal cost of additional regulation procurement is zero. Figure 25 shows the impact of the operation of the storage portfolio, under these assumptions, on the frequency of zero prices for regulation in the LTPP scenarios. The figure shows the result with and without added storage. It also shows recent historical data from the CAISO regulation market, indicating there are currently very few zero prices, which are limited to regulation down. As expected, the frequency of zero price hours increases significantly when the storage portfolio is dedicated to provision of regulation; most hours now have zero prices. This is in part because the storage resources in the LTPP model do not have a regulation bid cost or modeled energy usage associated with regulation provision [13]. 


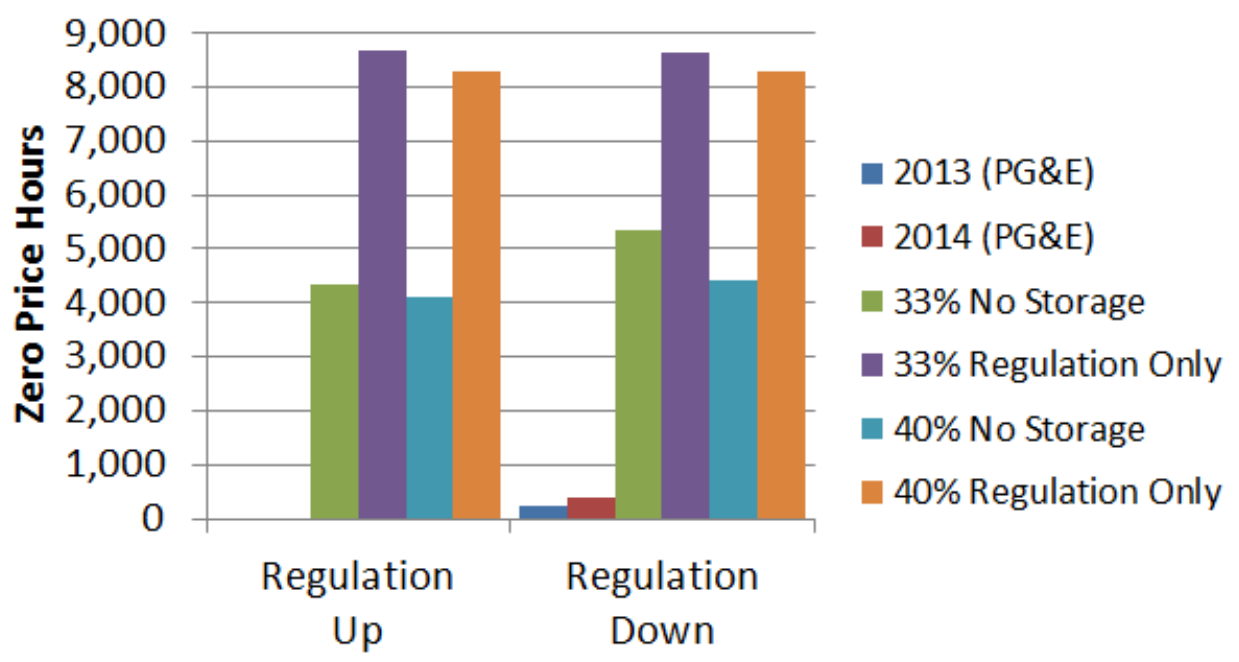

Figure 25: Zero price hours for regulation compared to historical values

In actual storage operations, the energy cycled to provide regulation will experience losses as a function of roundtrip efficiency. The impact of this energy usage, sometimes referred to as "make-up" energy, can be estimated using methods shown in previous analysis [2]. To provide an estimate, we assume that when providing regulation, storage has an energy usage rate of $14 \%$ [2]. When combined with the assumed efficiency of $83.3 \%$, a resource providing $100 \mathrm{MW}$ of regulation would require $2.34 \mathrm{MWh}$ of make-up energy for each hour of operation. This would add energy costs of about $\$ 2$ million - $\$ 5$ million per year when storage provides regulation. ${ }^{31}$ However, depending on the technology characteristics, the storage resources could also have lower operating costs associated with provision of regulation than conventional generators. This could provide some further benefits to market buyers. As seen in Section 5.4, the market price of regulation up in the CAISO SCE zone in 2014 is consistently about $\$ 3 / \mathrm{MWh}$ higher than the cost of spinning reserves. If the generators submitting those bids were displaced, then the cost of regulation could be decreased. ${ }^{32}$

To examine the impact of storage on the regulation market more comprehensively, and to provide guidance for storage procurement or market entry, further research within the production cost model framework would be necessary, including:

(1) testing small increments of new storage capacity entering the regulation market (similar to our testing of penetration in the next section; see also similar analysis in [10]);

\footnotetext{
${ }^{31}$ The range includes make-up energy estimates across the modeled cases. On the low end is the co-optimized energy and reserves cases, where storage provides the least regulation. The cases where more regulation is provided are, in rank order, "eligible reserves", "reserves only" and "regulation-only" (where storage provides the most regulation).

${ }^{32}$ An estimate of the hypothetical aggregate bid cost avoided by storage resources in aggregate, assuming a similar $\$ 3 / \mathrm{MWh}$ cost adder for both regulation up and regulation down, is between $\$ 4$ million - \$17 million per year. Because all resources are paid the market clearing price, these cost reductions would only be fully realized if the storage resources displaced the resources submitting the regulation bids. Similarly to the make-up energy cost range, this range is across the modeled cases in the same order.
} 
(2) improved modeling of regulation pricing, by including historical regulation bids;

(3) analysis of the cost of energy charging when providing regulation.

In addition, there are other effects of new storage technologies on regulation provision, such as the capability to more efficiently control area control error (ACE), which require other types of simulation tools [33].

\subsection{Effect of Progressive Entry of Storage Capacity}

The storage portfolio will be added to the power system progressively, with full compliance required by 2024. The effect of such entry on storage value is examined by varying power capacity (but not the portfolio composition in terms of energy capacity, or duration), adding first one-quarter (331 MW) of the full portfolio to the model, and then one-half (663 MW). In each case, the full production cost model is rerun. This is modeled as if new capacity is only added in 2024; interim years when the new storage resources first come on-line are not examined, although storage value in those years is likely to be different, in part due to lower levels of renewable energy penetration.

The results are consistent with previous analyses which demonstrate a decline in value of storage as a function of penetration in both energy and ancillary service markets (e.g., [10], [13]). Figure 26 provides the total system value, while Figure 27 provides the value per unit of storage capacity. The "first" unit of storage tends to provide the highest value, as it arbitrages the hours with the highest price differentials or provides reserves during the hours of highest cost. In addition, as shown in Figure 26, at lower storage penetrations, avoided start-up costs are a smaller percentage of total avoided costs, reflecting that storage has a greater impact on this factor as storage capacity increases. ${ }^{33}$ However, while other studies have examined this effect, this study also finds that the declining value of incremental additions is offset by the increasing value between the $33 \%$ scenarios and $40 \%$ scenarios. Additional research will help to clarify this effect using different renewable portfolios and higher renewable penetration levels.

\footnotetext{
${ }^{33}$ This finding is also relevant to the "price-taking" model assumption: as long as the incremental storage device is small enough, it will not fully displace generators from the power system and the avoided start-up costs can be ignored in valuation.
} 


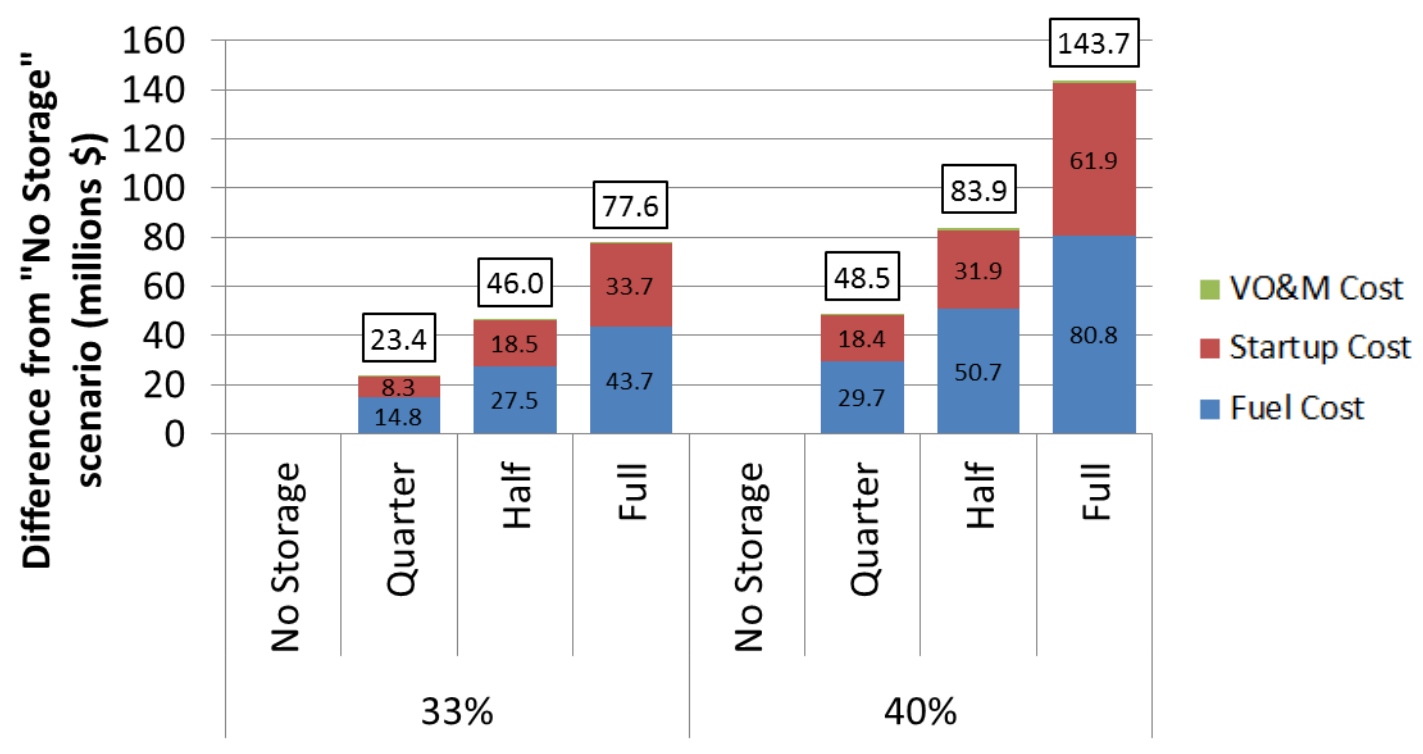

Figure 26: Production cost reduction with storage providing both energy and reserves for three levels of installed capacity

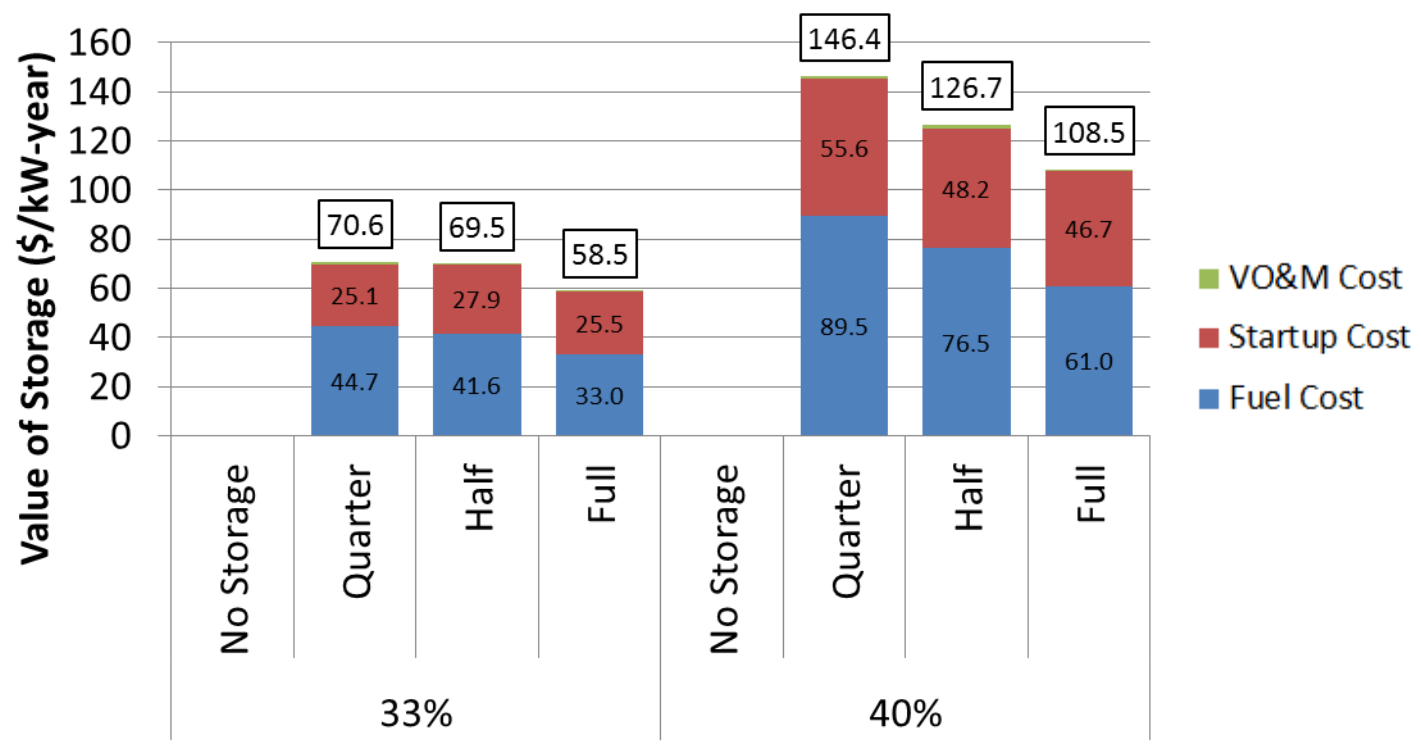

Figure 27: Value of storage providing both energy and reserves per unit of capacity for three levels of installed capacity

\subsection{Effect of Expansion in Storage Duration}

As noted, the California utilities have the flexibility to adjust procurement of storage resources to fit operational and reliability needs. While the LTPP storage portfolio includes long duration devices, there could be value to additional duration, particularly to address renewable curtailment. On the other hand, if the expected renewable curtailment is of the magnitudes shown in Figure 12, then additional power capacity (MW) may be required to fulfill this function. To examine how longer duration storage cases affect value, we developed two scenarios: for the " +1 hour" scenario, the duration of each storage resource is increased by 1 hour (e.g., 2-, 4-, and 6- 
hour resources become 3-, 5-, and 7-hour resources); the "+4 hour" scenario follows the same approach, but the storage capacity is increased instead by 4 hours. Adding one hour of capacity to the portfolio increases the total storage capacity by $28 \%$, and adding 4 hours of capacity increases the total storage capacity of the portfolio by $112 \%$. In each scenario modeled, only the co-optimized energy and reserves application was evaluated. Added value in these cases would come only from energy arbitrage, since the additional duration does not affect provision of operating reserves.

Figure 28 shows the effect of these new storage portfolios on avoided annual production costs and Figure 29 shows the value of storage per unit of installed capacity (MW). In each, only the co-optimized energy and reserves application was evaluated.

In the $33 \%$ scenario, increased energy capacity provides very little increase in value. However, in the $40 \%$ scenario, the +4 hour portfolio provides about $10 \%$ increased value because of the higher level of renewable curtailment and increased differences in off-peak to peak energy prices.

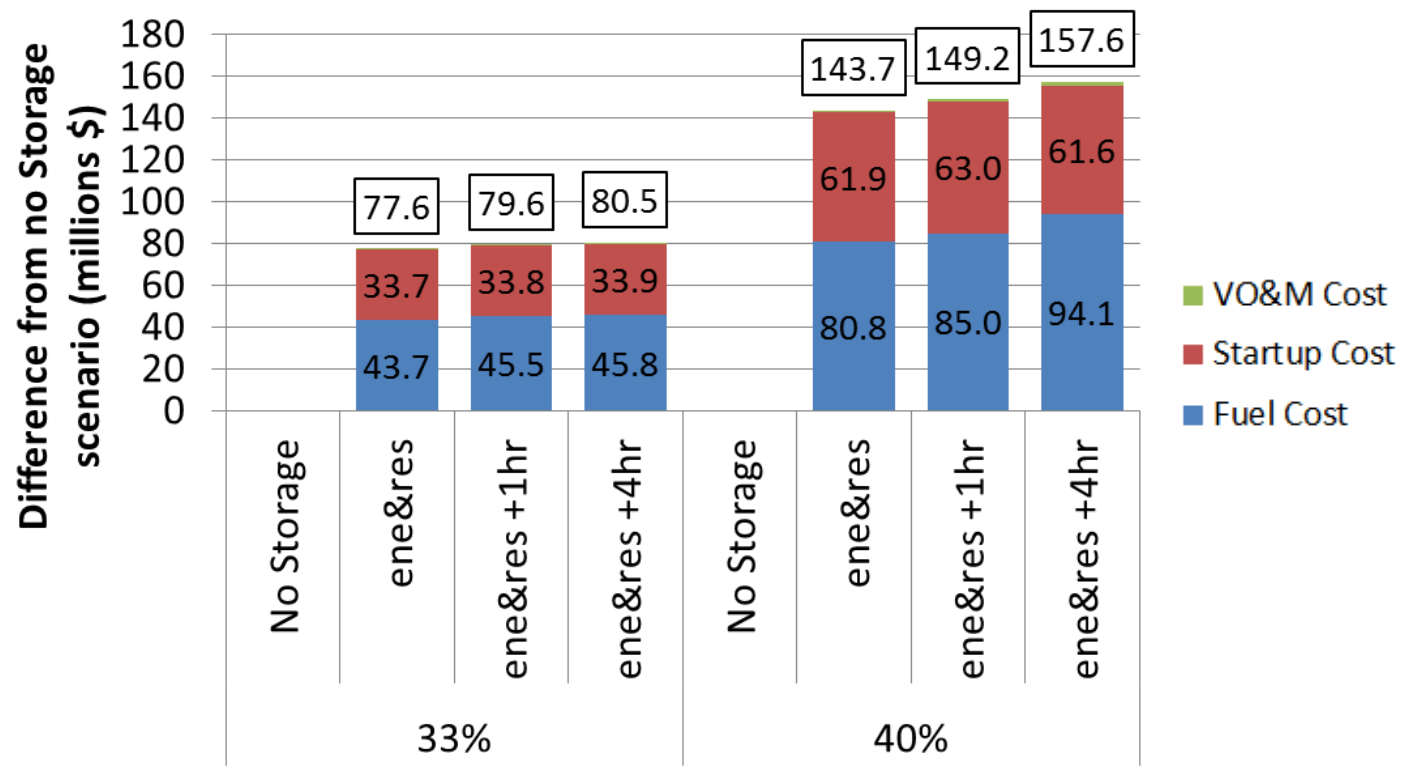

Figure 28: Production cost reduction in cases with longer duration storage 


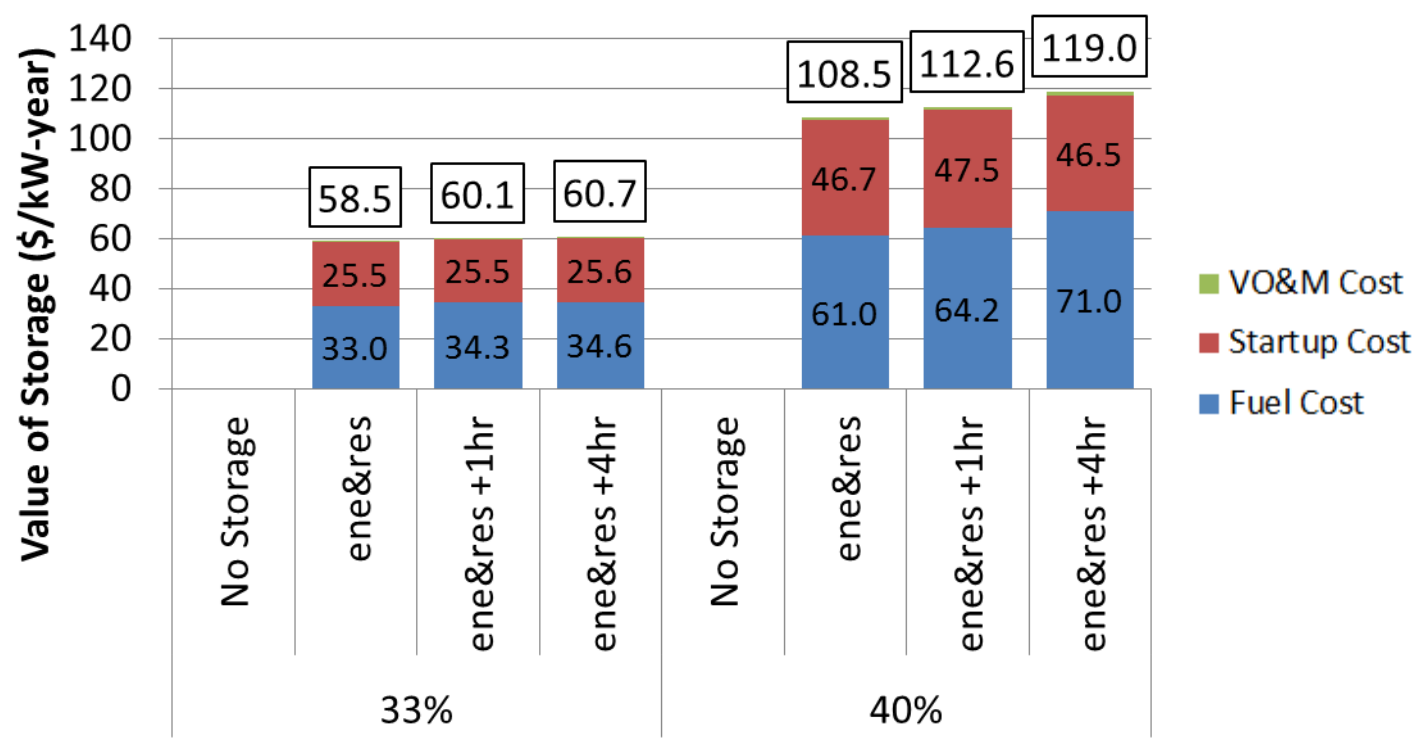

Figure 29: Value of storage in cases with longer duration storage

\subsection{Negative Bid Prices}

Negative prices are a growing concern in wholesale markets with increasing penetration of renewable generation, but also present an opportunity for storage technologies. For storage valuation, a key research issue is forecasting the frequency and magnitude of negative prices. In the CAISO markets, negative bids are currently allowed to reach $-\$ 150 / \mathrm{MWh}$ (called the "bid floor") and will be allowed to reach $-\$ 300 / \mathrm{MWh}$ before 2020 [28]. In the actual wholesale markets in 2024 (or before), the curtailment clearing price in 2024 is likely to be significantly less than $-\$ 300 / \mathrm{MWh}$, reflecting factors such as lower-cost renewable projects available to curtail at lower prices and competition among suppliers of surplus energy to set the price. (Alternatively, surplus power could be exported to other regions and retail load could be shifted to increase demand.) For example, the lowest-cost solar PPAs in the western United States at the time of this writing are reported to be below $\$ 50 / \mathrm{MWh}$ with current investment tax credits [34]. Wind PPAs that include production tax credits are typically reported as below \$40/MWh [35].

To date, the LTPP model does not use actual or forecast wind and solar contract costs directly, but rather curtailment costs for renewables are implemented with a uniform $-\$ 300 / \mathrm{MWh}$ operation cost. This cost is included in the production cost calculation to discourage curtailment of renewables, using the method described in Section 4.1, but is not intended as a forecast of market-clearing negative prices. However, because of the structure of the LTPP model, this curtailment cost has an impact on production costs and sets the marginal cost of energy during almost all periods with curtailment. All the prior storage valuation and operational results in this paper reflected this assumption, and hence contained a slight bias to increased storage value (an estimate of this bias is discussed below). In this section, we consider the impact of changing the cost of renewable curtailment.

\section{Effect on Production Costs}

We conducted two sensitivities on the negative bid floor, reducing it first to $-\$ 150 / \mathrm{MWh}$ and then to $\$ 0 / \mathrm{MWh}$. The full production cost model was re-run with and without storage for these 
alternative negative bids because they will affect the commitment and dispatch of other generating units, as well as the level of curtailment.

The number of zero or negative prices hours changes relatively little with changes to the bid floor. In the base case with a $-\$ 300 / \mathrm{MWh}$ bid floor, the addition of storage reduces the number of negative price hours from 198 to 146 for the $33 \%$ scenario and from 1,184 to 1,019 for the $40 \%$ scenario. This is because the quantity of surplus renewable energy is simply greater than the model can utilize, even with a high curtailment cost. For the remainder of this section we focus on the $40 \%$ scenario results because the impact on the $33 \%$ scenario is very small.

Figure 30 shows the impact on renewable curtailment associated with changing the curtailment cost of renewables. In this figure, curtailed energy reflects the portion of renewable generation that is eligible for the RPS in California. Without storage, reducing the cost of renewable curtailment from zero to $-\$ 300 / \mathrm{MWh}$ decreases curtailment as the model re-optimizes the system dispatch to avoid curtailment. The bid floor sensitivities also show that without storage a $-\$ 150 / \mathrm{MWh}$ bid is sufficient to achieve $93 \%$ of the curtailment reduction when compared to the $\$ 0 / \mathrm{MWh}$ case $(96 \%$ for the case with storage). This means that the $-\$ 300 / \mathrm{MWh}$ case achieves only a marginal additional reduction in curtailment when compared to the $-\$ 150 / \mathrm{MWh}$ case.

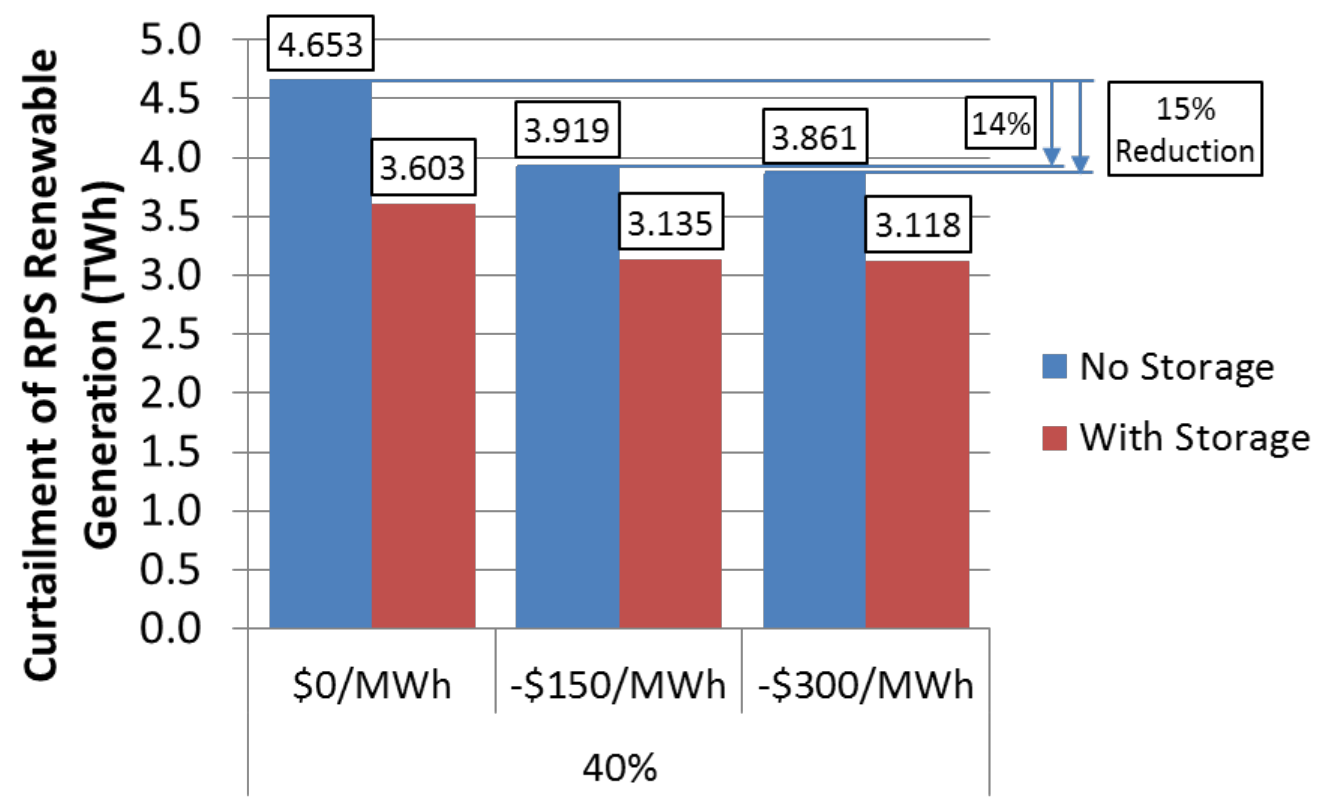

Figure 30: Change in renewable energy curtailment for different renewable bid prices, without and with storage 
The $-\$ 300 / \mathrm{MWh}$ curtailment cost also decreases the overall efficiency of system dispatch and increases production costs. Figure 31 shows the production cost difference between the $\$ 0 / \mathrm{MWh}$ renewable bid floor case to the $-\$ 300 / \mathrm{MWh}$ case. This figure isolates the changes in production cost components due to the lower bid floor. With a $-\$ 300 / \mathrm{MWh}$ curtailment cost, the fuel costs are reduced due the reduction in curtailment and increase in displaced fossil generation. However, at the same time, generator startup costs increase with the lower bid floor, shown as positive bars in Figure 31. In sum, implementing the more negative bid floor essentially reduces curtailment and fuel costs, but causes an increase in start costs and an overall increase in production costs. The net change in production cost when reducing the $\$ 0 / \mathrm{MWh}$ bid floor to $-\$ 300 / \mathrm{MWh}$ is an additional $\$ 39$ million without storage and $\$ 15$ million with storage.

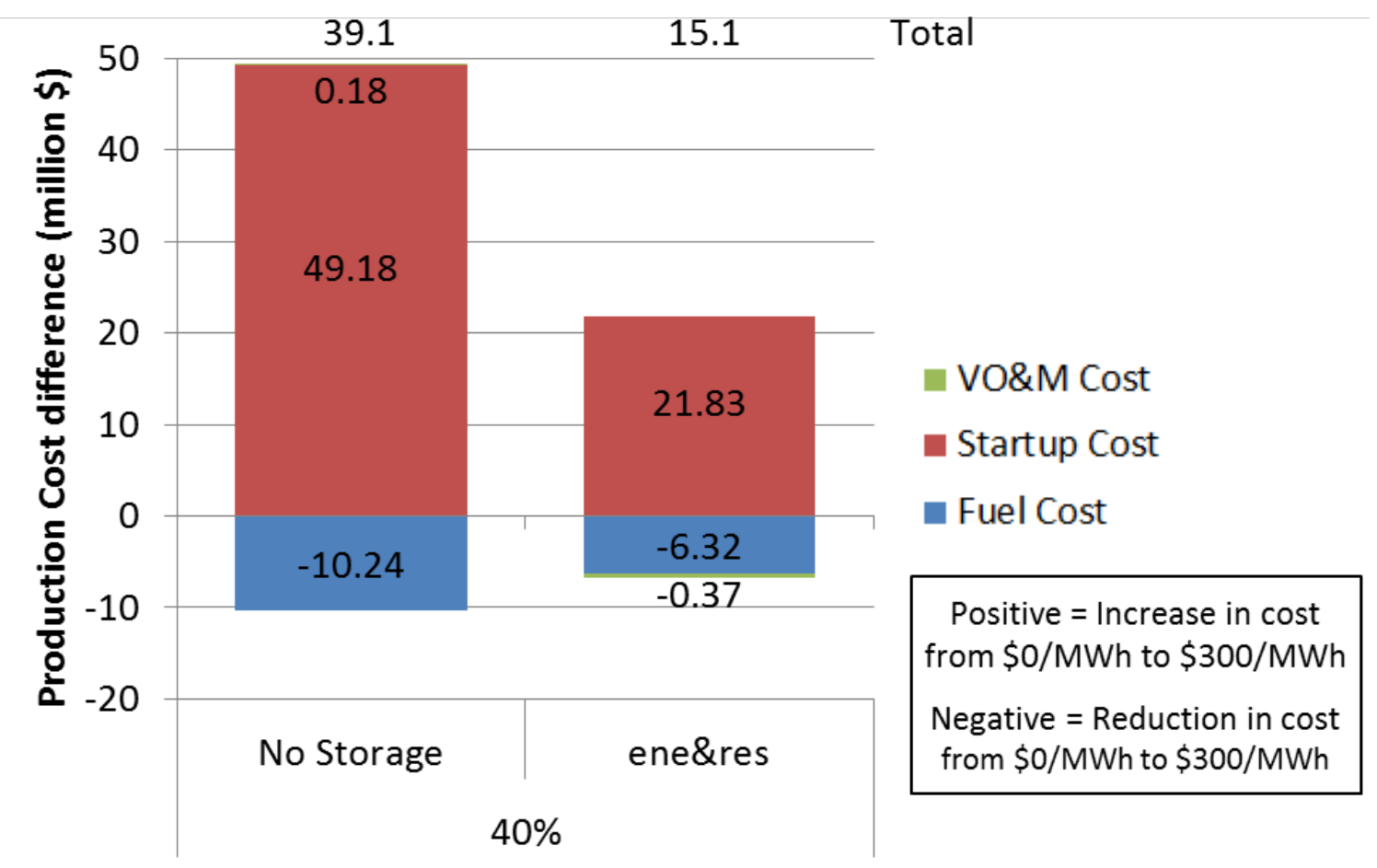

Figure 31: Change in production cost components moving from $\$ 0 / \mathrm{MWh}$ to $-\$ 300 / \mathrm{MWh}$ bid floor

By dividing the change in cost by the reduction in curtailment, we can construct a measure for the value of avoided curtailment resulting from the change in negative bid cost. The net reduction in curtailment from the $\$ 0 / \mathrm{MWh}$ bid floor to $-\$ 300 / \mathrm{MWh}$ is $792 \mathrm{GWh}$ without storage and $485 \mathrm{GWh}$ with storage. Hence, the additional reduction in curtailment, when modeling the bid floor at levels lower than $\$ 0 / \mathrm{MWh}$, costs the system $\$ 49 / \mathrm{MWh}$ without storage and \$31/MWh with storage.

\section{Market Revenues by Full Portfolio}

In Section 5.4, we examined the value of energy arbitrage using market revenue models. Figure 23 compared the results. Those results only considered the $-\$ 300 / \mathrm{MWh}$ bid floor; here we further evaluate arbitrage value by using the simulated energy prices resulting when the negative bids are varied. Figure 32 shows the "self-scheduled" results using both historical prices as well as modeled 2024 prices (the result for $-\$ 300 / \mathrm{MWh}$ bid floor lines is the same as in Figure 23). The storage portfolio is again normalized by installed capacity (i.e., $1,325 \mathrm{MW}$ ). 
The results suggest that the reductions in energy prices during periods of surplus generation will provide a significant increase in energy arbitrage value even if they are zero or close to zero. Under the zero price bid floor assumption, the value of energy arbitrage doubles between 2014 and 2024 under the $33 \%$ renewable case, and triples in the $40 \%$ case. Negative electricity prices could greatly augment this result because they provide positive revenue while charging. Increasing the value of avoided curtailment from zero to $\$ 300 / \mathrm{MWh}$ increases storage revenue by $43 \%$ in the $33 \%$ renewable scenario, and by more than $200 \%$ in the $40 \%$ case. These results with very negative curtailment costs are dependent on the unrealistic assumption that such negative prices would occur during all hours of curtailment. Hence, these results are shown here only to illustrate the impact of assuming very high negative prices from renewable curtailment.

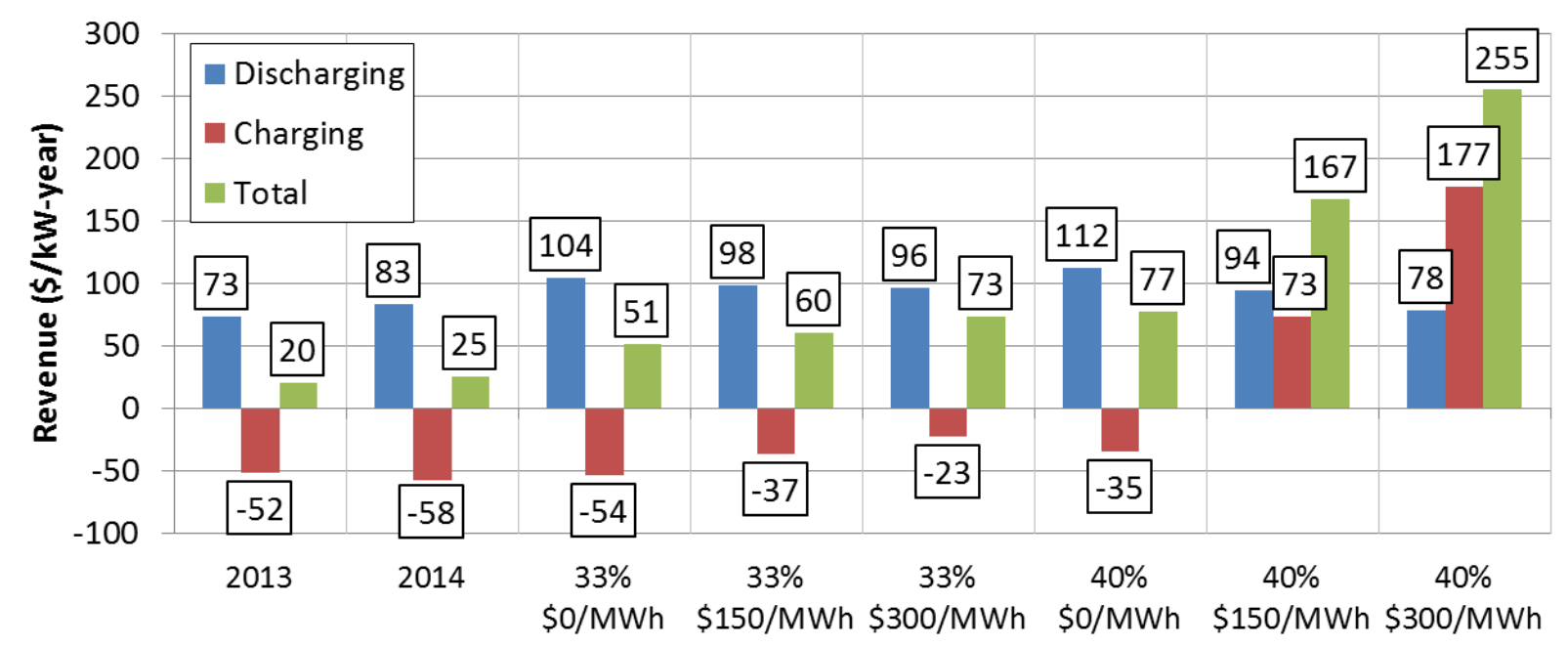

Figure 32: Arbitrage revenue from a price-taker model using historical and modeled prices (values under the renewable penetration scenarios are the maximum value of avoided curtailment)

\subsection{Disaggregated Storage Portfolio}

As shown so far, the price-taker results aggregate the revenues of the entire storage portfolio, which comprises the resources with the characteristics shown in Table 10. However, the individual storage resources of different durations ( 2 hour, 4 hour, 6 hour) will earn different annual revenues on a $\$ / \mathrm{kW}$-year basis. For energy arbitrage, we expect a declining rate of increase in annual revenue $(\$ / \mathrm{kW}$-year) for any fixed storage power capacity as duration increases, simply because fully utilizing the additional energy capacity requires operating across lower value arbitrage opportunities. To explore this relationship, we ran the same price-taker simulations against the price curves from the $33 \%$ and $40 \%$ scenarios that utilized the zero bid floor. Figure 33 provides the results, indicating the declining marginal value of additional storage in all cases. In the $40 \%$ case, both the absolute value is greater than the $33 \%$ case, and the rate of increase in annual revenues with additional hours of storage is slightly greater, reflecting the greater frequency of low or zero prices. Further research could explore how the composition of the storage portfolio (both storage duration and applications) could be optimized against forecasts of future prices and system operational needs. 


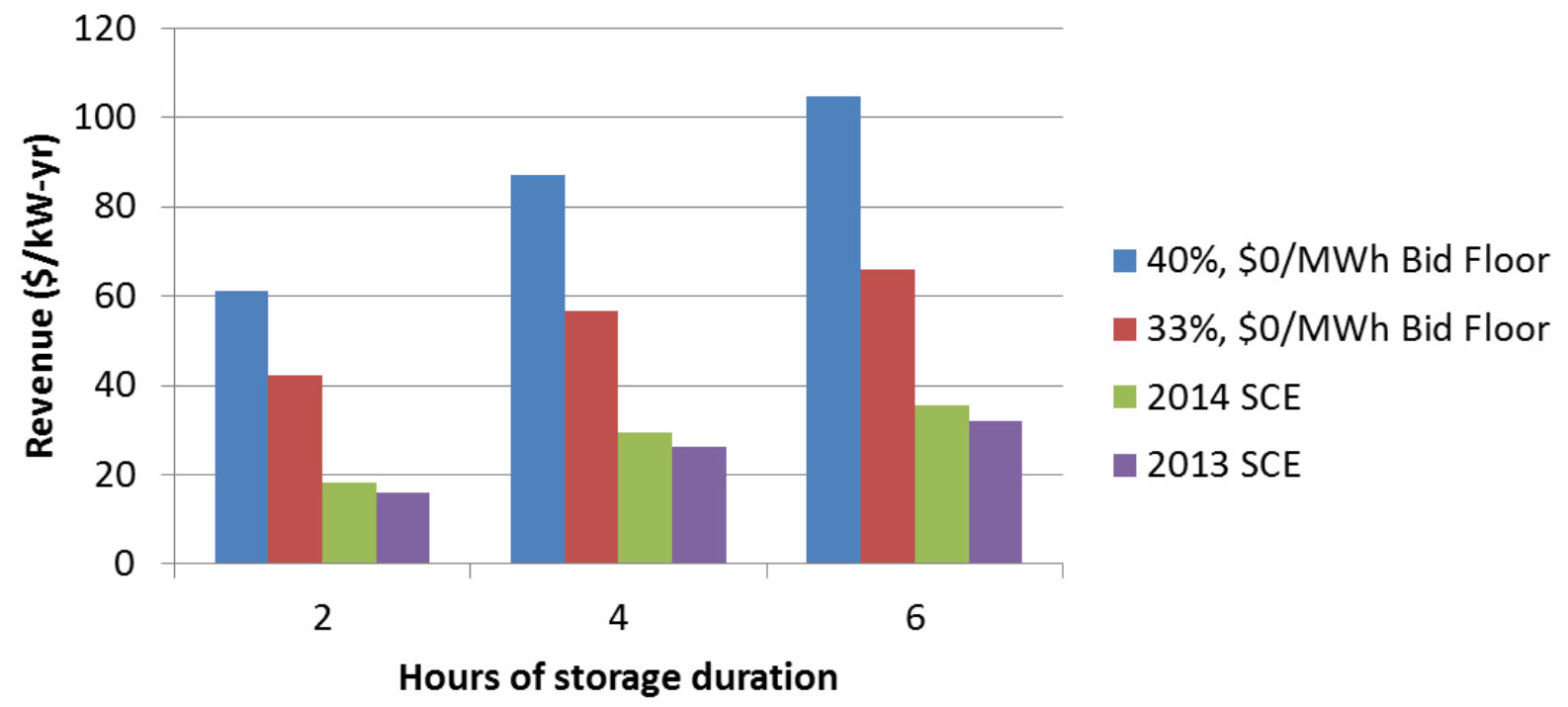

Figure 33: Aggregate storage revenues for energy arbitrage using a price-taker model as a function of storage duration

\subsection{Regional Market Integration: Relaxation of Export Constraints}

In the LTPP studies to date, the CAISO model has enforced a "net zero export constraint," which prevents exports of energy from the CAISO footprint to external regions [25]. This constraint was justified on the basis that historically the CAISO has been a net importer, and secondly, that the Energy Imbalance Market (EIM) is currently restricted to real-time energy transactions and therefore unable to fully capture the opportunities for regional dispatch improvements. However, if a more robust regional market for California energy exports and ancillary services was to develop, it could have a major impact on renewable curtailment and in turn on storage value. ${ }^{34}$

While this study did not conduct an in-depth assessment of regional market integration, relaxing the export limit allows for a partial examination of the effect on storage value. The net zero export constraint was removed but the transmission interfaces maintain their maximum power rating. As shown in Figure 34, the curtailment in both $33 \%$ and $40 \%$ cases with storage is completely relieved through re-dispatch of generation external to CAISO. This result has been documented previously [31], but not evaluated for its effect on storage value.

\footnotetext{
${ }^{34}$ Studies quantifying aspects of the benefits of the EIM, including reductions in renewable curtailment, can be found here: http://www.caiso.com/informed/Pages/EIMOverview/Default.aspx.
} 


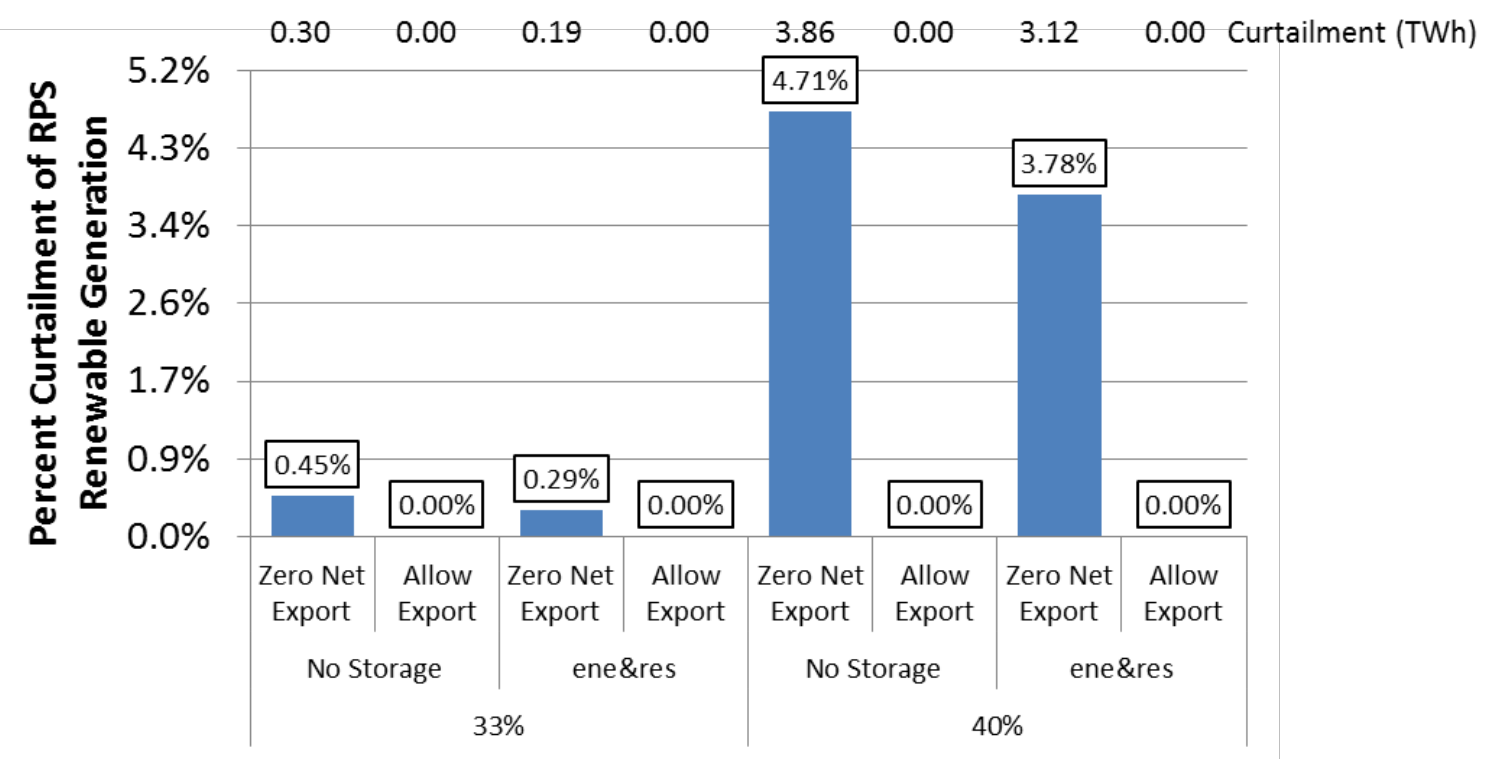

Figure 34: Curtailment values from relaxing California export limitations

Relaxing export constraints causes an overall reduction in the amount of imported electricity, as shown in Figure 35. For the 33\% scenarios, the relaxation of the export constraint minimally reduces the net import. When the RPS-eligible renewable energy is increased to $40 \%$, the total imports reduce and the impact from relaxing the export constraint increases. The overall imports reduce most notably because the additional renewable generation acquired to achieve the $40 \%$ scenario is exclusively from in-state renewables (shown in Table 7). The reduction in imports when export constraints are relaxed is largely caused by alleviation of renewable curtailment (Figure 34).

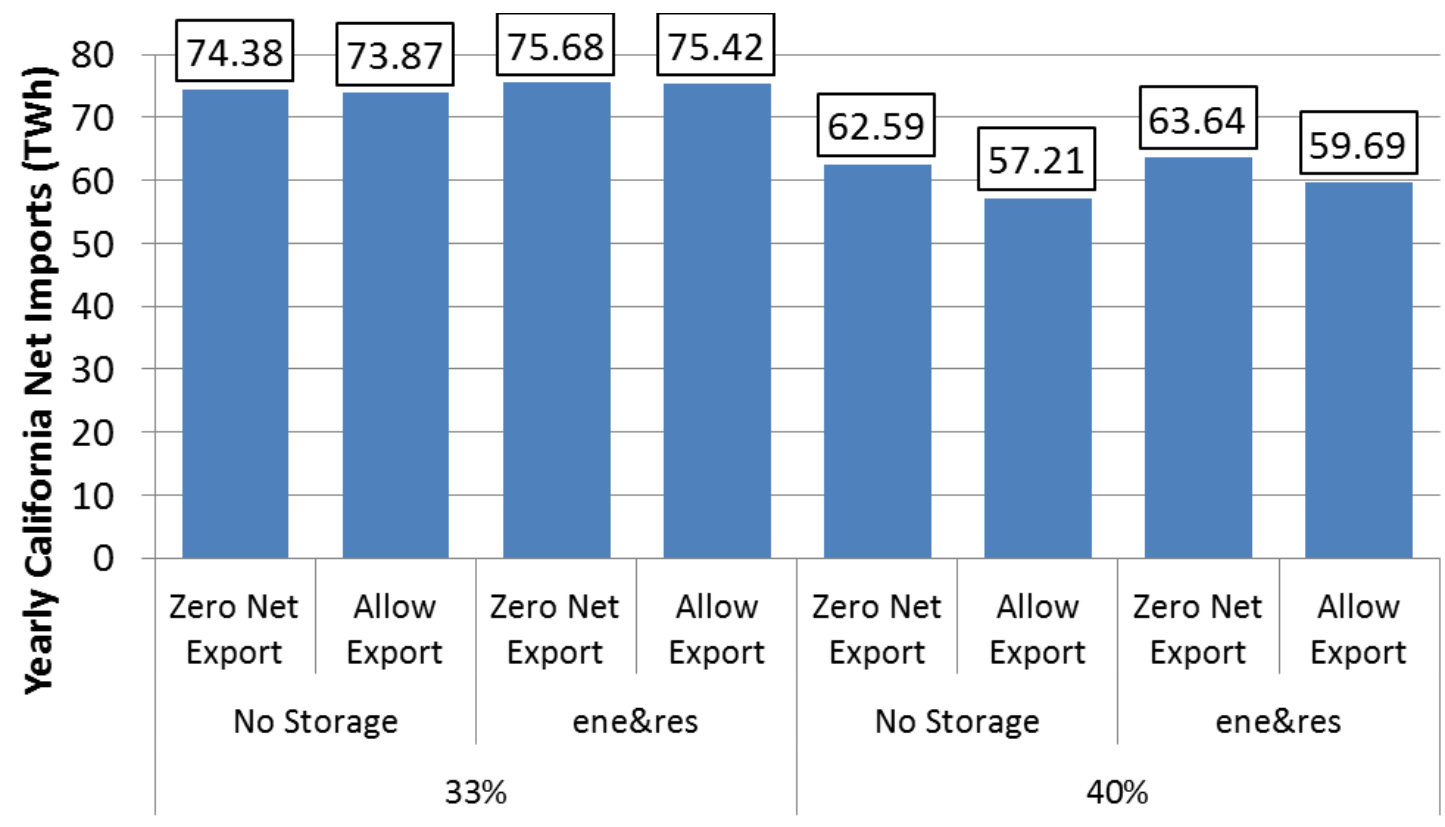

Figure 35: Yearly net import into California for zero net and relaxed export scenarios 
In addition to reducing system curtailment, relaxing export constraints also reduces production cost through wider-area optimization. To measure this effect, Figure 36 shows the reduction in annual production cost resulting from removing this constraint. Notice that relaxing the export constraint reduces the production cost in all cases, in large part because it allows the previously curtailed renewable energy to be fully utilized.

As would be expected, the reduction in renewable curtailment and improvement in regional dispatch diminishes some of the main drivers of storage value. To obtain this measure, we needed to calculate a baseline for the no export constraint without storage. Figure 36 shows that between the no-storage baseline for the net zero constraint case, and the case with storage under the same constraint, the value of storage is $\$ 77.6$ million in the $33 \%$ scenario (this is the same calculation shown in Figure 6). However, the production costs in the baseline case with the exports allowed are $\$ 10$ million lower than the baseline case without the export constraint, reflecting the ability to utilize curtailed renewable energy in regions outside California. The addition of the storage portfolio to that case results in an $\$ 82.5$ million reduction, which is $\$ 72.5$ million greater than the baseline ( $\$ 82.5$ million - $\$ 10$ million). Hence, storage provides $\$ 5.1$ million less value to this case (although starting from different baselines), due primarily to the fact that the renewable curtailment has already been reduced. The same calculation for the $40 \%$ scenario finds that storage provides $\$ 143.7$ million in reduced costs in the no export case, but only $\$ 91.3$ million in the case with exports. Hence, storage provides $\$ 52.4$ million less value in this case.

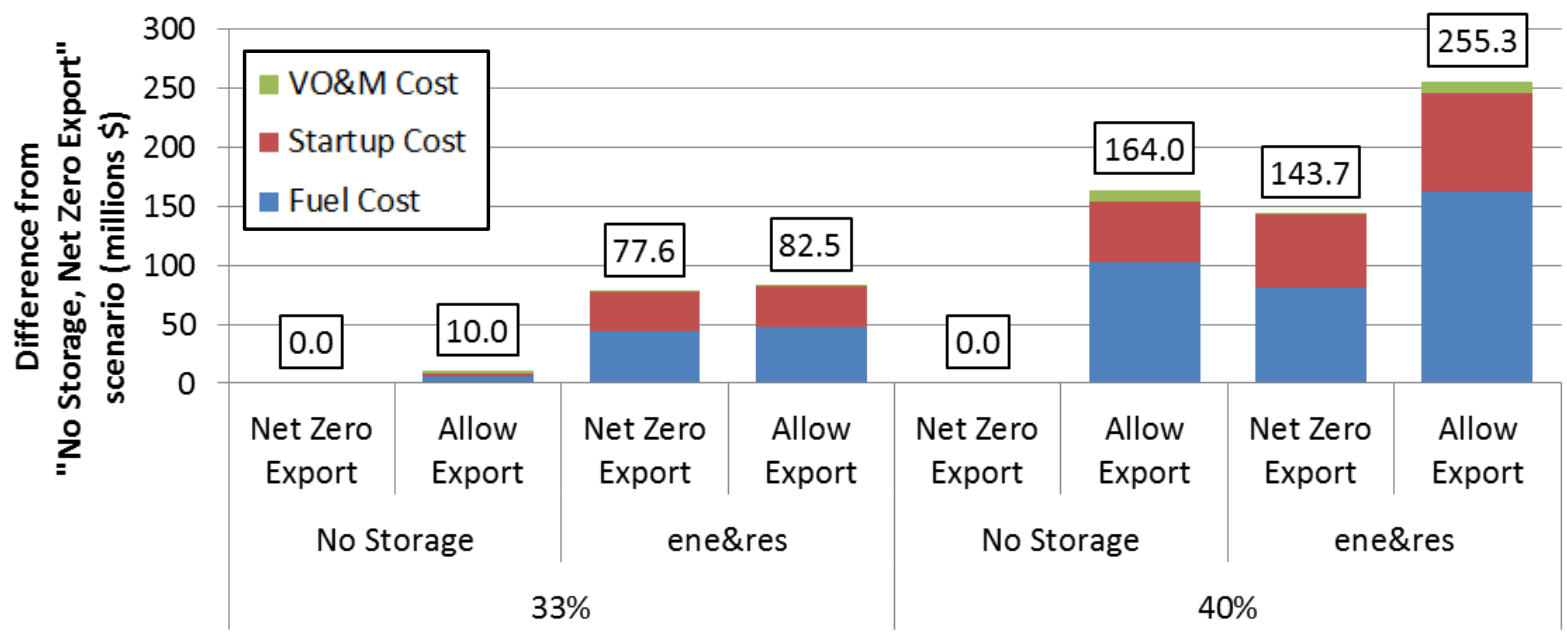

Figure 36: Production cost reduction from relaxing California export limitations ${ }^{35}$

These findings are general in nature, and reflect bounding cases due to several factors. First, the LTPP model dispatches the entire WECC region, while the current CAISO EIM does not cover this entire region. We did not evaluate the impact of re-dispatching a small region corresponding to the current EIM, but presumably this could also lead to a more limited reduction in curtailment and system costs. Second, the model effectively offers the curtailed energy to the rest of the West at a negative price, meaning that it is always taken. The actual export transactions of surplus renewable energy, if they take place, may not always find buyers. Third, the LTPP

\footnotetext{
${ }^{35}$ Each bar represents a difference from the no storage scenario for $33 \%$ or $40 \%$, respectively.
} 
assumptions are that renewable development in the rest of the West by 2024 will reach 97.6 TWh for both $33 \%$ and $40 \%$ scenarios, equal to $12-13 \%$ of the load for the rest of the West. If the actual level of renewable development is greater than this forecast, there may be less regional re-dispatch available than shown in the model. Less capacity available for re-dispatch in the West could mean that the storage in California has greater value than forecasted. Additional sensitivities could help evaluate this factor.

Storage value could be highly dependent on how regional western markets evolve, and the resulting prices and conditions within California. These simulations suggest that this value will be greater with less regional market integration because resources outside the current CAISO market will be a substitute for storage when providing operational services. At the same time, the forecasts of increasing renewable penetration throughout West suggest increased demand for both additional storage and a more robust regional market. 


\section{Capacity and Additional Sources of Value}

The results in the previous sections quantify only the operational benefits of storage, under the eligibility rules in the LTPP planning assumptions. There are several additional sources of value that can greatly increase the value of energy storage. The most significant of these is the capacity value of storage, or the ability to offset the need for conventional generation capacity.

The CPUC's Resource Adequacy (RA) program was instituted by legislation in 2004, with the first compliance year in 2006. The RA requirement is established as the next year forecast system peak load plus a reserve margin of $115 \%$ for each load-serving entity. Under current rules, the capacity rating of qualified storage (i.e., transmission-connected or distributionconnected) is based on the maximum output sustainable for 4 hours. Using these current rules, the qualifying capacity of the modeled 1,325 MW portfolio, under the LTPP planning assumptions about storage durations and eligibility to provide services, is $730 \mathrm{MW}$ (Table 16).

Table 16. Storage Generic Capacity Ratings under Current CPUC Rules

\begin{tabular}{|lcccc|}
\hline Values are MW in $\mathbf{2 0 2 4}$ & $\begin{array}{c}\text { Transmission- } \\
\text { Connected }\end{array}$ & $\begin{array}{c}\text { Distribution- } \\
\text { Connected }\end{array}$ & $\begin{array}{c}\text { Customer- } \\
\text { Sited }\end{array}$ & Total \\
\hline Total installed capacity & 700 & 425 & 200 & 1325 \\
\hline Amount eligible to provide capacity & 700 & 212.5 & 0 & 912.5 \\
\hline Net Qualifying Capacity (NQC): & & & & \\
\hline Storage with 2-hour capacity & 140 of 280 & 42.5 of 85 & 0 of 100 & 182.5 \\
\hline Storage with 4-hour capacity & 280 of 280 & 85 of 85 & 0 of 100 & 365 \\
\hline Storage with 6-hour capacity & 140 of 140 & 42.5 of 42.5 & 0 & 182.5 \\
\hline Total & 560 & 170 & 0 & 730 \\
\hline
\end{tabular}

Source: CPUC [Rulemaking 13-12-010,pg. 22]

The customer-sited storage could be indirectly providing capacity value to the load being served by reducing peak loads and thus help meet resource adequacy requirements assigned to the loadserving entity. However, it would have to be operated in a manner consistent with reducing the load-serving entities aggregate load shape rather than the individual commercial or residential demand consistent with retail rate incentives.

There are several measures of the capacity value of the storage added to the portfolio. A common approach is to use the avoided net capacity cost: the hypothetical additional revenue needed for a new generator, such as a combustion turbine or a combined cycle plant. This is the capacity cost avoided by the new storage resource. Data from the CEC provides estimates of the net capacity costs of gas-fired generation, with a large range of results depending on assumed ownership structure, financing, and other factors in addition to the cost of the turbine itself [36]. The CAISO market monitoring report uses an estimate for the annualized cost of a new combustion turbine equal to about $\$ 190 / \mathrm{kW}$-year [16]. After adjusting for energy market revenues that cover part of these costs (about $\$ 27 / \mathrm{kW}$ to $\$ 30 / \mathrm{kW}$ in 2014 ), this produces a "net cost of new entry" value of about $\$ 160 / \mathrm{kW}$-year [16]. This value could be significantly lower or higher depending on factors mentioned above plus the actual need for new capacity. There is extensive discussion of the costs of new capacity provided in $[37,38,39]$. Despite the range in capacity costs estimates, the value of capacity is likely to be a sizable portion of the total value of storage, and in many cases can exceed the operational value. This also points to the need for a more comprehensive assessment of storage value when comparing storage to other grid flexibility options. 
The potential market value of the storage portfolio should be enhanced by the ability to locate storage in local areas and also because it can qualify as flexible capacity under the current rules. The CPUC/CAISO flexible capacity requirement is currently defined as the qualified capacity needed to address the maximum 3-hour system ramp per month [40]. Under current rules for "bidirectional" storage, all of the LTPP storage portfolio modeled would qualify as flexible capacity.

Finally, customer and distribution sited storage provide additional benefits. Avoided T\&D losses increase both the operational value and capacity value when compared to centrally located facility. An estimate of benefits associated with distribution system upgrade deferral is provided in [7]. 


\section{Conclusions}

This study has analyzed the operational benefits of the CPUC's planned storage portfolio in 2024 by using the models and scenarios developed by the California state energy agencies. As storage procurement by the California utilities progresses over the remainder of the decade, the benefits of storage are likely to reflect continued changes in system operations and grid conditions. The study examined some of the likely drivers of these changes in value, such as increased renewable penetration, increased storage penetration, and regional market expansion.

A key finding, consistent with prior research, is that as renewable penetration increases, the benefits of storage will be tied to increases in off-peak to peak energy price differences and operational issues associated with renewable integration, particularly mitigation of renewable curtailment. Higher renewable production and associated curtailment could also offset the declining marginal value of additional storage as storage penetration increases. However, the study also shows that this result will be highly sensitive to the frequency and magnitude of negative prices, as well as to other policies that could mitigate over-generation in California, such as increased integration of system operations and markets across the western grid. A summary of key results follows.

\section{Overall Portfolio Storage Value}

Overall, the mandated storage requirement of 1,325 MW was estimated to reduce the total cost of production by up to $\$ 78$ million per year in the base 33\% scenario and $\$ 144$ million per year in the base $40 \%$ scenario. This translates to $\$ 59 / \mathrm{kW}$-year of storage capacity for the $33 \%$ scenario and $\$ 109 / \mathrm{kW}$-year of storage capacity for the $40 \%$ scenario. Between $29 \%$ and $67 \%$ of these avoided costs in the base cases are due to avoided generator startup costs.

\section{Energy Arbitrage Opportunities}

Consistent with prior study findings, this analysis suggests that energy arbitrage is of limited value in current markets. The price-taker model finds only $\$ 20-\$ 25 / \mathrm{kW}$-year in day-ahead energy market arbitrage revenues for 2013-2014, for a marginal resource. However, additional renewable penetration could lead to more volatile market prices and higher operational benefits. This is demonstrated by an increase in both market revenues and avoided production costs between the $33 \%$ to $40 \%$ scenario. For example, the increase in on/off peak price differences increases the avoided production costs of the storage portfolio by $73 \%$ when only providing arbitrage. Some of this volatility will come from price spikes due to net load system ramps.

Negative prices could be a much larger source of benefit for storage providing energy arbitrage. To be conservative, our starting assumption is that renewable energy curtailment will cost close to zero in 2024. In this case, the value of energy arbitrage is $\$ 51 / \mathrm{kW}$-year using the selfscheduled price-taker model, about double the 2014 result, and $\$ 77 / \mathrm{kW}$-year in the $40 \%$ case. In the cases with much more negative energy prices, storage value increases significantly. However, in the production cost model, at such low negative prices, the storage resource can dump energy to take advantage of roundtrip efficiency losses while still providing positive benefits to the system. The technical and policy implications of using storage in this manner need to be considered in future analysis. 
Two further findings from the energy arbitrage results were that (1) avoided production costs were lower than total market revenues based on the marginal prices from the LTPP model, and (2) market revenues calculated using the "self-scheduled" model are different to those from the system-optimized dispatch. The reasons for the first finding are the frequent negative prices and price spikes, particularly in the $40 \%$ case. The second finding appears to result from the fact that the system operator is minimizing generator start-up costs, which comprise a large percentage of the storage value. Therefore, the hours when the storage resource is charging and discharging aren't necessarily the lowest or highest price hours of the day. This result also needs additional research.

\section{Ancillary Services}

Ancillary services represent a potentially large fraction of the benefits of energy storage to the grid. In cases where the storage portfolio primarily provides reserves, they generate about $90 \%$ of the production cost savings compared to the cases when both energy and reserves are supplied. However, estimating the actual potential market revenue opportunities for storage in high renewable scenarios is difficult. Ancillary service markets are commonly described as "thin" markets, which in the case of the CAISO markets refer to the quantity (MW) of ancillary services being procured, rather than the number of eligible suppliers, which is potentially high. In a case where all the eligible new storage is used for regulation, the regulation market would be saturated by storage. However, in addition to existing regulation and spinning reserves, the CAISO will potentially carry several hundred MW of ramping reserves, and possibly add a frequency responsive reserve. The current planned storage portfolio will not exhaust all these future ancillary service and ramping reserve requirements, and forecasting potential ancillary service value will require additional research, using modeling approaches that can more fully assess the value of storage providing various reserve services.

\section{Other Operational Results}

These simulations find that storage operations reduce renewable curtailment, particularly in the $40 \%$ scenario. However, due to the magnitude (MW) of curtailment events, storage only reduced about $22 \%$ of the aggregate curtailment for the $33 \%$ scenario and $13 \%$ for the $40 \%$ scenario. Model results also show a consistent reduction in carbon emissions for California due to storage operations, but both modest reductions and increases in carbon emissions for the full WECC region.

\section{Capacity Valuation}

This analysis is limited in scope, analyzing only the operational value of California's energy storage mandate for the transmission system. However, the capacity value of storage may exceed its operational value, given the ability of storage with sufficient duration to replace conventional capacity (such as gas-fired combustion turbines) in the CPUC resource adequacy program [41]. The flexible nature of storage capacity may further increase its value compared to less flexible generators.

\section{Interaction of Wind, Solar, and Storage}

A number of studies have examined how different renewable technologies interact with storage technologies to uncover implications for resource portfolio development [42]. Because of PV's production profile, a fairly general result is that as PV penetration grows, it demonstrates 
declining marginal energy and capacity value, but also simultaneously creates new conditions on the power system - higher frequency of lower or negative energy prices during the sunlight hours and increased diurnal system ramps. These conditions benefit storage, more so than expansion of wind production, whose profiles tend to be more evenly distributed over the operating day, especially with increasing spatial distribution. The 2014 LTPP cases offer a demonstration of this relationship. The addition of $7.6 \mathrm{GW}$ of PV to the California grid in the $40 \%$ renewable energy scenario almost doubles the energy value of the storage portfolio, due primarily to the benefit of increased hours with low or negative prices and increased price spikes due to system ramps. While storage is not the only mitigating measure to address declining solar valuation, it is the one with the most operational flexibility and adaptability to persistently changing system conditions as renewable penetration continues.

\section{Future Work and Other Analysis Needs}

Overall, this study and others suggest that much of the future value of storage may be driven by the market impacts of renewable integration. This will require further analysis to consider the cost of curtailed energy under RPS contracts, or the resale value of such energy to other parts of the West. The expansion of regional energy markets will affect storage value, as will the introduction of other flexibility options such as demand response. Further analysis within the same basic model framework will provide greater insight into the role of storage in enabling additional penetration of wind and solar resources, particularly considering grid evolution and changes to generation mixes that may occur throughout the West.

The LTPP models could be expanded to conduct more detailed analysis on technologies and system operations. This study is intentionally agnostic with respect to the technology selected in an attempt to perform an assessment of the impacts of storage; however, specific technologies (e.g., pumped hydro, flow batteries, compressed air energy storage, hydrogen or methane powerto-gas) have very different operating parameters. Extending the model to evaluate specific storage technology properties could help clarify alternative storage procurement options [10, 43].

This work explores only the impact of energy storage which provides operational services. Because the CPUC targets specify that some distribution-connected and customer-side storage will not provide such services, additional analysis is needed to understand benefits associated with avoided losses and distribution system upgrade deferral, and retail rate reductions. 


\section{References}

1.) Denholm, P., E. Ela, B. Kirby and M. Milligan (2010). The Role of Energy Storage with Renewable Electricity Generation National Renewable Energy Laboratory. Golden, CO, NREL/TP-6A2-47187.

2.) Denholm, P., J. Jorgenson, M. Hummon, D. Palchak, B. Kirby, O. Ma and M. O’Malley (2013). The Impact of Wind and Solar on the Value of Energy Storage, National Renewable Energy Laboratory, U.S. Department of Energy, University College Dublin. Golden, CO, NREL/TP-6A20-60568.

3.) Lew, D., G. Brinkman, E. Ibanez, A. Florita, M. H. B.-M. Hodge, M. Hummon, G. Stark, J. King, S. A. Lefton, N. Kumar, D. Agan, G. Jordan and S. Venkataraman (2013). The Western Wind and Solar Integration Study Phase 2, National Renewable Energy Laboratory, RePPAE, Intertek-APTECH, and GE Energy Consulting. Golden, CO, NREL/TP-5500-55588.

4.) Nelson, J. H. and L. M. Wisland (2015). Achieving 50 Percent Renewable Electricity in California: The Role of Non-Fossil Flexibility in a Cleaner Electricity Grid, Union of Concerned Scientists, http://www.ucsusa.org/sites/default/files/attach/2015/08/Achieving-50-PercentRenewable-Electricity-In-California.pdf.

5.) California Public Utilities Commission Decision 13-10-040, Decision adopting energy storage procurement framework and design program, October 17 , 2013, http://docs.cpuc.ca.gov/PublishedDocs/Published/G000/M079/K533/79533378.PDF

6.) Abrams, A., R. Fioravanti, J. Harrison, W. Katzenstein, M. Kleinberg, S. Lahiri, C. Vartanian and (DNV KEMA Energy \& Sustainability) (2013). Energy Storage Costeffectiveness Methodology and Preliminary Results, California Energy Commission, Publication number: CEC-XXX-XXXX-XXX.

7.) Akhil, A. A., G. Huff, A. B. Currier, B. C. Kaun, D. M. Rastler, S. B. Chen, A. L. Cotter, D. T. Bradshaw and W. D. Gauntle (2013). DOE/EPRI 2013 Electricity Storage Handbook in Collaboration with NRECA, Sandia National Laboratory, Electric Power Research Institute, National Rural Electric Cooperative Association, AECOM Technical Services, Inc., and the U.S. Department of Energy. Albuquerque, NM, SAND2013-5131.

8.) Sioshansi, R., P. Denholm and T. Jenkin (2012). "Market and Policy Barriers to Deployment of Energy Storage." Economics of Energy and Environmental Policy 1(2): 47-63.

9.) Denholm, P., Y.-H. Wan, M. Hummon and M. Mehos (2013). An Analysis of Concentrating Solar Power with Thermal Energy Storage in a California 33\% Renewable Scenario, National Renewable Energy Laboratory. Golden, CO, NREL/TP-6A2058186, http://www.nrel.gov/docs/fy13osti/58186.pdf.

10.) Edmunds, T., A. Lamont, V. Bulaevskaya, C. Meyers, J. Mirocha, A. Schmidt, M. Simpson, S. Smith, P. Sotorrio, P. Top and Y. Yao Lawrence Livermore National Laboratory. (2013). The Value of Energy Storage and Demand Response for Renewable Integration in California, California Energy Comission, CEC-500-10-051. 
11.) Jorgenson, J., P. Denholm and M. Mehos (2014). Estimating the Value of Utility-Scale Solar Technologies in California Under a 40\% Renewable Portfolio Standard, National Renewable Energy Laboratory. Golden, CO, NREL/TP-6A20-61685.

12.) California Public Utilities Commission Rulemaking 13-12-010, Order Instituting Rulemaking to Integrate and Refine Procurement Policies and Consider Long-Term Procurement Plans, December 19, 2013, http://docs.cpuc.ca.gov/PublishedDocs/Published/G000/M084/K241/84241040.PDF

13.) Denholm, P., J. Jorgenson, M. Hummon, T. Jenkin, D. Palchak, B. Kirby, O. Ma and M. O'Malley (2013). The Value of Energy Storage for Grid Applications, National Renewable Energy Laboratory, United states Department of Energy, and University College Dublin. Golden, CO, NREL/TP-6A20-58465.

14.) Koritarov, V., T. Guo, E. Ela, B. Trouille, J. Feltes and M. Reed (2013). Modeling and Simulation of Advanced Pumped - Storage Hydropower Technologies and their Contributions to the Power System, Argonne National Laboratory, Energy Exemplar, LLC, National Renewable Energy Laboratory, MWH Americas, Inc., Siemens PTI, Inc., U.S. Department of Energy. White paper, http://energyexemplar.com/wp-content/uploads/2013/06/Koritarov-et-al-2014_HVPaper_final2.pdf.

15.) (2014). Consistent Evaluation Protocol (CEP) for Energy Storage Benchmarking and General Reporting Purposes, http://www.pge.com/includes/docs/pdfs/b2b/wholesaleelectricsuppliersolicitation/Ener gy Storage/Final CEP.pdf.

16.) California Independent System Operator (2014). 2014 Annual Report on Market Issues and Performance, Department of Market Monitoring - California

ISO, http://www.caiso.com/Documents/2014AnnualReport_MarketIssues Performance.pdf.

17.) California Public Utilities Commission Rulemaking 10-21-007, Order Instituting Rulemaking Pursuant to Assembly Bill 2514 to Consider the Adoption of Procurement Targets for Viable and Cost-Effective Energy Storage Systems., December 16, 2010, http://docs.cpuc.ca.gov/PUBLISHED/FINAL_DECISION/128658.htm

18.) California Public Utilities Commission (CPUC). "Storage proceeding webpage." from http://www.cpuc.ca.gov/PUC/energy/storage.htm.

19.) California Public Utilities Commission, Rulemaking 13-12-010, Assigned Commissioner's ruling on assumptions, scenarios and Renewable Portfolio Standard (RPS) portfolios for use in 2014 long term procurement plan (LTPP) and 2014-2015 California Independent System Operator (CAISO) transmission planning process (TPP), By Picker, December 19, 2013

20.) Open Access Same-time Information System, California Independent System Operator, http://oasis.caiso.com/mrtu-oasis.

21.) Cost-Effectiveness of Energy Storage in California: Application of the Energy Storage Valuation Tool to Inform the California Public Utility Commission Proceeding R. 10-12-007, EPRI. Palo Alto, CA: 2013, 3002001162. 
22.) Sioshansi, R., P. Denholm, T. Jenkin and J. Weiss (2009). "Estimating the Value of Electricity Storage in PJM: Arbitrage and Some Welfare Effects." Energy Economics. 31(269277).

23.) California Independent System Operator (2014). Phase I.A. Stochastic Study Testimony of Dr. Shucheng Liu on Behalf of the California Independent System Operator Corporation, CPUC R.13-12-

010, www.caiso.com/Documents/Nov20_2014_Liu_StochasticStudyTestimony_LTPP_R13-12010.pdf.

24.) California independent System Operator (2015). 2015-2016 Transmission Planning Process Unified Planning Assumptions and Study Plan, CAISO Market and Infrastructure Development Division, http://www.caiso.com/Documents/2015-2016FinalStudyPlan.pdf.

25.) California Independent System Operator (2014). Phase I.A. Direct Testimony of Dr. Shucheng Liu on Behalf of the California Independent System Operator Corporation, CPUC R.13-12-

010, http://www.caiso.com/Documents/Aug13 2014_InitialTestimony_ShuchengLiu_Phase1A LTPP R13-12-010.pdf.

26.) California Senate Bill No. 350, Clean Energy and Pollution Reduction Act of 2015, https://leginfo.legislature.ca.gov/faces/billNavClient.xhtml?bill_id=201520160SB350

27.) Bird, L., J. Cochran and X. Wang (2014). Wind and Solar Energy Curtailment: Experience and Practices in the United States, National Renewable Energy Laboratory. Golden, CO, NREL/TP-6A20-60983, http://www.nrel.gov/docs/fy14osti/60983.pdf.

28.) California Independent System Operator (2013). Lowering the Energy Bid Floor and Changing the Bid Cost Recovery Methodology with Additional Performance Based Refinement, Letter to the Federal Energy Regulatory Commission, http://www.caiso.com/Documents/Sep25 2013TariffAmendmentRenewableIntegrationMarket-ProductReviewPhase1_ER13-2452-000.pdf.

29.) California Air Resources Board (CARB). "Assembly Bill 32 Overview." from http://www.arb.ca.gov/cc/ab32/ab32.htm

30.) Townsend, A. K. (2013). A Grid-Level Assessment of Compressed Air Energy Storage in ERCOT. Mechanical Engineering. (Ph.D. Dissertation), The University of Texas at Austin.

31.) Union of Concerned Scientists and The Sierra Club (2014). Prepared Opening Testimony of Jimmy Nelson on Behalf of the Union of Concerned Scientists and Sierra Club, CPUC R.13-12010 .

32.) Hummon, M., P. Denholm, J. Jorgenson, D. Palchak, B. Kirby and O. Ma (2013). Fundamental Drivers of the Cost and Price of Operating Reserves, National Renewable Energy Laboratory and U.S. Department of Energy. Golden, CO, NREL/TP-6A20-58491. 
33.) Krad, I., E. Ibanez and E. Ela (2015). Analysis of the Effects of a Flexible Ramping Ancillary Service Product on Power System Operations: Preprint, National Renewable Energy Laboratory. Golden, CO, NREL/CP-5D00-65068.

34.) Barbose, G., N. Darghouth, D. Millstein, M. Spears, R. Wiser, M. Buckley, R. Widiss and N. Grue (2015). Tracking the Sun VIII: The Installed Price of Residential and Non-Residential Photovoltaic Systems in the United States, Lawrence Berkeley National Lab, Exeter Associates, National Renewable Energy Laboratory, United States Department of Energy.

35.) Wiser, R., M. Bolinger, G. Barbose, N. Darghouth, B. Hoen, A. Mills, K. H. LaCommare, D. Millstein, D. Hansen, K. Porter, R. Widiss, M. Buckley, F. Oteri, A. Smith and S. Tegen (2014). 2014 Wind Technologies Market Report, Lawrence Berkeley National Laboratory, Exeter Associates, National Renewable Energy Laboratory.

36.) Klein, J. (2010). Cost of Generation Model User's Guide Version 2, California Energy Commission, CEC-200-2010-002.

37.) Newell, S. A., M. Hagerty, K. Spees, J. P. Pfeifenberger, Q. Liao, C. D. Ungate and J. Wroble (2014). Cost of New Entry Estimates for Combustion Turbine and Combined Cycle Plants in PJM, Prepared for PJM

Interconnection, http://www.brattle.com/system/publications/pdfs/000/005/010/original/Cost_of New_Entry_Estimates_for_Combustion_Turbine_and_Combined_Cycle_Plants in_PJM.pdf?14 $\underline{00252453 .}$.

38.) Olson, A., N. Schlag, K. Patel and G. Kwok (2014). Capital Cost Review of Power Generation Technologies: Recommendations for WECC's 10- and 20-Year Studies, Prepared by Energy and Environmental Economics, Inc. Salt Lake City: Western Electric Coordinating Council, https://www.wecc.biz/Reliability/2014_TEPPC_Generation_CapCost_Report_E3.pdf.

39.) Pfeifenberger, J. P., K. Spees and S. A. Newell (2012). Resource Adequacy in California: Options for Improving Efficiency and Effectiveness, Prepared by The Brattle Group, Inc. for Calpine.

40.) California Independent System Operator (2015). Final Flexible Capacity Needs Assessment for 2016. Folsom, CA, http://www.caiso.com/Documents/FinalFlexibleCapacityNeedsAssessmentFor2016.pdf.

41.) Sioshansi, R., S. H. Madaeni and P. Denholm (2014). "A Dynamic Programming Approach to Estimate the Capacity Value of Energy Storage." IEEE Transactions on Power Systems 29(1): 395-403.

42.) Mills, A. D. and R. H. Wiser (2015). Strategies to mitigate declines in the economic value of wind and solar at high penetration in California. Applied Energy 147: 269-278.

43.) (2014). The California 2030 Low-Carbon Grid Study (LCGS): Phase I Results Summary, Center for Energy Efficiency and Renewable Technologies, National Renewable Energy Laboratory, General Electric Consluting and JBS Energy Inc., http://lowcarbongrid2030.org/. 


\section{Appendix A. The 2014 LTPP model}

The California Independent System Operator developed and maintains a database for use with the production cost model PLEXOS. This database contains detailed information about the size, type, and heat rate of generators as well as other information, including minimum generation, ramp-rate, and region in which a generator is located. This database is based on the 2014 Long Term Procurement Plan (LTPP) established through consultations between the CPUC, CAISO, and CEC and reviewed by stakeholders [25]. The database has hourly resolution and uses a full chronological year of modeled data to run deterministic simulations. Storage scenarios were run using PLEXOS version 6.208 with the August 2014 release of the CAISO database.

The database includes several thousand generators. All of the Western Energy Coordinating Council (WECC) is represented by 43 nodes in 26 regions. Categories are abstracted to states in the United States, Canada, and Mexico. Regions represent finer groupings within each of the 12 categories. Finally, nodes are typically utilities, control areas, or balancing authorities. The database has the greatest amount of detail within California, which represents one category but 8 of the 26 regions and 8 of the 43 nodes (e.g., IID, LDWP, PG\&E_BAY, PG\&E_VLY, SCE, SDGE, SMUD, and TIDC). For the purpose of the database there are 43 "nodes"; however, the model runs zonally, with each node representing one zone in the western interconnect. Figure 37 shows many of the nodes in the database. Connecting the nodes there are 151 transmission lines used to capture the transmission interactions. These lines represent aggregation of the individual lines in the system. Therefore these results cannot fully evaluate the role of storage in relieving local transmission congestion or in deferring new transmission investments. 


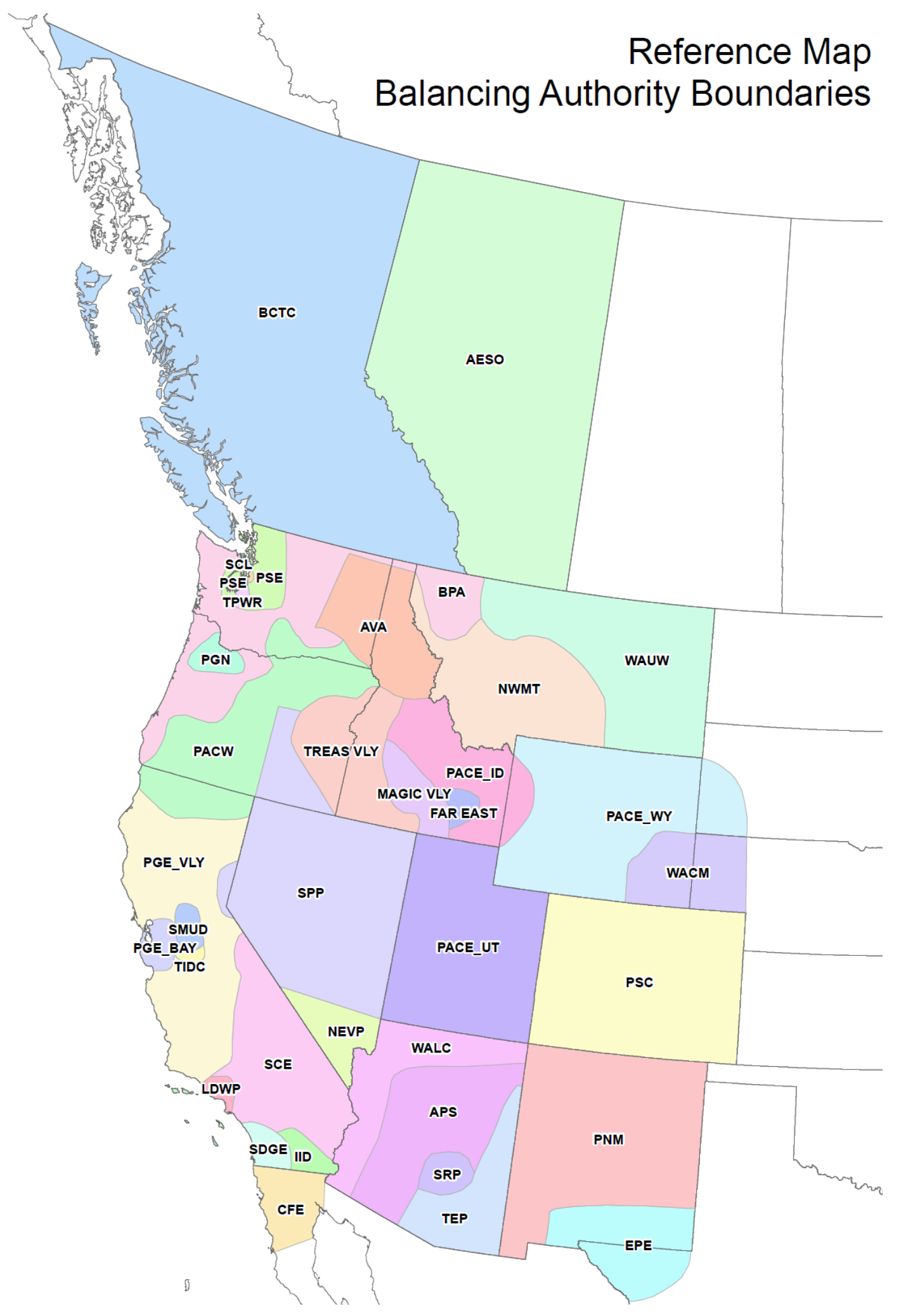

Figure 37: Map of nodes in CAISO database. 
Much of the policy and market interest in storage in California is due to the expectation that nonfossil-based resources - renewable generation, demand response, and storage - will need to provide the operational flexibility on the future power system. Hence, the level of operational detail in the models is fairly high, although still not sufficient for a comprehensive operational analysis. In terms of ancillary services and load-following, the six market products or operational constraints are modeled as reserve capacity for a subset of the zones: load-following up, loadfollowing down, regulation up, regulation down, spinning reserve, and non-spinning reserve.

The CAISO model uses one year of chronological modeled data with an hourly resolution. Additionally, the model runs with day-ahead unit commitment and one day of look-ahead. A mixed integer programming gap of $0.2 \%$ is used as a default in the model. That means that the minimum production cost from the final result each day is within $0.2 \%$ of the linear solution. As a result, production cost changes larger than $0.2 \%$ are considered significant. 


\section{Appendix B. Benchmarking to CAISO Results}

CAISO testimony on the 2014 LTPP deterministic study includes model results, labeled "CAISO - Original" below. To demonstrate that we could closely replicate CAISO's results for the base cases, NREL performed the same runs, "NREL - Original," as shown in Table 17. In addition, several changes were subsequently made to the original model to improve the output of the model and to allow the storage sensitivities to be run. Those runs are called "NREL - Base" and the changes include:

1) Removed regulation up, load following up, and spinning reserve capacity constraint for three storage units (PGE Bay_4_TC, PGE Bay_6_TC, PGE Valley_4_TC). While the impact is small, it was recognized that this was an error in the original model.

2) Added charge and discharge constraints to ensure that there is sufficient energy in storage to provide ancillary services if they are called upon. The model does not have a mechanism for knowing when reserves will be called and the base model does not ensure that storage resources have sufficient energy in storage to meet the half hour reserve provision requirements if they are called. A constraint was added to ensure that each resource has sufficient energy in storage to meet their agreements for one-half hour, if called upon.

3) Removed minimum stable level for all new storage resources except for Lake Hodges. Removing the minimum stable level only affects the discharging part of the storage resources and allows them to provide ancillary services without being turned on. This adjustment was required to allow the eligible reserve case and reserve only case to correctly provide reserves.

4) Adjusted round-trip efficiency from $80 \%$ to $83.3 \%$, as prescribed in the CPUC testimony [25].

5) Added a constraint to the distribution-connected resources to limit the amount of load following down and regulation down that the resources can provide to half of their capacity. This ensures consistency with Rulemaking 13-12-010 and Decision 13-10-040 $[5,19]$. The base model limits load-following up, regulation up, and spinning reserve to half of the capacity but does not limit the down products.

A comparison of the RPS-eligible generation and curtailment for the original CAISO scenarios, the original NREL model and the base NREL model are shown in Table 17. This establishes that the results from the NREL model are very close to those from the CAISO model. The RPS eligible generation is nearly identical with less than $2 \%$ difference between the CAISO and NREL results. The resulting curtailment percentage is $3.48 \%$ for the original CAISO model, $3.42 \%$ for the original NREL model, and $3.78 \%$ for the base NREL model. 
Table 17. Comparison of 2014 LTPP Deterministic Model Results for CAISO and NREL

\begin{tabular}{|c|c|c|c|c|c|c|c|c|c|c|c|c|c|c|}
\hline Property and Model & RPS & 1 & 2 & 3 & 4 & 5 & 6 & 7 & 8 & 9 & 10 & 11 & 12 & Total \\
\hline \multicolumn{15}{|l|}{ RPS Generation (TWh) } \\
\hline CAISO - Original & $33 \%$ & 4.53 & 4.78 & 6.13 & 6.32 & 6.50 & 6.47 & 6.22 & 5.40 & 5.26 & 5.16 & 4.69 & 4.61 & 66.07 \\
\hline NREL - Original & $33 \%$ & 4.53 & 4.78 & 6.15 & 6.36 & 6.51 & 6.47 & 6.21 & 5.40 & 5.26 & 5.16 & 4.69 & 4.61 & 66.14 \\
\hline NREL - Base & $33 \%$ & 4.53 & 4.78 & 6.15 & 6.35 & 6.50 & 6.47 & 6.21 & 5.40 & 5.26 & 5.16 & 4.69 & 4.61 & 66.12 \\
\hline CAISO - Original & $40 \%$ & 5.54 & 5.83 & 7.16 & 7.17 & 7.72 & 8.05 & 8.06 & 7.08 & 6.75 & 6.48 & 5.80 & 5.58 & 81.20 \\
\hline NREL - Original & $40 \%$ & 5.54 & 5.85 & 7.43 & 7.66 & 8.02 & 8.19 & 8.08 & 7.08 & 6.79 & 6.53 & 5.83 & 5.58 & 82.58 \\
\hline NREL - Base & $40 \%$ & 5.54 & 5.85 & 7.40 & 7.62 & 7.98 & 8.17 & 8.08 & 7.08 & 6.78 & 6.52 & 5.82 & 5.58 & 82.43 \\
\hline \multicolumn{15}{|l|}{ Curtailment (GWh) } \\
\hline CAISO - Original & $33 \%$ & - & 0.5 & 48.4 & 76.7 & 21.7 & 6.2 & - & - & - & - & - & - & 153.0 \\
\hline NREL - Original & $33 \%$ & - & 0.5 & 48.4 & 76.7 & 21.9 & 6.2 & - & - & - & - & - & - & 153.7 \\
\hline NREL - Base & $33 \%$ & - & 0.9 & 58.7 & 96.4 & 30.0 & 8.3 & - & - & - & - & - & - & 194.4 \\
\hline CAISO - Original & $40 \%$ & 15.0 & 59.0 & 583 & 1,013 & 594 & 291 & 47.0 & 2.0 & 70.0 & 88.0 & 48.0 & 17.0 & 2,825 \\
\hline NREL - Original & $40 \%$ & 14.6 & 58.5 & 583 & 1,019 & 591 & 292 & 46.5 & 1.5 & 70.2 & 87.0 & 47.9 & 16.9 & 2,828 \\
\hline NREL - Base & $40 \%$ & 19.3 & 68.9 & 635 & 1,087 & 655 & 334 & 53.0 & 3.5 & 82.7 & 98.0 & 61.0 & 20.7 & 3,118 \\
\hline
\end{tabular}




\section{Appendix C. Breakdown of Reserve Provision}

Different resource types provide different amounts of reserves based on their flexibility and availability. A summary of which resources provide reserves is shown for the $33 \%$ no storage case in Figure 38 and the 33\% energy and reserves scenario in Figure 39. In the LTPP model, reserve requirement is separated into reserves for IOUs and MUNIs. The new 1,325MW of storage can only provide reserves to meet the IOU portion of the reserve requirements, so the figures below show the results for only the IOU portion of reserves.

Not all plants can provide reserves. Most resource types have several plants that can provide reserve except for nuclear power, which does not provide any reserves in the model. Combined cycles (CC) provide the largest portion of reserves followed by hydro, combustion turbines (CT), and storage resources. Figure 38 shows the reserve provision breakdown for the $33 \%$ no-storage scenario. Resources favor certain reserve types. For example, hydro provides all reserve types except for non-spin. CCs provide the largest portion of all reserves except for non-spin, which is dominated by CTs because of their higher fuel cost but greater flexibility and lower startup cost than coal and CCs.

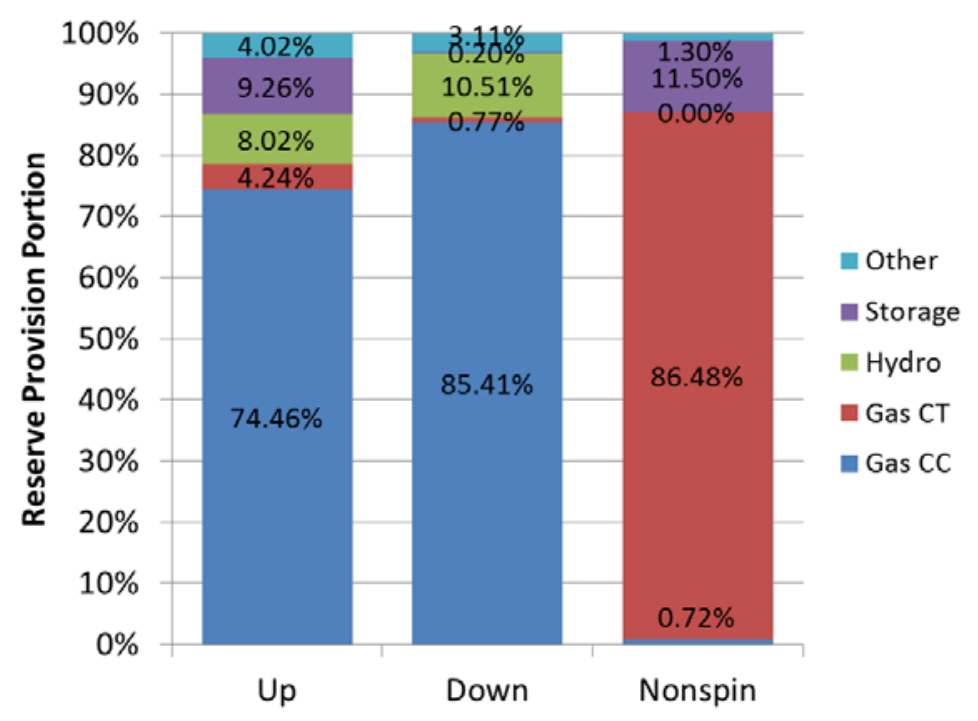

Figure 38: Reserve provision for California IOUs by resource type for $33 \%$ no-storage scenario.

Reserve provision for the no-storage scenario can be compared to the breakdown with storage (Figure 39). The storage most notably contributes to up reserve products, followed closely by down reserve products. Adding storage reduces reserve provision from most other resources; however, the reserves provided by existing storage generally increase as a result of additional storage. Because of their significant contribution, CCs are the most affected by the addition of storage in California. 


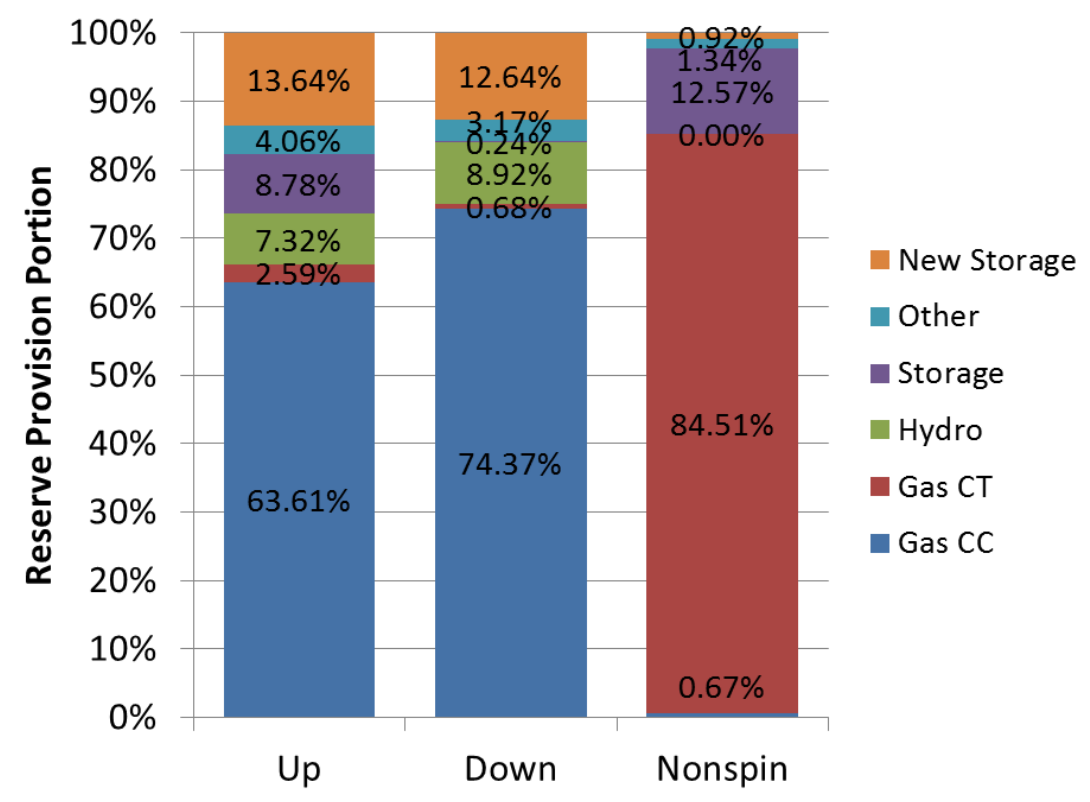

Figure 39: Reserve provision for California IOUs by resource type for $33 \%$ ene\&res storage scenario. 


\section{Appendix D. Additional Results on Modelled Electricity Prices}

This appendix contains additional material to show how energy prices are distributed. Figure 40 presents a scatter plot of energy prices for each hour of the day, including the maximum at $\$ 2,000 / \mathrm{MWh}$.

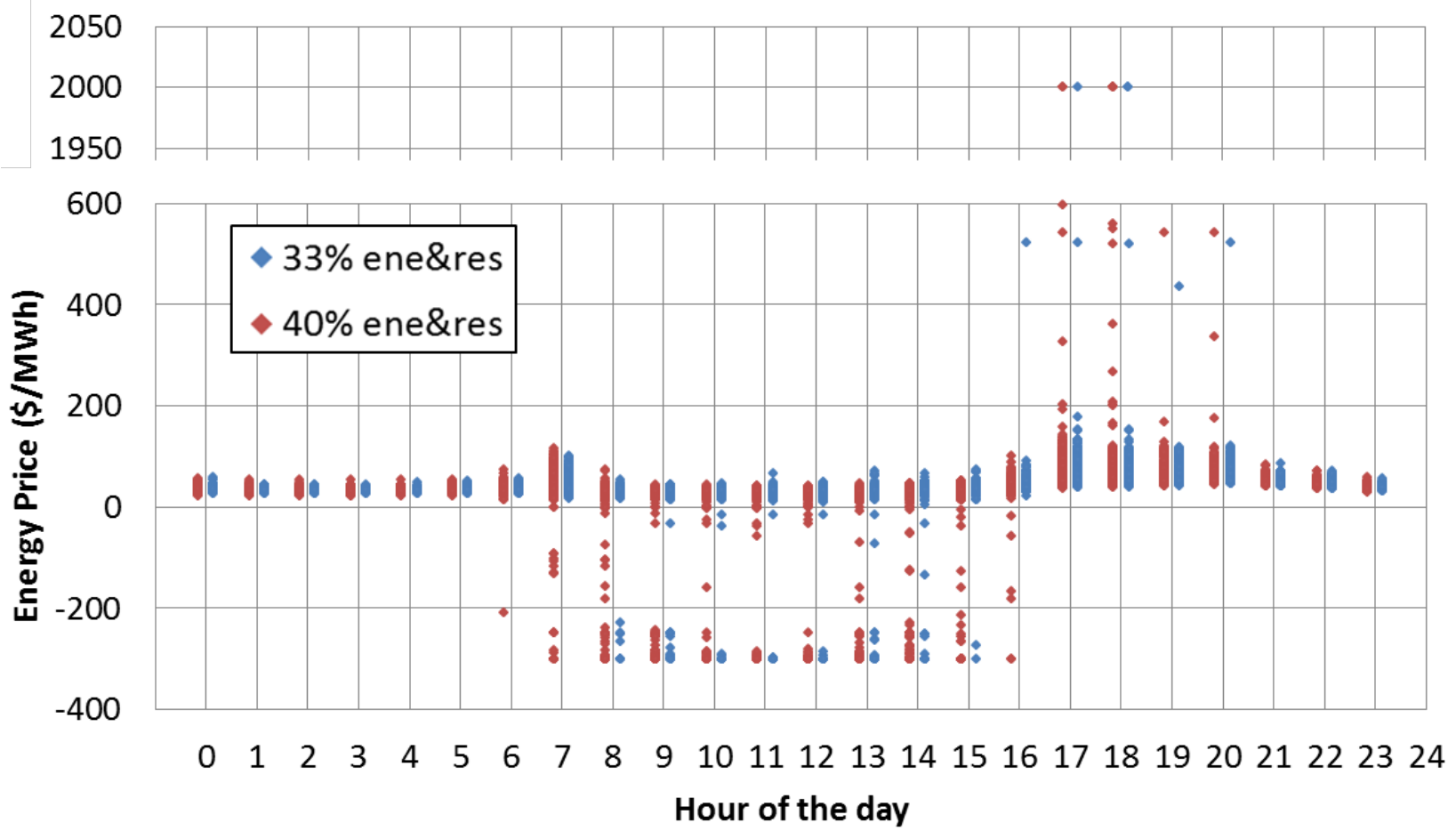

Figure 40: Scatter plot of energy prices for $33 \%$ and $40 \%$ ene\&res scenarios (-\$300/MWh bid floor). Energy prices can also be represented using a price duration curve as shown in Figure 41. Notice that there are relatively few hours at the price maximum and that changing the bid floor changes the value of the price but does not greatly affect the distribution. 


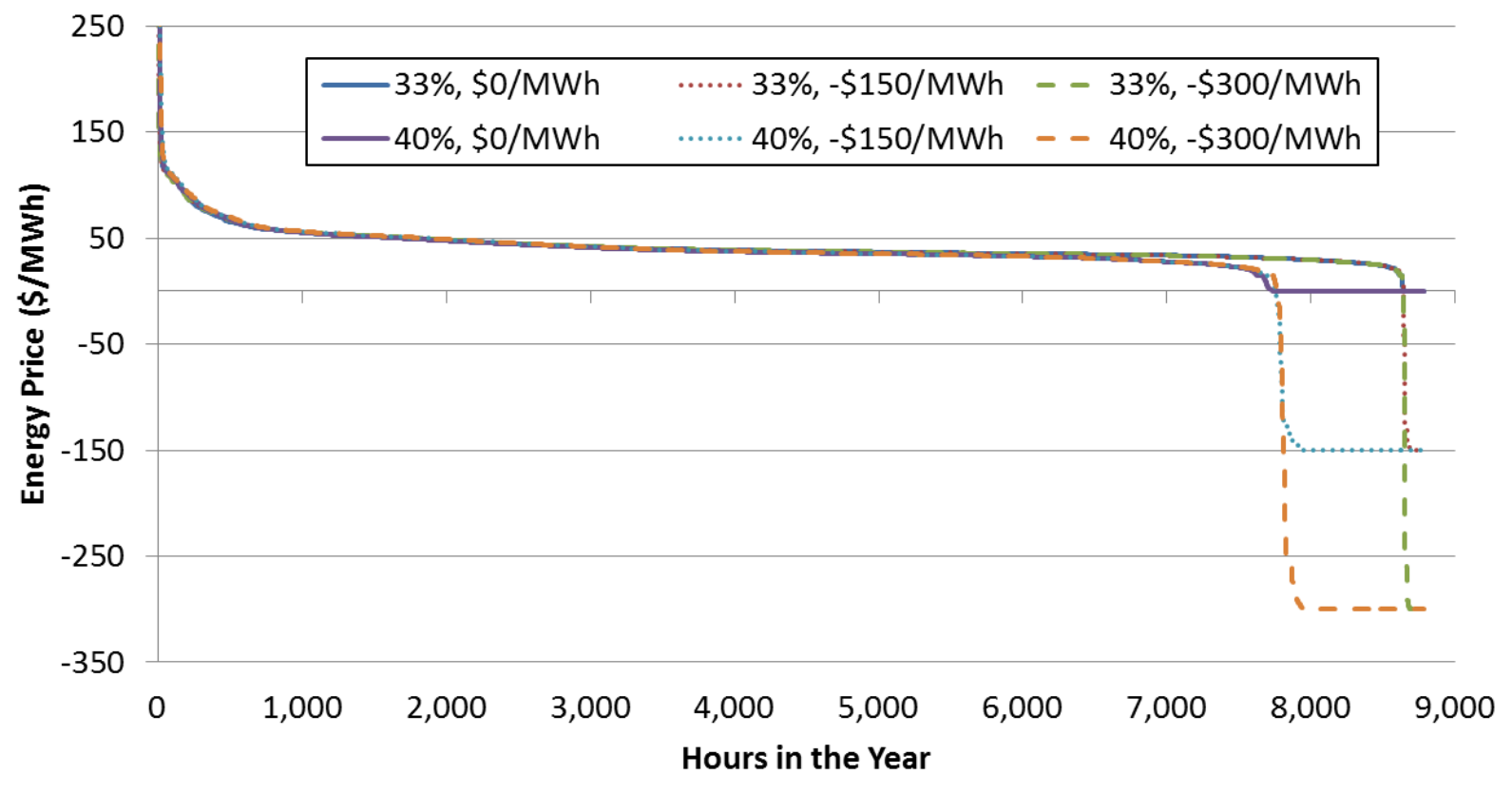

Figure 41: Price duration curve for $33 \%$ and $40 \%$ ene\&res scenarios. 